U.S. Department of Transportation National Highway Traffic Safety Administration

\title{
Configurations Of EMS Systems: A Pilot Study
}

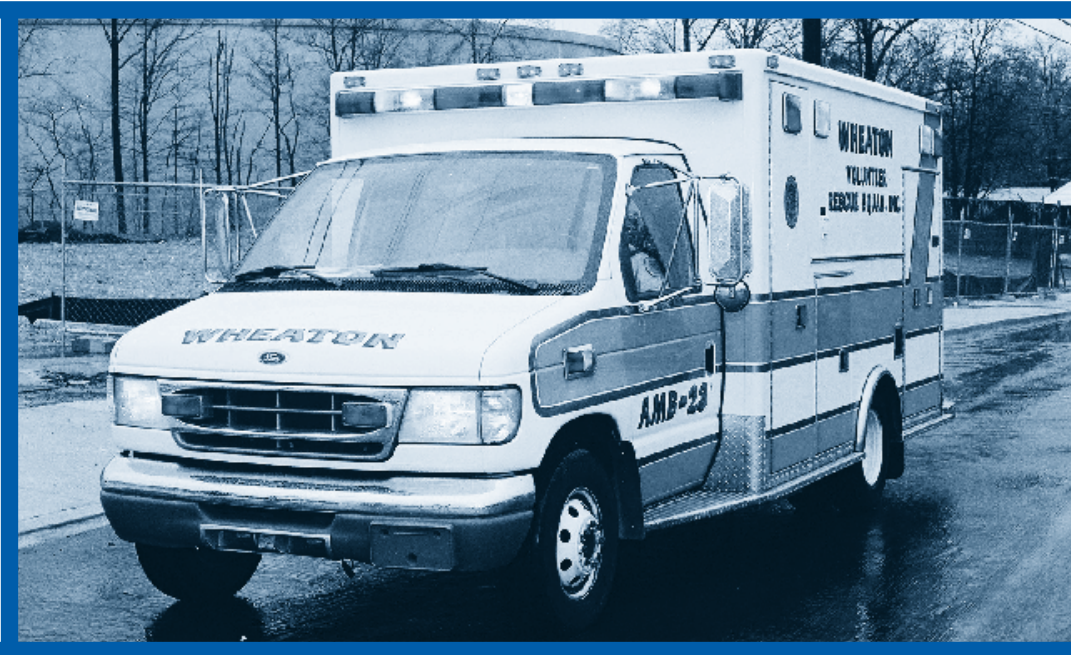


This publication is distributed by the U.S. Department of Transportation, National Highway Traffic Safety Administration, in the interest of information exchange. The opinions, findings, and conclusions expressed in this publication are those of the authors and not necessarily those of the Department of Transportation or the National Highway Traffic Safety Administration. The United States Government assumes no liability for its contents or use thereof. If trade or manufacturers' names or products are mentioned, it is because they are considered essential to the object of the publication and should not be construed as an endorsement. The United States Government does not endorse products or manufacturers. 
Technical Report Documentation Page

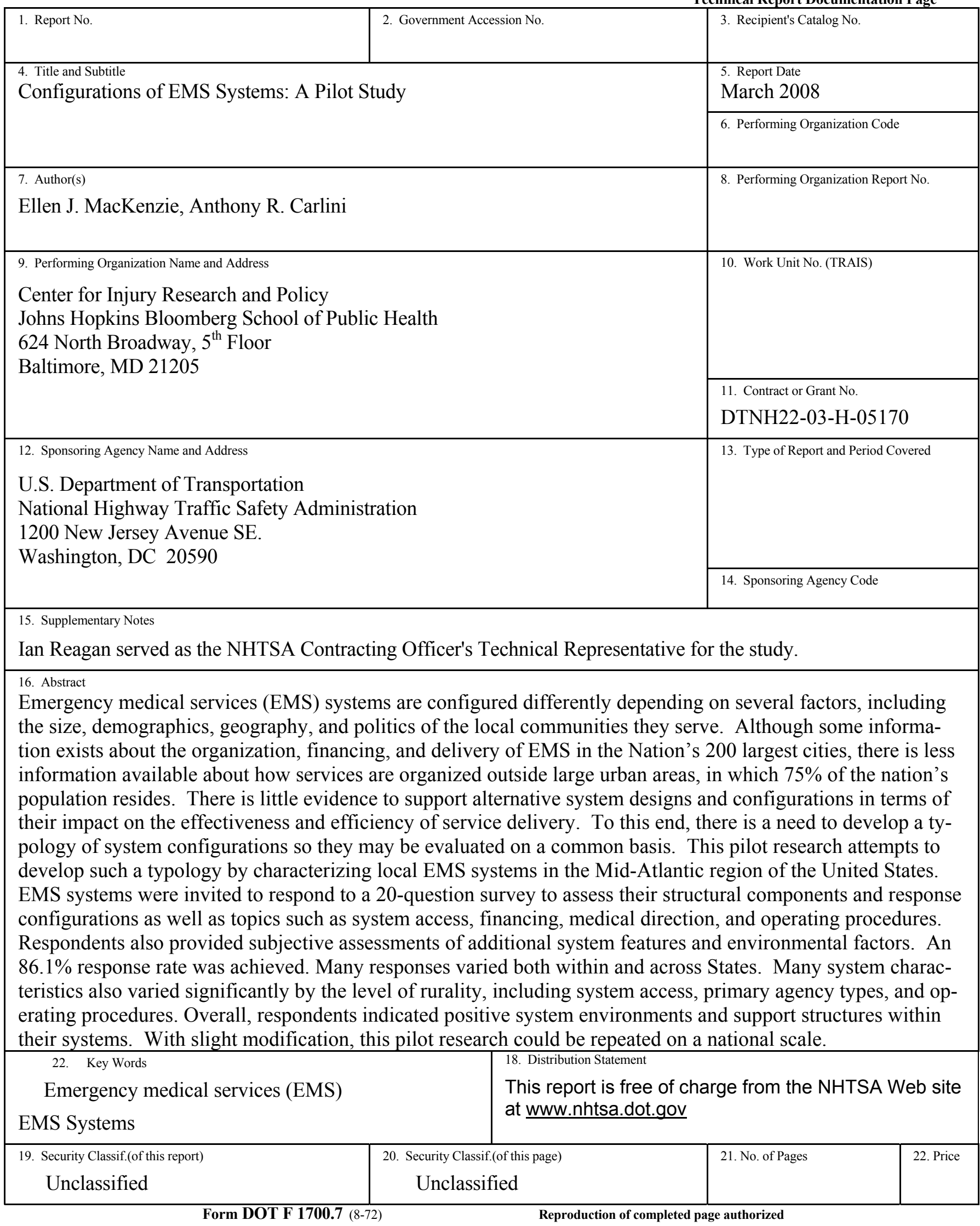


DEPARTMENT OF TRANSPORTATION

NATIONAL HIGHWAY TRAFFIC SAFETY ADMINISTRATION

\section{TECHNICAL SUMMARY}

\begin{tabular}{l|l}
\hline \hline CONTRACTOR & CONTRACT NUMBER \\
Center for Injury Research and Policy (Johns Hopkins University) & DTNH22-03-H- \\
\hline $\begin{array}{l}\text { REPORT TITLE } \\
\text { Configurations of EMS Systems: A Pilot Study }\end{array}$ & REPORT DATE \\
& March 2008 \\
\hline REPORT AUTHOR(S) \\
Ellen J. MacKenzie, Anthony R. Carlini
\end{tabular}

\section{BACKGROUND}

Emergency medical services (EMS) systems are configured differently depending on several factors, including the size, demographics, geography and politics of the local communities they serve. Although some information exists about the organization, financing, and delivery of EMS in 200 of the Nation's largest cities (Williams, 2007), this information is incomplete and does not provide any information on how services are organized for proportion of the nation's population (75\%) who resides outside of these urban areas. What we do know, however, is that there is wide variability in how systems are structured and organized with little evidence to support alternative configurations in terms of their impact on the effectiveness and efficiency of service delivery (IOM, 2007).

\section{OBJECTIVE}

To understand which EMS systems work well, an important first step is the development of a typology of system configurations so they may be evaluated on a common basis. This pilot research is a first step toward developing such a typology by characterizing local EMS systems in the Mid-Atlantic region of the United States.

\section{METHODS}

The Mid-Atlantic region chosen for this pilot study consists of seven States (Delaware, Maryland, New Jersey, North Carolina, Pennsylvania, Virginia, and West Virginia) and the District of Columbia. This geographic region was chosen for the pilot study for several reasons. First and perhaps most important, we expected that most of the archetypal systems mentioned above would be present in one or more of these States. In addition, the States themselves vary with respect to how EMS is organized at State and regional levels. Moreover, the region is diverse in terms of geography and demographic composition of the resident population. This diversity would allow an examination of variations in EMS configurations by level of rurality and size of the service area.

(Continued on additional pages)

"PREPARED FOR THE DEPARTMENT OF TRANSPORTATION, NATIONAL HIGHWAY TRAFFIC SAFETY ADMINISTRATION UNDER CONTRACT NO:DTNH22-05-D-15043 Task Order No. 001. THE OPINIONS, FINDINGS, AND CONCLUSIONS EXPRESSED IN THIS PUBLICATION ARE THOSE OF THE AUTHORS AND NOT NECESSARILY THOSE OF THE NATIONAL HIGHWAY TRAFFIC SAFETY ADMINISTRATION."

HS Form $321 \quad$ July 1974 
The States vary considerably by size and population demographics as well as how EMS is organized at the State and regional levels. The total percent of the population that lives within large metropolitan areas ranges across States from over 85\% (Maryland and District of Columbia) to less than 20\% (West Virginia, North Carolina and Delaware). The only States with more than $1 \%$ of the population living in completely rural areas are West Virginia, and North Carolina. A total of 81 counties in the study region are categorized as large metropolitan; 100 as small metropolitan; 31 as large non-metropolitan; 112 as small non-metropolitan and 81 as completely rural.

Traditionally, an EMS system has been defined as a comprehensive, coordinated arrangement of resources and functions organized to respond to medical emergencies in a timely manner (P.L. 93-154, 1973). In order to promote some level of consistency between systems and to ensure potential respondents would have a sufficiently broad perspective (e.g., including areas such as policy development or regionalization of services), this definition needed to be refined. For the purpose of this study, an EMS system is operationally defined as present when there is an identifiable local entity within a State EMS system's administrative hierarchy below the State level (if the State is sufficiently large enough) and immediately above the level of an individual provider agency. In instances where an agency is the sole provider for a jurisdiction and/or that agency serves in a leadership capacity to other services (i.e., there is not an independent administrative body for the jurisdiction), it is regarded as an EMS system. At the core of this particular definition is a desire to evaluate EMS at a level sufficiently close to the localities served by care personnel, but also a need to ensure that we could measure features that looked beyond the organizational boundaries of just a single agency. It should be noted that aeromedical and inter-facility transport service entities were not considered as part of this study.

The identification of systems within the participating States involved the following steps. First, each State EMS office was contacted several times in person, by phone, and by e-mail to learn more about the unique EMS environment and organization within the State. After being informed of the project, its overall goals, and our working system definition, every State EMS official provided contact information for each EMS system in their respective areas. The majority of systems identified were at a county (or equivalent) level, with a handful of additional systems representing multi-jurisdictional areas, independent cities or miscellaneous systems (e.g., an airport authority, or military installation or facility).

In three States (New Jersey, Virginia, and West Virginia), there were geographic areas identified that contained no EMS systems based on our definition. Conversations with the relevant State EMS offices revealed that while there were EMS agencies operating within these areas, they did not do so under a coordinated, local administration. As a result, these EMS agencies operated almost completely independent of each other and would interact directly with the State EMS agency on any matters (e.g., protocols, certification) that was outside the scope of its organizational walls. To characterize areas such as these at some cursory level, contact information for these counties (often an emergency services, public health or related contact) was obtained from the National Association of Counties (NACO).

All EMS systems, as defined using the criteria above, were mailed a 20 -question survey, along with a postagepaid return envelope. The survey addressed the following topics:

- Overall size of the system, as characterized by the annual number of EMS responses and transports, as well as the total number of EMS personnel;

- Access to the system through 911;

- Provider and dispatch agency types;

- Response configurations, operating procedures, and use of volunteers;

- Mutual aid agreements and response to calls outside the primary service area;

- Medical control;

- Source of funding for the system. 
The survey also contained a series of opinion questions focusing on resource levels, system support, system environment, and system change. Counties without systems meeting our criteria were sent an abbreviated 6question survey designed to gather basic EMS information.

Analyses were primarily of a descriptive nature, focusing on frequencies of characteristics and exploration of differences across the States. Differences between geographic and demographic categories were also examined using chi-square and analysis of variance techniques as appropriate.

\section{RESULTS}

A total of 273 systems and 82 non-system counties were identified across the 7 States and the District of Columbia. No systems were identified in New Jersey. Of the 273 system surveys sent out, 235 were returned, yielding a response rate of $86.1 \%$. Response rates among systems did not vary significantly by State or rurality, though the response rate among the 'non-system' counties was considerably lower (56\%).

The size of the systems included in the survey is characterized by self-reported information on: (1) number of EMS care personnel (at all levels, including volunteers); (2) annual number of EMS responses; and (3) annual number of EMS transports. Given the skewed distributions of these variables, as well as extreme outlier data pushing up the value of the means, the standard deviations observed are quite large. As a measure of central tendency, the median is thought to better represent the size of a typical EMS system within a particular category. Mean (standard deviation) and median statistics for the size measures broken down by rurality are shown below:

\begin{tabular}{|c|c|c|c|c|c|c|}
\hline & & $\begin{array}{l}\text { Large } \\
\text { Metro } \\
(\mathbf{n}=52)\end{array}$ & $\begin{array}{l}\text { Small } \\
\text { Metro } \\
(\mathrm{n}=60)\end{array}$ & $\begin{array}{l}\text { Large } \\
\text { Non-Metro } \\
(n=23)\end{array}$ & $\begin{array}{l}\text { Small } \\
\text { Non-Metro } \\
(n=61)\end{array}$ & $\begin{array}{l}\text { Completely } \\
\text { Rural } \\
(n=39)\end{array}$ \\
\hline \multirow[t]{2}{*}{$\begin{array}{l}\text { Annual } \\
\text { EMS Responses }\end{array}$} & Mean (SD) & $\begin{array}{l}42,001 \\
(76,406)\end{array}$ & $\begin{array}{l}23,049 \\
(43,250)\end{array}$ & $\begin{array}{l}19,374 \\
(26,218)\end{array}$ & $\begin{array}{l}6,055 \\
(4,103)\end{array}$ & $\begin{array}{l}2,417 \\
(3,229)\end{array}$ \\
\hline & Median & 17,000 & 13,000 & 11,000 & 4,844 & 1,500 \\
\hline \multirow[t]{2}{*}{$\begin{array}{l}\text { Annual } \\
\text { EMS Transports }\end{array}$} & Mean (SD) & $\begin{array}{l}27,853 \\
(56,837)\end{array}$ & $\begin{array}{l}14,804 \\
(19,291)\end{array}$ & $\begin{array}{l}12,258 \\
(14,463)\end{array}$ & $\begin{array}{l}4,256 \\
(2,491)\end{array}$ & $\begin{array}{l}1,779 \\
(2,432)\end{array}$ \\
\hline & Median & 9,300 & 9,500 & 8,321 & 3,900 & 1,200 \\
\hline \multirow[t]{2}{*}{$\begin{array}{l}\text { Number of } \\
\text { Personnel }\end{array}$} & Mean (SD) & $\begin{array}{l}1,032 \\
(2,284)\end{array}$ & $\begin{array}{l}634 \\
(1,349)\end{array}$ & $\begin{array}{l}470 \\
(816)\end{array}$ & $\begin{array}{l}147 \\
(229)\end{array}$ & $\begin{array}{l}136 \\
(476)\end{array}$ \\
\hline & Median & 283 & 250 & 254 & 91 & 40 \\
\hline
\end{tabular}

Nearly all respondents (94\%) report the availability of E-911, although only $59 \%$ note access is available through wireless. Access through wireless E-911 varies by both State and rurality. As expected, wireless E911 is less available in more rural systems and in smaller systems.

Most respondents (60\%) report that more than one type of agency is involved in first response as well as transport activities. Of those systems using first responders ( $98 \%$ of all systems report using first responders), $70 \%$ of respondents indicate use of a fire department to provide these services and $52 \%$ report that the fire service is the primary group responsible for first response. Additionally, large systems are significantly more likely to use fire-based first response than their smaller counterparts. Nearly two-thirds of respondents in large metro areas report a fire department as the primary agency used for transport. In less urban areas, the use of a third service agency is more typical. Emergency dispatch functions are primarily handled by a city or county communications department for nearly half (48\%) of responding systems, with an additional $22 \%$ served by a public safety department. The primary type of agency used for first response, transport, and dispatch varies across and within States. 
First response personnel are used nearly all systems (98\%). However, the results indicate that only $36 \%$ of first response workers are dispatched to all 911 calls. The results indicate that first responders were most likely (93\%) to be dispatched to 911 calls in conjunction with a transport ambulance.

Advanced life support (ALS) was the primary form of EMS transport in over $80 \%$ of the systems. In general, large metro areas included ALS first response and transport to a greater extent to less urban systems (52\% compared to $25 \%$ to $41 \%$ elsewhere). Estimates of population coverage associated with primary agency types and response configurations are shown below:

\begin{tabular}{|l|c|}
\hline & Resident Population Coverage (\%) \\
\hline Primary First Response & 11.6 \\
\hline Private & 67.2 \\
\hline Fire department & 8.6 \\
\hline Government-based/third service & 12.6 \\
\hline Other (or no 1 ${ }^{\text {st }}$ response) & \\
\hline Primary Transport Agency & 31.0 \\
\hline Private & 36.1 \\
\hline Fire department & 20.2 \\
\hline Government-based/third service & 12.7 \\
\hline Other & \\
\hline Primary Dispatch & 63.2 \\
\hline City/County & 16.9 \\
\hline Public safety & 19.8 \\
\hline Other & \\
\hline Primary Configuration & 7.9 \\
\hline BLS 1st response/BLS transport & 40.9 \\
\hline BLS 1st response/ALS transport & 7.6 \\
\hline ALS 1st response/BLS transport & 36.0 \\
\hline ALS 1st response/ALS transport & 1.6 \\
\hline BLS transport only & 5.9 \\
\hline ALS transport only & \\
\hline
\end{tabular}

The majority of respondents ( $86 \%$ ) report the use of volunteers, although the percentage of personnel serving in such a capacity has a tendency to be lower in larger systems. Over two-thirds of respondents note that call coverage is of major concern due to staffing shortages, however this unease was more prevalent among less urban systems (over $80 \%$ of the small non-metro and completely rural counties indicate call coverage as a major concern compared to only $57 \%$ of the large and small metro areas).

Nearly all respondents (94\%) report their systems having mutual aid agreements, although the components addressed by these agreements vary widely across and within States. While the majority (88\%) of mutual aid agreements addresses issues of service coverage, only one-half address communication linkages and merely one-third address licensure or certification of personnel, financial reimbursement or liability issues. Over onequarter $(29 \%)$ of respondents indicate that their primary transport agency often responds to calls outside the primary service area; an additional $44 \%$ indicate they sometimes respond to these calls.

Nearly all respondents (96\%) indicate medical direction is present at the system level. In $40 \%$ of these systems, this leadership is provided by a system-wide, "in-house" medical director who is a physician chosen or hired by the system's coordinating organization (as opposed to being imposed or required by some external entity). For another $50 \%$ of the systems, medical oversight is provided by an external director who is a physician administering from a remote organization, such as a local hospital. 
Multiple sources of funding are used to finance EMS systems. The majority of respondents in 4 States as well as the District of Columbia indicate their primary source of funding stems from tax subsidies, while in two other States (Pennsylvania and West Virginia), systems are primarily financed by fees or billing for services. There is a strong relationship between the source of primary funding (tax subsidies versus fee for service) and the rural-urban continuum, with more urban areas depending more extensively on tax subsidies. Most systems also report that they receive donations.

Opinion-based questions allowed respondents to rank their agreement with statements on a 5-point Likert scale ranging from strong disagreement (1) to strong agreement (5). Mean summary scores were generated for each of four topical areas (resource levels, public participation, system support, and system environment). The subjective assessments of the respondents reflect a generally positive outlook on EMS systems in their areas.

\section{DISCUSSION}

Following a surge of activity in the 1960s and 1970s, Federal support of EMS systems has steadily declined, leaving State and local governments to take the lead in program development and system design. In addition to dwindling Federal support, heterogeneity across regions with regard to factors such as population size, rurality, geographic layout, and funding sources affects EMS priorities in these regions. The lack of centralized funding coupled with the qualitative differences across regions that dictate different needs have led authors to conclude that EMS configurations vary significantly across the nation (IOM, 2006; Shah, 2006). The results of this study support these earlier conclusions with the exception of a few variables that were universally skewed, such as the use of first responders and the presence of medical control..

The rural - urban continuum is useful for establishing patterns of various features of EMS configurations. Urban systems have higher call volumes, use volunteers less frequently, support greater use of a tiered response structure and non-response vehicles, have increased non-emergent use, and have more-developed administrative structures (Giordano \& Davidson, 1994). Rural jurisdictions often must rely on volunteers, have longer response times, face high personnel turnover and service coverage issues, lack quality medical direction, and may lack advanced prehospital care. Further, rural areas often encounter greater financial constraints and sometimes even lack the infrastructure for complete public access to the emergency care system (IOM, 2006; NHTSA, 2004; Garnett \& Spoor, 1994). This study supports some of these characterizations; for example, urban areas rely on fire-based agencies for transport, whereas rural systems tended to use private and thirdservice agencies to provide transport. However, some factors did not vary as a function of rurality. Nearly all respondents reported the use of first responders (98.3\%) and ALS personnel (97.9\%) within their systems.

Medical control was present at the system level for over $96 \%$ of systems; however, the likelihood that the director was in-house was higher for more urbanized systems. More rural systems were more often supported by an external director. This may be because urbanized systems have complex administrative structures in place to support their size, personnel, and budgets. As anticipated, urban and suburban systems have a significantly higher presence of operating protocols that allowed for response to the scene and patient transports without the use of lights and sirens for less emergent cases.

Availability of wireless E-911 in the EMS system differed significantly by rurality. This is an important issue for rural areas and our data indicate this difference to be largely dependent on the availability of wireless 911. It is notable that despite this variation, $90 \%$ or more the small non-metro and completely rural areas could still use the EMS system through hardwire-enhanced 911.

Although the primary source of system funding did not vary by rurality, there were significant differences in individual finance categories. With the exception of Pennsylvania, the use of taxes to finance EMS generally increases as the system becomes more urban. A similar trend was observed for systems in receipt of nonhomeland security grants. Whereas the commitment of municipal or county funding is often logically a matter of having a large enough population to support the tax base, the difference in grant funding may be a result of 
having the more sophisticated administrative systems generally needed to apply for and manage these funding streams. It is also possible that this difference may reflect a divide in the focus areas of those organizations awarding the grants. The true source of this difference in grant funding warrants further study. Billing and reimbursement continues as a source of significant funding, and it is interesting that rural systems receive a higher proportion from these sources. Although rural systems may be thought to rely more often on fundraising and donations, these data may indicate that the EMS industry is evolving and systems of all backgrounds are learning to "make do" with new tools and services.

At its core, health care is local, so variation in system configurations is expected. We recognize that no single model, design, or delivery system is suitable for every locality. Local systems must select elements of EMS based on needs and available resources to survive and provide essential community services. As a result, EMS systems incorporate multiple agency types, response configurations, and funding streams, and strive to integrate these elements into a cohesive whole. This study shows significant differences between and within States and verifies many distinctions across categories of system size and rurality. Despite the variations, EMS systems presented fairly consistent views through the survey's opinion questions, noting pervasive system change and positive environments and support structures, although adequate resources remain a key concern.

This pilot study of mid-Atlantic EMS systems, especially given the high response rate, demonstrates that a similar process could be executed on a national scale. The ability to link descriptive EMS system data on a national level with these datasets would only increase the usefulness of these data, allowing for greater comparison of system designs and outcomes. 


\section{Table of Contents}

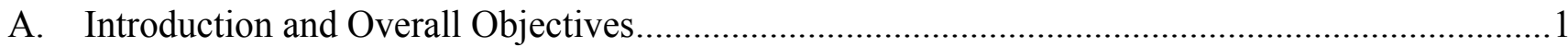

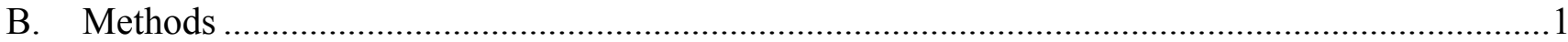

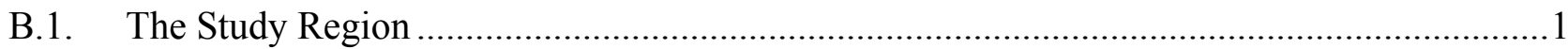

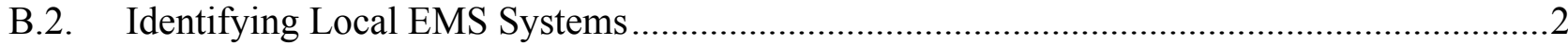

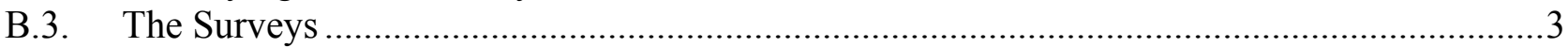

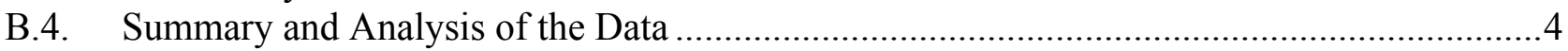

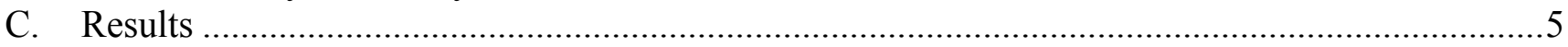

C.1. Categorization of Systems and Non-Systems Within States and Response Rates ...................5

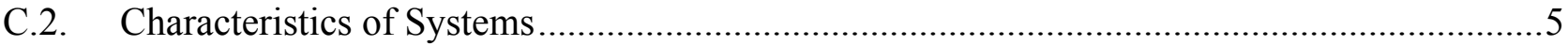

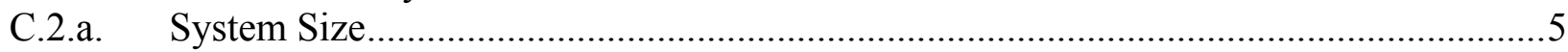

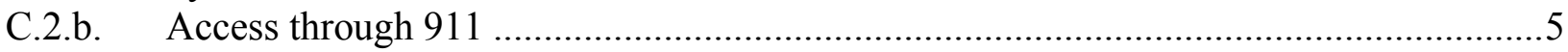

C.2.c. Provider Agency Organizations................................................................................. 6

C.2.d. Response Configurations and Use of Volunteers ........................................................

C.2.e. Response to Calls Outside Primary Service Areas ...........................................................

C.2.f. Medical Control............................................................................................

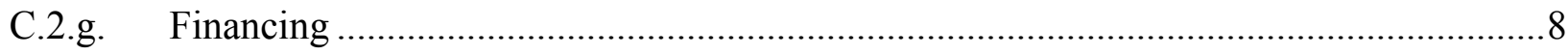

C.2.h. Assessment of the System .................................................................................

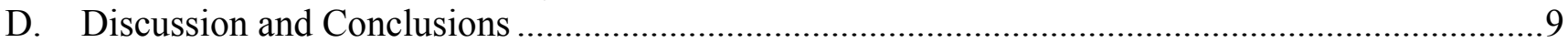

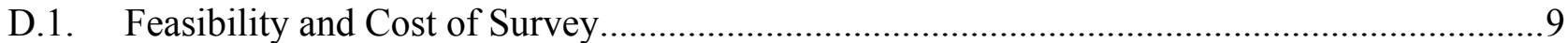

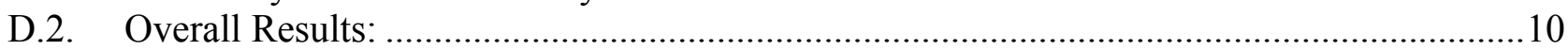

D.2.a. Common Themes: Variability Within and Across States..............................................10

D.2.b. Variability by Rurality of the Service Area................................................................... 10

D.2.c. Comparisons With EMS System Data Cited by the IOM Report .................................12

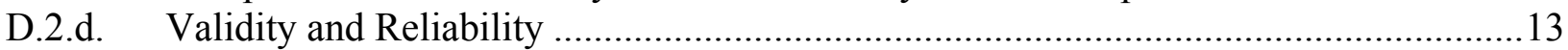

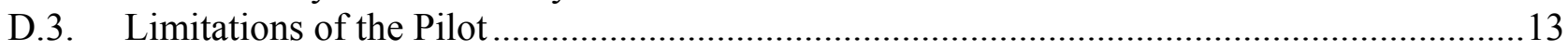

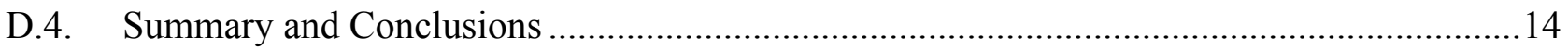

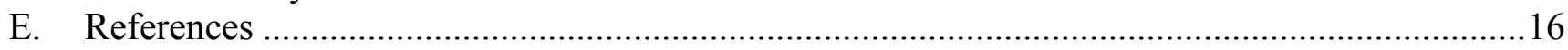

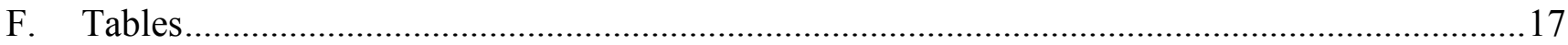

1. Size and Demographics of Study Region by State ...........................................................

2. Organization of the State EMS Office by State ……......................................................18

3. Response Rates by System Status, State and Rural-Urban Continuum of Service Area .....21

4. Characteristics of Non-System Counties …………........................................................22

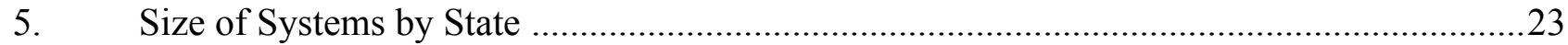

6. Size of Systems by Rurality of the Service Area ...........................................................24

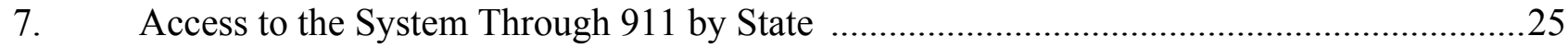

8. Access to the System Through 911 by Rurality of the Service Area ……............................26

9. Access to the System Through 911 by Size of System ……...............................................27

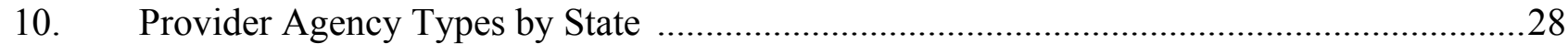

11. Provider Agency Types by Rurality of the Service Area …………………......................30

12. Provider Agency Types by Size of System ……………………………….....................32

13. Estimated Population Coverage of Primary EMS Agency Type and Primary Response

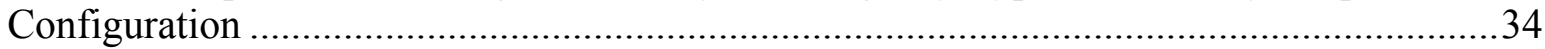

14. Response Configurations and Use of Volunteers by State …………………......................35

15. Response Configurations and Use of Volunteers by Rurality of the Service Area ................36

16. Response Configurations and Use of Volunteers by Size of System …………………….....37 
17. Response to Calls Outside Primary Service Areas by State ...........................................38

18. Response to Calls Outside Primary Service Areas by Rurality of the Service Area ............39

19. Response to Calls Outside Primary Service Areas by Size of System ...............................40

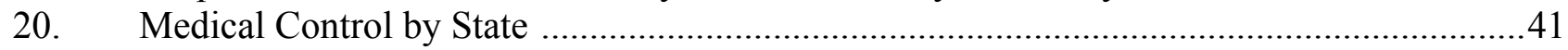

21. Medical Control by Rurality of the Service Area .........................................................42

22. Medical Control by Size of System ..........................................................................43

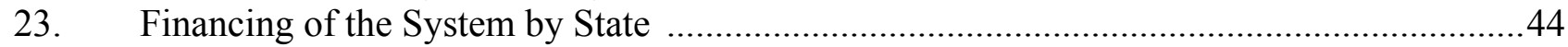

24. Financing of the System by Rurality of the Service Area ............................................45

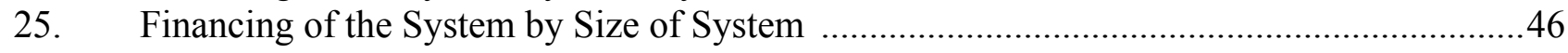

26. Subjective Assessments by State ...........................................................................47

27. Subjective Assessments by Rurality of the Service Area .............................................49

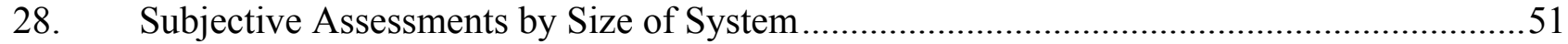

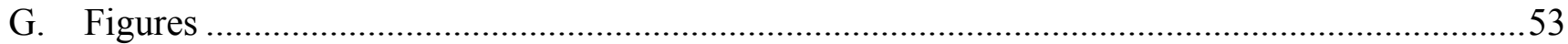

1. Counties by Rural-Urban Continuum............................................................................5

2. Counties by System Status and Response Status .......................................................54

3. $\quad$ Systems by Size of Service: \# EMS Responses per Year ..............................................55

4. $\quad$ Systems by Size of Service: \# EMS Responses per 1,000 population ..............................56

5. Systems by Number of Personnel per 1,000 Population ..............................................5

6. Systems by Wireless 911 Access .............................................................................58

7. Systems by Primary (Most Frequently Used) Agency Type: First Response .....................59

8. Systems by Primary (Most Frequently Used) Agency Type: Transport ............................60

9. $\quad$ Systems by Primary (Most Frequently Used) Agency Type: Dispatch .............................61

10. Systems Categorized by Primary (Most Frequently Used) Response Configurations ..........62

11. Systems Categorized by How Often Transport Agency Responds to Outside Primary

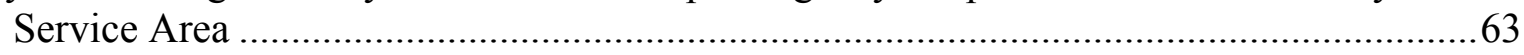

12. Systems Categorized by Medical Control …............................................................64

13. Systems Categorized by Primary Source of Funding ..............................................65

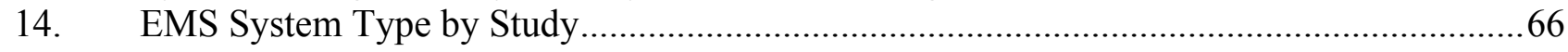

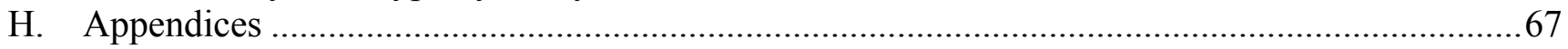

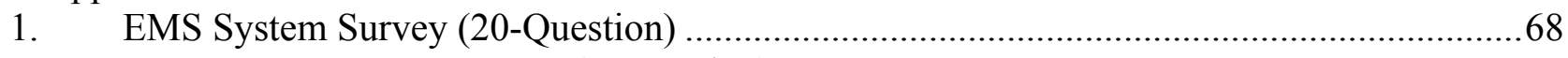

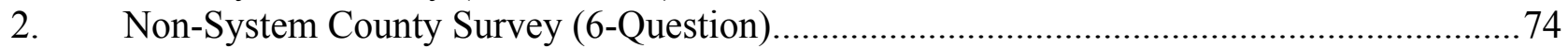




\section{A. Introduction and Overall Objectives}

Emergency medical services systems are configured differently depending on several factors, including the size, demographics, geography, and politics of the communities they serve. Although some information exists about the organization, financing, and delivery of EMS in 200 of the Nation's largest cities (Williams, 2007), this information is incomplete and does not provide any information on how services are organized outside of these large urban areas. The lack of information about lesspopulated regions is significant given that $75 \%$ of the Nation's population resides outside of the areas discussed by Williams. What we do know, however, is that there is wide variability in how systems are structured and organized, with little evidence to support alternative configurations in terms of their impact on the effectiveness and efficiency of service delivery (IOM, 2007).

To understand which EMS systems work well, an important first step is the development of a typology of system configurations so that they may be evaluated on a common basis. This pilot research attempts to develop such a typology by characterizing local EMS systems in the Mid-Atlantic region of the United States. This typology will also assist in establishing a common EMS language and provide the basis for tracking progress in the development of EMS systems in the future. The need for these data is important. In its effort to better prepare for mass casualties and disasters, the Nation must have a better understanding how emergency medical services are organized and delivered at the local level so these resources are appropriately integrated into an overall systems response capability (IOM, 2007).

Initially, the project was to use a case study approach and focus on the collection of detailed information from a limited number of prototypical EMS delivery models. The project team convened a panel of EMS experts to discuss the types of systems of interest and their prominent features. The panel also helped identify a handful of (mostly larger and well known) EMS systems located around the country. The identification of these systems was difficult, however, due to the great variability in how local EMS systems were organized. Subsequently, it was decided that a more appropriate first step would be a census-style survey of EMS systems. This change to the study methodology would allow for wider exploration of the variation in EMS system design and response configurations. After further consultation with NHTSA, it was agreed that relying on specific details from a limited number of archetypal systems would likely not be useful in generalizing ideas to a national scope given the enormous number of derivatives that would need to be considered. A full accounting of EMS systems would yield a data set thought to be far more useful as a research and planning tool, similar to the way the National Inventory of Trauma Centers has benefited the trauma community. With this revised approach, NHTSA began this accounting and characterization of EMS systems as a pilot project, beginning in the Mid-Atlantic region.

\section{B. Methods}

\section{B.1. The Study Region}

The Mid-Atlantic region consists of seven States, Delaware, Maryland, New Jersey, North Carolina, Pennsylvania, Virginia, and West Virginia, and the District of Columbia. This region was chosen for the pilot study for several reasons. First, and perhaps most important, we expected that most of the archetypal systems would be present in some of these States. In addition, the States themselves vary with respect to how EMS is organized at the State and local levels. Moreover, the region is diverse in geography and demographic composition. This diversity allows an examination of variations in EMS 
configurations by level of rurality and size of the service area. Finally, we expected the support of the Mid-Atlantic EMS Council, a long-standing collaboration of the seven States and the District, would greatly assist in the execution of the project.

Table 1 summarizes the characteristics of the States in the study region. Data to characterize the States and their counties come from the 2003 Area Resource File (Department of Health and Human Services, 2003). The States vary considerably by size and demographics. Of particular relevance is the distribution of counties within States by rurality as defined by the rural-urban continuum (Butler, 1994) (see below). The total percentage of the population that lives in large metropolitan areas ranges across States from over 85\% (Maryland and District of Columbia) to less than 20\% (West Virginia, North Carolina, and Delaware). The only States with more than 1\% of the population living in completely rural areas are West Virginia (21 of its 55 counties are categorized as completely rural), Virginia (32 of its counties are categorized as completely rural), and North Carolina (23 of its 100 counties are categorized as completely rural). A total of 81 counties in the study region are categorized as large metropolitan; 100 as small metropolitan; 31 as large non-metropolitan; 112 as small non-metropolitan, and 81 as completely rural (Figure 1). As shown in Table 1, there is also wide variation in rates of injury fatality both across and within States (ranging from 38.2 per 100,000 population in New Jersey to 80.7 per 100,000 in West Virginia).

Based on data from the National Association of State EMS Officials (NASEMSO, 2005), States are categorized according to selected characteristics of the State EMS authority (Table 2). Maryland is the only State in which the State EMS agency is an organizationally independent unit reporting directly to the Governor. In the District of Columbia, EMS is incorporated in a cabinet level department. The remaining States position these authorities within an "Office of EMS," situated in the organizational hierarchy of a State health department. The 29 functions over which the State EMS agency has definitive authority are also summarized in Table 2. In Maryland and North Carolina, the State EMS office has authority over nearly all of the functions (28 of 29 in Maryland and 27 of 29 in North Carolina). In contrast, Delaware has definitive authority over only 13 of the 29 and Virginia, 17 of the 29.

\section{B.2. Identifying Local EMS Systems}

With the study region for the pilot defined, the next task involved the identification of "systems" present at the jurisdictional or county level. Traditionally, an EMS system has been defined as a comprehensive, coordinated arrangement of resources and functions organized to respond to medical emergencies in a timely manner (P.L. 93-154, 1973). This definition serves well when looking at the broader functions or components of the system, but falls short in terms of clarity when attempting to identify system entities at the jurisdictional level. For example, a single provider agency may be able to adequately act upon the 15 components originally outlined in the Emergency Medical Services Act of 1973 or later modified in the EMS Agenda for the Future (NHTSA, 1996), but this would only illustrate enough coordination to internally operate and often does not touch on broader issues such as policy development and implementation or regionalization of services. For the purpose of this study, an EMS system is operationally defined as present when there is an identifiable local entity within a State EMS system's administrative hierarchy below the State level (if the State is sufficiently large enough) and immediately above the level of an individual provider agency. In instances where an agency is the sole provider for a jurisdiction and/or that agency serves in a leadership capacity to other services (i.e., there is not an independent administrative body for the jurisdiction), it is regarded as an EMS system. At the core of this particular definition is a desire to evaluate EMS at a level suffi- 
ciently close to the localities served by care personnel, but also a need to ensure that we could measure features that looked beyond the organizational boundaries of just a single provider. It should be noted that aeromedical and interfacility transport services were not considered as part of this study.

The identification of systems in these States involved the following steps. First, each State EMS office was contacted several times in person, by phone, and by e-mail to learn more about the specific EMS environment and organization in the State. After being informed of the project, its overall goals, and our working system definition, every State EMS official provided contact information for each EMS system in their respective areas. The majority of systems identified were at a county (or equivalent) level, with a handful of additional systems representing multi-jurisdictional areas, independent cities, or miscellaneous systems such as an airport authority or a military installation.

In three States (New Jersey, Virginia, and West Virginia), there were geographic areas identified that contained no EMS systems based on our definition. Conversations with the State EMS offices revealed that while there were EMS agencies operating in these areas, they did not do so under a coordinated, local administration. As a result, these EMS agencies operated almost completely independent of each other and would interact directly with the State EMS agency on any matters (e.g., protocols, certification) that was outside the scope of its organizational walls. New Jersey presented a unique illustration of this circumstance. According to the State EMS director, the State has no regional EMS structure and local agencies are not aligned in any meaningful or consistent way with regard to their administration (Halupke, 2006). EMS services are credentialed at the level of the locality and have no administrative layers between the individual townships and the State. To characterize areas such as these at some cursory level, contact information for these counties (often an emergency services, public health, or related contact) was obtained from the National Association of Counties (NACO).

\section{B.3. The Surveys}

All EMS systems, as defined using the criteria above, were mailed a 20 -question survey, along with a postage paid return envelope (see Appendix A for a copy of the survey). This survey was sent to the contact identified by the State EMS office, typically the Director of EMS for the system. To maximize the response rate, we limited the number of questions in the survey to 20 . The survey addressed the following topics:

$>$ Overall size of the system, as characterized by the annual number of EMS responses and transports, as well as the total number of EMS personnel;

$>$ Access to the system through 911;

$>$ Provider and dispatch agency types;

$>$ Response configurations, operating procedures, and use of volunteers;

$>$ Mutual-aid agreements and response to calls outside the primary service area;

$>$ Medical control; and

$>$ Source of funding for the system.

The survey also contained a series of opinion questions focusing on resource levels, system support, system environment, and system change. Finally, respondents were given the opportunity to provide additional narrative to better describe any unusual system structure, functions, or arrangements.

State EMS directors were given an opportunity to review drafts of this survey and provide feedback as part of several Mid-Atlantic EMS Council meetings. Several State EMS directors chose to assist us 
by providing agency envelopes and a signed note on official letterhead to accompany our cover letter. This was done to mimic a package mailed by the State itself and to encourage survey completion through the endorsement of the State director.

Counties without EMS systems meeting our criteria were sent an abbreviated 6-question survey (Appendix B) designed to gather basic data on access, provider agencies, and funding from a contact in the county government. Recipients of the abbreviated survey were given an opportunity to provide contact information for a county government office or a lead organization responsible for the oversight of EMS in their jurisdictions (consistent with our definition above). When they did, we followed up with the larger 20-question survey to more fully explore the EMS features of that area.

For both the full and abbreviated surveys, non respondents received second mailings with pre-paid return envelopes as well as follow-up phone calls or faxes as needed.

\section{B.4. Summary and Analysis of the Data}

Data collected were entered into a Microsoft Access (v. 2002) database and analyzed using the SAS statistical software package (v. 9.1,). Analyses were primarily descriptive, focusing on frequencies of characteristics and exploration of differences across the States. Differences between geographic and demographic categories were also examined using chi-square analysis for dichotomous and categorical variables and analysis of variance (ANOVA) techniques were used to explore differences across continuous variables. In instances where ANOVA results showed significant differences, Duncan's multiple range test was used to determine the sources of the variation. Maps were generated using ArcMap GIS software (v. 8.2).

System characteristics were summarized by: (1) State; (2) rurality of the area serviced by the system; and (3) size of the area serviced by the systems as measured by the annual number of EMS responses (as reported by the systems). The rural-urban continuum classification scheme (Butler, 1994) was used to categorize counties by rurality. The standard categorization scheme defines 4 metropolitan (metro) and 6 non-metropolitan (non-metro) categories. Metropolitan areas are grouped by population size and non-metro counties by degree of urbanization and proximity to metro areas. For the purpose of this analysis, these 10 codes were further collapsed into 5 categories:

$>$ Large Metro Areas (RUC Codes 0 and 1): counties in metro areas of 1 million population or more (including both central and fringe counties of metro areas)

$>$ Small Metro Areas (RUC Codes 2 and 3): counties in metro areas of less than 1 million population (includes both those of greater than or less than 250,000 population)

$>$ Large Non-Metro Areas (RUC Codes 4 and 5): urban population of 20,000 or more (including those adjacent to and not adjacent to a metro area)

$>$ Small Non-Metro Areas (RUC Codes 6 and 7): urban population of 2,500 to 19,999((including those adjacent to and not adjacent to a metro area)

$>$ Completely Rural: (RUC Codes 8 and 9): population less than 2,500 (including those adjacent to and not adjacent to a metro area)

The size of the EMS systems were categorized by tertiles of the distribution of annual number of EMS responses and labeled as small, medium and large ( small $=<3,968$ calls; medium $=3,968-12,000$ calls; and large $=>12,000$ calls). Self reported data on size were not available for 13 of the systems. 


\section{Results}

\section{C.1. Categorization of Systems and Non-Systems within States and Response Rates}

The total number of systems and non-systems by State and rurality are summarized in Table $\mathbf{3}$ and in Figure 2. A total of 273 systems and 82 non-system counties were identified across the seven States and the District of Columbia. No systems were identified in New Jersey. Of the 273 system surveys sent out, 235 were returned, yielding a response rate of $86.1 \%$. Response rates among systems did not vary significantly by State or rurality, although the response rate among completely rural systems was lower (79.6\%) than less rural systems (Range: $86.7 \%$ to $92.0 \%$ ). The response rate among the non-system counties was considerably lower; only 48 of the 82 non-system counties returned the survey for a response rate of $55.8 \%$. These response rates were consistent across States and rurality of the service area.

Before proceeding with a detailed description of the systems surveyed, we describe the responses from the non-system counties (summarized in Table 4). Of the 48 non-system respondents, $60.4 \%$ indicated that there was some oversight of EMS by the county government. An additional $29.2 \%$ indicated that while there was no county oversight, there was a single lead organization outside the county government that provided oversight of EMS in their areas. In New Jersey, over one-fifth of the respondents (21.4\%) indicated there was no lead organization or county oversight of EMS (Compared to $4.4 \%$ in Virginia and $9.1 \%$ in West Virginia). Nearly two-thirds of the respondents indicated their counties could access EMS through wireless 911 and nearly all (95.7\%) denoted the use of ALS personnel. A combination of fire-based, private, and hospital-based agencies can be found throughout the non-system counties and the majority (89.6\%) also use volunteers in their EMS environments.

\section{C.2. Characteristics of Systems}

In this section, we describe the characteristics of the systems that responded to our survey.

\section{C.2.a. System Size}

The size of the systems included in the survey is characterized by self reported information on: (1) number of EMS care personnel at all levels, including volunteers; (2) annual number of EMS responses; and (3) annual number of EMS transports. These numbers were divided by the resident population to obtain estimates of the totals per 1,000 population. The mean and median numbers across counties by State and by rurality are summarized in Tables 5 and 6. Variation in these numbers by system within States is evident in Figures 3-5.

\section{C.2.b. Access through 911}

Although slightly more than one-quarter of the respondents across all States indicate that individuals can call EMS though a 7 or 10 digit number, only two respondents (representing an airport and a military installation in Maryland) report that this is the only way individuals can access EMS (Tables 79). Nearly all respondents (94\%) report the availability of enhanced 911 (E-911, systems in which caller's phone number and geographic location appear on screen), although only $59 \%$ note access is available through wireless E-911. Access through wireless E-911 varies by both State and rurality (Figure 6). As expected, wireless E-911 is less available in more rural systems and in smaller systems. For example, only $41 \%$ of respondents from rural systems report that wireless E-911 is available to them while that percentage is at least $15 \%$ higher within all other levels of rurality (ranging from almost $57 \%$ in large metro areas to nearly $70 \%$ in large non-metro areas). 


\section{C.2.c. Provider Agency Organizations}

Most respondents (60\%) report that more than one type of agency is involved in first response as well as transport activities (Tables 10-12). Only 19\% of the systems surveyed report that more than one type of agency is involved in dispatch. The involvement of multiple agency types in first response and transport is fairly consistent across States and categories of the urban-rural continuum.

For the purpose of the survey, we defined first response as "the dispatch of medical personnel to the scene in a non-transport vehicle." Of those systems using first responders ( $98 \%$ of all systems report using first responders), $70 \%$ of respondents indicate use of a fire department to provide these services. Approximately half (52\%) report that the fire department is the primary (most frequently used) agency involved in first response, although this percentage is highest for more urban areas $(76 \%$ for large metro areas) and lowest for rural areas ( $22 \%$ for completely rural areas). Large systems are significantly more likely to use fire-based first response than their smaller counterparts $(85 \%$ compared to $50 \%$ ). In rural areas, the primary agency identified for first response is more equally likely to be fire, third service or a private agency. The primary type of agency used for first response also varies across and within States (Figure 7).

The primary type of agency used for transport (from the scene to a health care facility) also varies across and within States (Figure 8). Over all systems, there is no predominate type of agency providing transport. Within States, one or two types of agencies typically predominate. Nearly two thirds $(65 \%)$ of respondents in large metro areas report a fire department as the primary agency used for transport. In less urban areas, this percentage is considerably lower, ranging from $0 \%$ in completely rural areas to $22 \%$ in smaller urban areas. In these areas, the use of a third service agency is more typical than in the large metro areas (ranging from $25 \%$ in the large non-metro areas to $41 \%$ in the small metro areas). The reported use of a fire department as the primary transport agency varies by system size, increasing from $16 \%$ in small systems to $27 \%$ in medium-sized systems and $38 \%$ in large systems. Interestingly, use of independent volunteer ambulance services (either as a participating or primary transport agency), does not vary consistently across the rural-urban continuum.

Nearly one half (48\%) of respondents affirm that emergency medical dispatch of response vehicles is performed primarily by a city or county communications department. An additional $22 \%$ of systems are primarily served by a public safety department. These agency types closely resemble each other and are likely responsible for all emergency services (police, fire and EMS) communications. However, they remain distinct based on either additional functions performed (e.g. a county communications department might also be responsible for airports or public works) or on the name of the governmental department in which it resides. As with first response and transport, these percentages vary across and within States (Figure 9) as well as by rurality (Table 11).

Estimates of the total population within and across all States that are served by the different types of first response, transport, and dispatch agencies were derived by applying the percent distributions of the most frequently used agency type by the population figures for each system. The results are summarized in Table 13. Across all systems, we estimate that approximately $36 \%$ of the resident population lives in counties served primarily by fire-based agencies, $31 \%$ by private agencies and $20 \%$ by government-based / third service agencies. However, these percentages vary substantially by State. 


\section{C.2.d. Response Configurations and Use of Volunteers}

Although first responders are used in most systems (98\%), only $36 \%$ of respondents indicate they are commonly dispatched to all 911 calls. Respondents were asked to indicate the response configuration most frequently used within their systems; the results are summarized in Tables 14-16 and Figure 10. The majority of respondents $(80 \%)$ said that ALS transport was most frequently used. This percentage was slightly higher in the large and small metro areas ( $89 \%$ and $92 \%$, respectively) compared to non-metro and rural areas $(76 \%-78 \%)$. In general, it was more frequent in large metro areas for the common response configuration to include both ALS first response and ALS transport (52\% compared to $25 \%$ to $41 \%$ elsewhere). Estimates of the total population within and across all States that are served by ALS and BLS personnel are summarized in Table 13. The majority of the population $(83 \%)$ live in areas served primarily by ALS transport personnel (41\% live in areas where the primary configuration is BLS first response/ALS transport, $36 \%$ in areas where the primary configuration is ALS first response/ALS transport, $6 \%$ in areas where ALS transport only is the norm).

The majority of respondents ( $86 \%$ ) report the use of volunteers, although this percentage varies by State (Table 14). Among EMS systems that deploy volunteers, the average percent of personnel serving in such a capacity is similar across the urban-rural continuum ( $45 \%$ across all systems, Table 15). However, there is a tendency for this percentage to be lower for larger systems (29\%) compared to medium and small systems ( $36 \%$, Table 16). The percentage of systems in which volunteers typically respond to calls from a fire or EMS station house as opposed to from their homes, work, or other locations within a designated response area varies significantly by both rurality and system size $(68 \%$ in large metro areas, $43 \%$ in large non-metro areas and $9 \%$ in completely rural areas). Over two-thirds of respondents note that call coverage is of major concern due to staffing shortages, however this unease was more prevalent among less urban systems (over $80 \%$ of the small non-metro and completely rural counties indicate call coverage as a major concern compared to only $57 \%$ of the large and small metro areas).

Nearly all (92\%) of the systems surveyed have operating procedures that allow EMS transports without use of lights and sirens, whereas only $70 \%$ have operating procedures that permit response to a scene in a similar manner. The transport of patients to non-hospital destinations is sanctioned in only $19 \%$ of all systems, with significant variation noted by rurality of the service area.

\section{C.2.e. Response to Calls Outside Primary Service Areas}

Nearly all respondents (94\%) report their systems having mutual aid agreements, although the components addressed by these agreements vary widely across and within States (Tables 17 - 19). While the majority (88\%) of mutual aid agreements address issues of service coverage, only a half address communication linkages and merely one-third address licensure or certification of personnel, financial reimbursement or liability issues.

Over one-quarter (29\%) of respondents indicate that their primary transport agency often responds to calls outside the primary service area; an additional $44 \%$ indicate they sometimes respond to these calls. (Tables 17-19 and Figure 11) The percentage of systems in which the primary first response agency often or sometimes responds to calls outside the primary service area is slightly lower $(12 \%$ and 39\% respectively). The percentage of systems in which the primary transport agency or first response agency responds to calls outside the service area is lower for less urban as compared to more urban areas (e.g., $43 \%$ of the transport agencies in large urban areas often respond to calls outside the service area compared to only $23 \%$ of transport agencies in completely rural areas). 


\section{C.2.f. Medical Control}

Nearly all respondents (96\%) indicate medical direction is present at the system level (Tables 20 -22 and Figure 12). In $40 \%$ of these systems, this leadership is provided by a systemwide, in-house medical director who is a physician chosen or hired by the system's coordinating organization. For another $50 \%$ of the systems, medical oversight is provided by an external director who is a physician administering from a remote organization, perhaps based at a local hospital. The percent of systems with a systemwide, in-house medical director is considerably higher for more urban areas and larger systems ( $52 \%$ for large metro areas compared to $26 \%$ for completely rural areas, $54 \%$ in large systems and $32 \%$ in small systems).

\section{C.2.g. Financing}

Multiple sources of funding are used to finance EMS systems (Tables 23-25 and Figure 13). When asked about their primary source of funding, the majority of respondents in 4 States as well as the District of Columbia indicate their primary source of funding stems from tax subsidies, while in Pennsylvania and West Virginia, systems are primarily financed by fees or billing for services. There is a strong relationship between the source of primary funding (tax subsidies versus fee for service) and the rural-urban continuum, with more urban areas depending more extensively on tax subsidies (e.g., $72 \%$ of systems in large metro areas compared to $43 \%$ of systems in completely rural areas).

\section{C.2.h. Subjective Assessment of System-wide Features}

In the last part of the survey, respondents were asked their opinions about the adequacy of resource levels, public participation, system support, and the system environment. For each of the items listed within a particular subcategory, respondents were asked to indicate whether they: (1) strongly disagreed, (2) disagreed, (3) were neutral, (4) agreed or (5) strongly agreed with the statement. The percent agreeing or strongly agreeing with the statements is presented in Tables 26-28. To summarize responses within each category, scores were computed for each respondent by assigning scores of 1 to 5 as indicated above, adding the scores and taking the average across the items (2 items were reversed scored to be consistent with the direction of the other items). Respondents were also queried about the extent of change within their systems, both experienced in the past and anticipated in the future. Results suggest the following:

$>$ Resource Levels: Only 30\% of respondents across all States agreed or strongly agreed that their systems had adequate staff to meet demand; $58 \%$ agreed or strongly agreed they had adequate resources (vehicles, equipment). These percentages varied somewhat across States. There was no consistent correlation with rurality of the service area. The mean overall score for Resource Levels was 2.97 (range across States: 2.75 - 3.27).

$>$ Public Participation: Although 70\% of the respondents agreed that the public is satisfied with EMS services, most felt the public did not have a high level of awareness of the system (i.e., only $28 \%$ agreed or strongly agreed that the population served had a high level of EMS awareness, participation or support). Defibrillators can be found in many public places in $44 \%$ of the systems, although this percentage was significantly higher in larger metro areas (65\%) compared to less urban areas (e.g., 36\% in completely rural areas). The percentage of systems in which bystanders often provide CPR prior to EMS arrival was low $(25 \%)$ and did not vary significantly by State or rurality of the service area. The mean overall score for Public Participation was 3.06 (range across States: 2.97-3.35).

$>$ System Support: Most respondents (74\% agreed or strongly agreed) noted that hospitals in the system are supportive of the EMS personnel and agencies (74\% agreed or strongly agreed that hospitals are supportive). Overall, this satisfaction was consistent across States 
and levels of rurality. A lower percentage was satisfied with the level of physician involvement; only $59 \%$ of respondents agreed or strongly agreed that their system has a high level of physician involvement. Physician involvement was somewhat lower in the more rural versus urban areas. Most respondents were positive with regard to collaboration with non-EMS organizations (76\% agreed or strongly agreed that the EMS system collaborates with non-EMS organizations), although satisfaction varied somewhat across States and rurality of the service area; only $61 \%$ of systems in large metro areas agreed or strongly agreed that EMS systems collaborate with non-EMS agencies compared to $74 \%$ for completely rural and over $85 \%$ for non-metro areas. Over three-quarters of the respondents (79\%) agreed that the flow of patients through the system is generally smooth, with a tendency for a greater percentage of more rural areas positively endorsing this item ( $85 \%$ of the small non-metro and completely rural areas compared to $67 \%$ of the large metro areas). The mean overall score for System Support was 3.76 (range across States: $3.25-4.25)$.

System Environment: Over three-quarters (77\%) of all respondents said that their personnel enjoyed working within the system, with some variation evident across States and rurality. "Turf Wars" were noted as a problem for only one-quarter of the systems, with a tendency for more rural systems to indicate this as a problem. Politics were noted as a problem for $41 \%$ of the systems, but again, there was variation across States. The mean overall score for System Environment was 3.41 (range across States: 2.67 - 3.64).

Few respondents (18\%) agreed that their systems looked much the same as 10 years ago and even fewer $(8 \%)$ agreed that their systems will look much the same 10 years into the future. Further, less than one-half (46\%) agreed or strongly agreed that their systems adapt well to change.

\section{Discussion and Conclusions}

\section{D.1. Feasibility and Cost of Survey}

This pilot confirmed the feasibility of conducting a survey of local EMS systems. Overall, the response rate of the systems identified through the State EMS directors was high (86\%), with slightly lower response rates from systems in completely rural areas $(80 \%)$. This high response rate can be attributed to: (1) the reasonable length of the survey; (2) good contact information (i.e., surveys were sent directly to the individuals responsible for overseeing the system); (3) endorsement from the State EMS agency; and (4) multiple contacts by mail and telephone. The typical number of contacts, either by mail or phone, needed to receive a completed survey from the majority of EMS systems was 1, although this ranged as high as 4 for a handful of locations.

Not surprisingly, the response rate from non-system counties was considerably lower $(56 \%)$. In many instances, these surveys were sent to county officials with some responsibility for emergency services or public health. These contacts were obtained from the National Association of Counties (NACO), which maintains commercial mailing lists of government officials at the county level. Obtaining completed surveys from this group of respondents may have been hindered through inaccuracies in the NACO database or the lack of EMS focus or professional interest on the part of the identified individual.

This pilot study of mid-Atlantic EMS systems, especially given the high response rate, clearly demonstrates that a similar process could be executed on a national scale. As part of a national effort, the 
support of the State and regional EMS officials would be critical, not only in the identification and recruitment of systems, but also in the interpretation of the results. The benefits of a national research study would be remarkable. As data standardization continues to become more firmly established in EMS with efforts such as the National EMS Information System (NEMSIS) (http://www.nemsis.org) and the Performance Measures Project (http://www.nasemsd.org/Projects/PerformanceMeasures/), extending this pilot research on a national scale would be useful. The ability to link descriptive EMS system data on a national level with these datasets would only increase the usefulness of these data, allowing for greater comparison of system designs and outcomes.

\section{D.2. Overall Results:}

\section{D.2.a. Common Themes: Variability in and Across States}

Following a surge of activity in the 1960s and 1970s, Federal support of EMS systems has steadily declined, leaving State and local governments to take the lead in program development and system design. This shift has created a fractional system of care nationwide and continues to promote regional and individual approaches to system design (IOM, 2006; Shah, 2006). As noted in Table 2, States have evolved quite differently in how they handle the oversight of EMS. With such contrasting approaches in State regulation and policy, along with differences in overall size, demographics and geography, it is not surprising that we see many differences in our data across these States. The only consistency observed across our pilot States in our analyses were in variables where the data were universally skewed (e.g., the use of first responders was reported by $98.3 \%$, or almost all responding systems).

It is interesting to note, however, that there were many differences observed within each State as well. With the exception of Delaware and the District of Columbia, both quite small geographically and in the number of systems identified, the tables and maps overwhelmingly present a diverse view of EMS within a State's borders with few exceptions (e.g., all responding Pennsylvania systems indicate fees or billing for services as a primary source of funding, see Table 23 and Figure 13). Localities have long played an active role in how EMS should be delivered in their areas, and accordingly, jurisdictions have made choices that suit their local circumstances. As anticipated, differences are observable at the State level, although this may be in part due to the natural variation of systems along other lines, such as rurality and size. It is notable that even in areas where State policy might be able to impose consistency (e.g., system access through wireless E-911), this was often not observed within our sample.

\section{D.2.b. Variability by Rurality of the Service Area}

EMS has developed very differently throughout the country based on varied histories, economics, policies, and local needs. Perhaps the most pronounced demarcation of such differences is with respect to the rurality of a system's service area. Urban, suburban, and rural jurisdictions vary greatly with regard to population demographics, industry, and economics. Such diversity has led to equally varied expectations of an EMS system within those areas. In urban areas, systems are likely to have higher call volumes, use volunteers less frequently, support greater use of a tiered response structure and non-response vehicles, increased non-emergent use, and have a more developed administrative structure (Giordano \& Davidson, 1994). Conversely, rural jurisdictions often must rely on volunteer personnel, have longer response times, face high personnel turnover and service coverage issues, lack quality medical direction, and may lack access to advanced prehospital care. Further, these areas often encounter greater financial constraints and sometimes even lack the infrastructure needed to en- 
sure complete public access to the emergency care system (IOM, 2006; NHTSA, 2004; Garnett \& Spoor, 1994). Additionally, in urban and suburban areas where multiple agency types are used, the need for improved coordination and integration among disparate agencies increases (Williams, 2004).

When evaluated by level of rurality, our data support many of the differences noted above. The mean number of EMS responses was significantly higher for more urbanized systems, although the higher than expected use of volunteers was interesting. Nearly $80 \%$ of the respondents from large metropolitan systems reported the presence of volunteers and the average percent of system personnel that serve in some volunteer capacity was nearly $45 \%$, regardless of rurality. One item potentially affecting response time, particularly in volunteer-rich rural areas, is where individual personnel are based when on duty. In outlying areas, workers may not be at the same location as a fully equipped response vehicle, but somewhere within a designated response area and initiated via cell phone or pager. Rural volunteer personnel were far less likely to respond to calls from a fire or EMS station house (9.4\%) when compared to those in large metro areas (68.3\%). As expected, significant differences were noted between rural systems, whose respondents expressed far more concern about call coverage due to staffing shortages, and their more urban counterparts. Mutual aid agreements, formal arrangements between agencies to lend assistance across jurisdictional boundaries, are critical in rural systems, especially when service coverage is an issue. Our data indicate that such agreements were consistently present for a large majority $(>85 \%)$ of systems across all levels of the rural-urban continuum.

Although urban and suburban EMS systems would be expected to make greater use of tiered response configurations and advanced life support personnel than their rural counterparts (Giordano \& Davidson, 1994), it was noteworthy that this was not the case among our pilot systems. No significant differences were observed across the rural-urban continuum in either instance, but perhaps the most remarkable observances are that nearly all respondents reported the use of first responders $(98.3 \%)$ and ALS personnel (97.9\%) in their systems. Based on these findings, it seems apparent that the more rural areas of our study population have begun to consider a wider array of system designs in order to meet the unique needs of their jurisdictions. A modestly higher number of first response and transport agency types were reported in more urban areas when compared to rural systems. Although it was suggested earlier that this could lead to difficulties with interagency cooperation and integration, this does not seem to be the case among the pilot systems given the low reported incidence of problems associated with "turf wars" and politics.

Medical control was present at the system level (as opposed to the individual agencies) for over $96 \%$ of systems; however, the likelihood that the director to be in-house was higher for more urbanized systems. More rural systems were more often supported by an external director. This may be due to the fact that urbanized systems have more complex administrative structures in place to support their size, personnel, and budgets. As anticipated, respondents from urban and suburban systems reported a significantly higher presence of operating protocols that allowed for both response to the scene and patient transports without the use of lights and sirens for less emergent cases. It remains interesting, however, that there was a significantly higher occurrence of operating procedures allowing for transport to non-hospital destinations associated with rural systems. In general, the allowance for nonhospital destinations could be associated with a non-emergent transport, though the higher prevalence in the completely rural areas may be due to the fact that there are fewer acute care hospitals available in those areas. 
The technological sophistication of public access to the EMS system differed significantly by rurality. This is an important issue for more rural areas and our data indicate this difference to be largely dependent on the availability of wireless 911 access. It is notable that despite this variation, $90 \%$ or more of the small non-metro and completely rural areas could still access the EMS system through hardwire enhanced 911.

Although the primary source of system funding did not vary by rurality, there were significant differences found in individual finance categories. As expected, the use of tax subsidies to finance EMS generally increases as the system becomes more urban in nature. A similar trend was observed for systems in receipt of non-homeland security grants. Whereas the commitment of municipal or county funding is often logically a matter of having a large enough population to support the tax base, the difference observed in grant funding may be a result of having the more sophisticated administrative systems generally needed to apply for and manage these funding streams. It is also possible that this difference may reflect a divide in the focus areas of those organizations awarding the grants. As EMS continues to eye billing and reimbursement as a means to remain financially viable, it is interesting that a higher proportion of respondents from more rural systems receive funding from fees or billing for their services. While rural systems may be thought to rely more often on fundraising and donations, these data may be an indication that the EMS industry is evolving and systems of all backgrounds are learning to "make do" with tools and services perhaps newly available to them.

\section{D.2.c. Comparisons With EMS System Data Cited by the IOM Report}

Descriptive EMS system data cited in the Emergency Medical Services at the Crossroads (IOM, 2006) draws from two primary sources: the JEMS 200-City Survey, which annually evaluates EMS agencies in the Nation's largest cities, and the 2003 National Emergency Medical Services Survey, which conducted a nationwide evaluation by surveying State EMS offices. While clear differences exist between each of these projects and this pilot study, including the sampling frames and system definitions used, some comparisons are of their findings are warranted.

For EMS systems in our research containing one of the 200 cities surveyed by JEMS, a direct comparison was made between reported agency types and levels of service. Because the systems from our project were often larger in physical size and scope then the cities they encompass, we expected that agency types and service levels reported by a JEMS city may not be precisely the same as a whole system, but at least present within the system. Our study region contained 22 cities from the JEMS sample and 16 of our EMS systems provided data for comparison. Overall, the categorizations of first response and transport agency types as well as service levels were fairly consistent. More than $90 \%$ of the variable-to-variable comparisons were deemed equivalent. It is possible the small number of inconsistencies may have been from genuine changes within those systems or the use of historical data by JEMS (necessary for non-responding cities).

It is often convenient to categorize EMS systems into general headings such as fire-based, private, third service, or hospital-based. When looking at our pilot data in contrast with the groupings provided by JEMS and Mears, it is not surprising we see some differences (Figure 14). When looking at the area of first response, the JEMS survey clearly shows an over-representation of the fire service, which is likely due to its urban sampling frame, though data from our pilot study and Mears' work seem comparable. However, the comparison of transport types shows clearer differences, especially in the "fire-based" and "other" categories. Mears shows a higher proportion of fire-based systems and a comparable lower percentage of other (non-fire, non-hospital) types while the JEMS data reflect 
percentages firmly in between the other studies. The differences shown between the pilot and the Mears studies may be due to a higher representation of government-based and volunteer systems (47.5\% combined) in our work and is perhaps a function of the choice of States included in this research.

\section{D.2.d. Validity and Reliability}

Although similar nationwide data are lacking to evaluate data validity and reliability, additional perspectives are available from State and regional EMS officials overseeing the systems within this study. In an effort to begin evaluating such issues, the investigators reviewed preliminary results with the State EMS Director of Maryland. This initial discussion proved interesting and we were encouraged to continue the dialogue in greater detail by including several regional EMS administrators within Maryland. Through a teleconference, individual survey responses for every jurisdiction under each regional administrator's charge were reviewed to check for potential inaccuracies. While recognizing the potential drawbacks that could arise from any self-reported data, the State and regional EMS officials noted several issues that seemed to illuminate either minor inaccuracies or misinterpretations on the part of the survey respondents.

Our teleconference discussions focused on definitions used to classify response categories, question wording, as well as how to best interpret and present results for select questions. As an example of potentially misinterpreted response categories, several jurisdictions indicated the presence of private agencies providing either first response or transport, although regional administrators were not aware of any commercial ambulance organizations contracted to provide such services in these areas. It was speculated that respondents may have mistakenly selected these response categories to reflect fire service agencies that were thought to be private by way of their IRS 501(c)(3) status. Further, certain words within several questions were thought to be open to interpretation. An illustration of this point is the use of the word "primary" to describe an agency type, response configuration or source of funding. Current question formatting does not specify whether "primary" should be taken from the perspective of a system's population or geography. Having the opportunity to discuss an overall viewpoint of local EMS with the Maryland administrators in an interview-style conversation confirmed that the systems we discussed were indeed hybrid in nature. It was widely noted that the presentation of results from the perspective of a "primary" grouping should be taken cautiously because such categorizations may not best fully describe the complex, interconnected system underneath.

Overall, the feedback process was quite informative for the investigators and both interesting and useful according to the Maryland officials. The investigators will continue to follow up with each State EMS director to discuss State-specific results as well as the Mid-Atlantic EMS Council in order to provide feedback, make improvements to the survey instrument, and revise analysis plans for future consideration.

\section{D.3. Limitations of the Pilot}

There were several limitations associated with this pilot research and indeed, some of them are challenges in the broader realm of EMS systems research. The lack of existing, standardized definitions in describing the most fundamental elements of EMS presented survey design challenges. With widely varied State and local regulations, norms, and personal perspectives, the language used to classify agencies, and service levels becomes more difficult to develop. As an example, terms such as "volunteer agency" and "rescue squad" may mean the same thing in certain areas of the country or could be completely unique in others. Such issues, along with reliance on respondent self- 
classification, only compound the difficulties in designing survey instruments with a national scope in mind and could lead to overuse of "other" categories within particular questions.

Moreover, there will be a need to align the definitions of EMS elements used in any national census with definitions used with the NEMSIS database. As examples, the NEMSIS includes alternative levels of 'rurality' and 'EMS agency types.' As mentioned previously, a goal of completing this census

on a national level is to link the descriptive data collected with the NEMSIS, and this necessitates that the data sources have compatible terminology.

The classification of EMS systems, as opposed to individual cities or provider organizations, presents challenges due to their underlying complexity and the potential for heterogeneity even within the system itself. By definition, systems are created from the combination of many pieces, each of which may be very different. As an example, within a single countywide system, fire departments, private agencies, government and volunteer organizations may all be providing services, at a variety of levels in a multitude of ways. To this end, EMS can vary from town to town, even within a highly organized system. Multi-county as well as airport, tribal, or military EMS systems also present challenges.

Very large land areas, such as the 10-county system surrounding Pittsburgh, Pennsylvania, are difficult to classify with regard to demography and geography, irrespective of the EMS being provided. Atypical systems, while important to their respective State EMS structures and likely fairly homogeneous as individual units, may prove difficult to compare with the majority of jurisdictional systems.

Throughout our geographic area of interest, it is clear that EMS is credentialed in a variety of ways. At opposite ends of the spectrum are North Carolina, which defines through regulation the minimum service area of an EMS system to be one county, and New Jersey, which only credentials agencies at the local level but does not organize these agencies in any way below the State level (Halupke, 2006). As Mears (2004) convincingly stated, "The definition of an EMS system varies from State to State, which make any analysis of EMS systems impossible." This pilot study attempted to standardize the definition of an EMS system to promote more fluid analyses, but this design has excluded certain geographic areas from consideration. Further deliberation is warranted to determine whether these excluded areas should be considered differently and how they may be brought into the larger framework on a more uniform basis.

While the survey was designed to be broad and generic in nature to ensure brevity and answerability, it is by no means complete in terms of what should be asked of an EMS system. The questions address many of the key facets of system structure and environment, but some specific areas require further inquiry and there is a need to examine yet another class of quantitative and performance variables to assess the relative value of any given configuration. While the system as an entity works to improve the operations it governs, the effective administration of an EMS system requires a different perspective and knowledge-base than is found in field operations. Therefore, the identification of appropriate survey recipients is critical. As first-line administrators at the local level, it is difficult to gauge the consistency of respondents' backgrounds and whether their system roles generally take on a broad perspective (e.g., policy setting) or more targeted focus (e.g., field operations), hence a potential response bias exists.

\section{D.4. Summary and Conclusions}

At its core, all health care is local and to this end, variation is something we have come to expect within EMS. It is broadly recognized that no single model, design, or delivery system will be suitable 
for every locality, as local EMS systems must choose elements based on needs and available resources to survive and provide essential community services. As a result, EMS systems incorporate multiple agency types, response configurations, and funding streams while striving to best integrate these into a cohesive whole. The results of this study highlight noticeable differences between and within States and verified many of the expected distinctions across various categories of system size and rurality. Despite the variation observed in the structural elements assessed, EMS systems presented fairly consistent views through the survey's opinion questions, noting pervasive system change as well as positive environments and support structures, although adequate resources remain a key concern. 


\section{E. References}

1. Area Resource File (ARF). 2003. U.S. Department of Health and Human Services, Health Resources and Services Administration, Bureau of Health Professions, Rockville, MD.

2. Butler, M.A., \& Beale, C.L. 1994. Rural-Urban Continuum Codes for Metro and Nonmetro Counties. Washington, DC: Agriculture and Rural Economy Division, Economics Research Service, U.S. Department of Agriculture.

3. Garnett, F.G., \& Spoor, J.E.. "Rural Systems" in Kuehl, A.E. Prehospital Systems and Medical Oversight, Second Edition. 1994. Baltimore, MD: Mosby Lifeline.

4. Giordano, L.M., \& Davidson, S.J. "Urban Systems" in Kuehl, A.E. Prehospital Systems and Medical Oversight, Second Edition. Baltimore, MD: Mosby Lifeline, 1994.

5. Institute of Medicine. Emergency Medical Services at the Crossroads. 2006. Washington, DC: National Academies Press.

6. Halupke, K. A., director, Office of EMS, State of New Jersey. Personal conversation. May 1, 2006.

7. McGinnis, K.K. Rural and Frontier Emergency Medical Services Agenda for the Future. 2004. Kansas City, MO: National Rural Health Association.

8. Mears, G. 2003 National Emergency Medical Services Survey. 2004. Chapel Hill, NC: University of North Carolina at Chapel Hill.

9. NASEMSO. The Organization, Staffing and Function of State and Territorial EMS Offices. December 2005. Falls Church, VA: National Association of State EMS Officials.

10. NHTSA. EMS Agenda for the Future. August 1996. Washington, DC: National Highway Traffic Safety Administration.

11. North Carolina Administrative Code (NCAC). http://ncrules.State.nc.us/ncac/title $\% 2010 \mathrm{a} \% 20$ $\% 20$ health\%20and\%20human\%20services/chapter\%2013\%20-

$\% 20 \mathrm{nc} \% 20$ medical\%20care\%20commission/subchapter\%20p/subchapter\%20p\%20rules.html, Section .0200 - EMS Systems. Accessed May 15, 2007.

12. Public Law 93-154, EMS System Act of 1973. Washington, DC, 1973.

13. Shah, M.N. "The Formation of the Emergency Medical Services System." American Journal of Public Health, 96(3) March 2006.Williams, DM. "2006 JEMS 200-City Survey: EMS from all angles." JEMS. 2007 Feb ;32 (2):38-54

14. Williams, D.M. “2006 JEMS 200-City Survey: EMS from all angles.” JEMS. 2007 Feb ;32 (2):38-54

15. Williams, M. "Local EMS System Components and Current Issues" [presentation slides] Available at http://www.iom.edu/File.aspx?ID=20952. Accessed September 5, 2006. 
Table 1: Characteristics of States in the Study Region

\begin{tabular}{|c|c|c|c|c|c|c|c|c|}
\hline & DC & $\mathrm{DE}$ & MD & NC & NJ & PA & VA & WV \\
\hline Total Population & 572,059 & 783,600 & $5,296,486$ & $8,049,313$ & $8,414,350$ & $12,281,054$ & $7,078,515$ & $1,808,344$ \\
\hline Land Area (sq. mi.) & 61 & 1,954 & 9,774 & 48,711 & 7,417 & 44,817 & 39,594 & 24,078 \\
\hline $\begin{array}{l}\text { Population Density } \\
\text { (people per sq. mi.) }\end{array}$ & 9,317 & 401 & 542 & 165 & 1,134 & 274 & 179 & 75 \\
\hline \multicolumn{9}{|l|}{$\begin{array}{l}\text { Number of Counties by } \\
\text { Urban-Rural Continuum } \\
\text { (and \% of State's pop'n) }\end{array}$} \\
\hline All counties & 1 & 3 & 24 & 100 & 21 & 67 & 134 & 55 \\
\hline Large Metro & $1(100.0 \%)$ & $0(0.0 \%)$ & $12(87.2 \%)$ & $7(16.8 \%)$ & $17(89.9 \%)$ & $12(50.9 \%)$ & $31(52.5 \%)$ & $1(2.3 \%)$ \\
\hline Small Metro & $0(0.0 \%)$ & $2(80.0 \%)$ & $3(5.5 \%)$ & $28(50.7 \%)$ & $4(10.1 \%)$ & $21(33.7 \%)$ & $31(25.6 \%)$ & $11(40.0 \%)$ \\
\hline Large Non-Metro & $0(0.0 \%)$ & $0(0.0 \%)$ & $2(3.2 \%)$ & $8(8.9 \%)$ & $0(0.0 \%)$ & $6(5.0 \%)$ & $11(6.7 \%)$ & $4(15.8 \%)$ \\
\hline Small Non-Metro & $0(0.0 \%)$ & $1(20.0 \%)$ & $6(3.5 \%)$ & $35(19.3 \%)$ & $0(0.0 \%)$ & $23(9.6 \%)$ & $29(9.3 \%)$ & $18(27.9 \%)$ \\
\hline Rural & $0(0.0 \%)$ & $0(0.0 \%)$ & $1(0.6 \%)$ & $22(4.2 \%)$ & $0(0.0 \%)$ & $5(0.7 \%)$ & $32(6.0 \%)$ & $21(13.9 \%)$ \\
\hline \multicolumn{9}{|l|}{ Percent of Population... } \\
\hline Male & 47.1 & 48.6 & 48.3 & 49.0 & 48.5 & 48.3 & 49.0 & 48.6 \\
\hline 65 Years and Older & 12.2 & 13.0 & 11.3 & 12.0 & 13.2 & 15.6 & 11.2 & 15.3 \\
\hline Below Poverty Line & 20.2 & 9.2 & 8.5 & 12.3 & 8.5 & 11.0 & 9.6 & 17.9 \\
\hline \multicolumn{9}{|l|}{ Percent of Population $^{\mathrm{a}} \ldots$} \\
\hline White & 32.2 & 75.9 & 65.4 & 73.1 & 74.4 & 86.3 & 73.9 & 95.9 \\
\hline African-American & 61.3 & 20.1 & 28.8 & 22.1 & 14.4 & 10.5 & 20.4 & 3.5 \\
\hline Indian/Alaska Native & 0.8 & 0.8 & 0.7 & 1.6 & 0.6 & 0.4 & 0.7 & 0.6 \\
\hline Asian & 3.1 & 2.4 & 4.5 & 1.7 & 6.2 & 2.0 & 4.3 & 0.7 \\
\hline Some Other Race & 5.1 & 2.7 & 2.6 & 2.9 & 7.0 & 2.0 & 2.8 & 0.3 \\
\hline \multicolumn{9}{|l|}{ Percent of Population... } \\
\hline Hispanic or Latino & 7.9 & 4.8 & 4.3 & 4.7 & 13.3 & 3.2 & 4.7 & 0.7 \\
\hline $\begin{array}{l}\text { Age-Adjusted Injury } \\
\text { Death Rates - All Injury } \\
\text { (per } 100,000 \text { pop'n) }^{+}\end{array}$ & 79.6 & 51.6 & 55.4 & 67.2 & 38.2 & 56.5 & 52.7 & 80.7 \\
\hline
\end{tabular}

${ }^{\text {a }}$ Alone or in combination with other races listed; percentages may add up to more than $100 \%$

${ }^{+}$Available through WISQARS (http://www.cdc.gov/ncipc/wisqars/) 
Table 2: Organization of EMS at the State Level in Study Region ${ }^{a}$

\begin{tabular}{|c|c|c|c|c|c|c|c|c|}
\hline & DC & $\mathrm{DE}$ & MD & NC & NJ & PA & VA & WV \\
\hline Number of EMS regions & 0 & 0 & 5 & 17 & 0 & 16 & 11 & 7 \\
\hline \multicolumn{9}{|l|}{$\begin{array}{l}\text { Closest description of organizational position } \\
\text { of EMS unit within the governmental hierarchy: }\end{array}$} \\
\hline Organizationally independent unit & - & & - & & & & & \\
\hline \multicolumn{9}{|l|}{ Cabinet-level department } \\
\hline Division of a government department & & & & - & - & D & D & \\
\hline Lower section of a government division & & - & & & & & & - \\
\hline \multicolumn{9}{|l|}{$\begin{array}{l}\text { Closest description of the State agency in } \\
\text { which the EMS office is organized: }\end{array}$} \\
\hline Public Health & & - & & & - & - & - & - \\
\hline Public Safety & - & & & & & & & \\
\hline Health and Human Services & & & & D & & & & \\
\hline Separate Agency & & & - & & & & & \\
\hline \multicolumn{9}{|l|}{$\begin{array}{l}\text { Closest description of principal EMS board or } \\
\text { committee: }\end{array}$} \\
\hline Regulatory Board With Formal Authority & & & 口 & & & & & \\
\hline Advisory Board With Little Formal Authority & 0 & D & & 0 & 0 & D & D & D \\
\hline
\end{tabular}

${ }^{a}$ Data obtained from the National Association of State EMS Officials monograph, December 2005. 
Table 2: Organization of EMS at the State Level in Study Region ${ }^{\text {a }}$ (continued)

\begin{tabular}{|c|c|c|c|c|c|c|c|c|}
\hline & DC & DE & MD & NC & NJ & PA & VA & WV \\
\hline \multicolumn{9}{|l|}{ State EMS office has definitive authority over... } \\
\hline EMS personnel training and certification course standards & $\mathbf{0}$ & $\mathbf{0}$ & - & - & - & - & $\mathbf{0}$ & - \\
\hline EMS instructor credentialing or qualifications & 口 & $\mathbf{0}$ & $\mathbf{0}$ & 口 & 口 & 0 & D & - \\
\hline EMS continuing education session approval & 口 & 口 & - & - & - & 0 & - & - \\
\hline $\begin{array}{l}\text { Administration of EMS personnel licensure or certification } \\
\text { examinations }\end{array}$ & - & & - & - & - & - & - & - \\
\hline Development or approval of EMS field treatment protocols & - & 口 & $\mathbf{0}$ & $\mathbf{0}$ & - & $\mathbf{0}$ & & - \\
\hline Ambulance design specifications & & & $\mathbf{0}$ & $\mathbf{0}$ & $\mathbf{0}$ & - & & \\
\hline Ambulance staffing requirements & $\mathbf{0}$ & & $\mathbf{0}$ & $\mathbf{0}$ & $\mathbf{0}$ & D & 口 & - \\
\hline Ambulance equipment and medications approval & 口 & & $\mathbf{0}$ & $\mathbf{0}$ & 口 & D & 口 & - \\
\hline Ambulance operational requirements & 口 & & $\mathbf{0}$ & $\mathbf{0}$ & - & D & 口 & - \\
\hline Ambulance inspection & $\mathbf{0}$ & & $\mathbf{0}$ & - & - & 0 & D & - \\
\hline Ambulance certification or licensing & - & & 口 & - & 口 & व & - & - \\
\hline Ambulance service area approval & 口 & & & - & & & & \\
\hline Ambulance service establishment requirements & 口 & & 口 & D & - & D & & - \\
\hline $\begin{array}{l}\text { Ambulance service operational/level of service } \\
\text { requirements }\end{array}$ & $\mathbf{0}$ & & D & - & $\mathbf{0}$ & D & & - \\
\hline Specialty EMS transport systems credentialing or licensure & $\mathbf{0}$ & $\mathbf{0}$ & $\mathbf{0}$ & $\mathbf{0}$ & $\mathbf{0}$ & d & 口 & - \\
\hline Ambulance service investigation and discipline & - & & - & - & 口 & व & - & - \\
\hline EMS medical director qualifications & - & - & - & - & - & 0 & D & - \\
\hline EMS field treatment protocol or standing order approval & D & D & 口 & 口 & - & D & & - \\
\hline EMS triage transport protocols & - & - & - & - & - & D & - & - \\
\hline Mutual aid agreements between EMS provider agencies & $\mathbf{0}$ & $\mathbf{0}$ & $\mathbf{0}$ & & & & & - \\
\hline Dispatch agency approval & $\mathbf{0}$ & & 口 & D & & & & \\
\hline
\end{tabular}

${ }^{a}$ Data obtained from the National Association of State EMS Officials monograph, December 2005. 
Table 2: Organization of EMS at the State Level in Study Region ${ }^{\mathrm{a}}$ (continued)

\begin{tabular}{|c|c|c|c|c|c|c|c|c|}
\hline & DC & DE & MD & NC & NJ & PA & VA & $\mathbf{W V}$ \\
\hline EMS dispatcher training or credentialing & & & 0 & व & & & & \\
\hline Pre-hospital data reporting & & $\mathbf{0}$ & 口 & - & 口 & - & - & - \\
\hline $\begin{array}{l}\text { Trauma center review and designation or } \\
\text { categorization }\end{array}$ & - & D & - & - & & & D & \\
\hline $\begin{array}{l}\text { Other specialty care center review and } \\
\text { designation or categorization (i.e., burn, cardiac, } \\
\text { pediatrics) }\end{array}$ & - & - & D & & & & - & \\
\hline Trauma registry reporting & & D & 口 & D & 口 & & D & \\
\hline $\begin{array}{l}\text { Domestic preparedness and response planning } \\
\text { for EMS at local or regional levels }\end{array}$ & D & & - & - & & • & & - \\
\hline $\begin{array}{l}\text { Coordination of domestic planning drills and } \\
\text { exercises at local or regional levels }\end{array}$ & व & & D & D & & - & & \\
\hline $\begin{array}{l}\text { Coordination of local or regional resources } \\
\text { during a disaster or terrorist attack }\end{array}$ & - & & - & - & - & - & & - \\
\hline $\begin{array}{l}\text { Total Number and Percentage Endorsed (of } 29 \\
\text { categories) }\end{array}$ & $\begin{array}{l}25 \\
86.2 \% \\
\end{array}$ & $\begin{array}{ll}13 \\
44.8 \%\end{array}$ & $\begin{array}{l}28 \\
96.6 \%\end{array}$ & $\begin{array}{l}27 \\
93.1 \%\end{array}$ & $\begin{array}{ll}21 \\
72.4 \%\end{array}$ & $\begin{array}{l}22 \\
75.9 \% \\
\end{array}$ & $\begin{array}{l}17 \\
58.6 \%\end{array}$ & $\begin{array}{l}21 \\
72.4 \%\end{array}$ \\
\hline
\end{tabular}

${ }^{a}$ Data obtained from the National Association of State EMS Officials monograph, December 2005. 
Table 3: Response Rates by System Status, State, and Rural-Urban Continuum of Service Area

\begin{tabular}{|c|c|c|c|c|c|}
\hline & & \multicolumn{2}{|c|}{ System Counties } & \multicolumn{2}{|c|}{ Non-System Counties } \\
\hline & $\begin{array}{c}\text { Total Number of } \\
\text { Counties }\end{array}$ & $\begin{array}{c}\text { Total Number of } \\
\text { Systems }\end{array}$ & $\begin{array}{c}\text { Number } \\
\text { Responding } \\
\text { (and Percent) }\end{array}$ & $\begin{array}{c}\text { Total Number of } \\
\text { Non-System } \\
\text { Counties }\end{array}$ & $\begin{array}{c}\text { Number } \\
\text { Responding } \\
\text { (and Percent) }\end{array}$ \\
\hline \multicolumn{6}{|l|}{ By State: } \\
\hline Delaware & 3 & 3 & $2(66.7 \%)$ & $\mathrm{N} / \mathrm{A}$ & $\mathrm{N} / \mathrm{A}$ \\
\hline District of Columbia & 1 & $2^{a}$ & $2(100.0 \%)$ & $\mathrm{N} / \mathrm{A}$ & $\mathrm{N} / \mathrm{A}$ \\
\hline Maryland & 24 & $28^{b}$ & $25(89.3 \%)$ & $\mathrm{N} / \mathrm{A}$ & $\mathrm{N} / \mathrm{A}$ \\
\hline New Jersey & 21 & $0^{\mathrm{C}}$ & $\mathrm{N} / \mathrm{A}$ & 21 & $14(66.7 \%)$ \\
\hline North Carolina & 100 & $100^{d}$ & $90(90.0 \%)$ & N/A & $\mathrm{N} / \mathrm{A}$ \\
\hline Pennsylvania & 67 & $16^{\mathrm{e}}$ & $15(93.8 \%)$ & $\mathrm{N} / \mathrm{A}$ & $\mathrm{N} / \mathrm{A}$ \\
\hline Virginia & 134 & $85^{f}$ & $70(82.4 \%)$ & 49 & $23(46.9 \%)$ \\
\hline West Virginia & 55 & 39 & $31(79.5 \%)$ & 16 & $11(68.8 \%)$ \\
\hline \multicolumn{6}{|l|}{ By Rurality: } \\
\hline Large Metro & 81 & 60 & $52(86.7 \%)$ & 20 & $13(65.0 \%)$ \\
\hline Small Metro & 100 & 69 & $60(87.0 \%)$ & 16 & $8(50.0 \%)$ \\
\hline Large Non-Metro & 31 & 25 & $23(92.0 \%)$ & 2 & $1(50.0 \%)$ \\
\hline Small Non-Metro & 112 & 70 & $61(87.1 \%)$ & 21 & $12(57.1 \%)$ \\
\hline Completely Rural & 81 & 49 & $39(79.6 \%)$ & 27 & $14(51.9 \%)$ \\
\hline All States & 405 & 273 & $235(86.1 \%)$ & 86 & $48(55.8 \%)$ \\
\hline
\end{tabular}

${ }^{a}$ Includes data for Washington Metropolitan Airports Authority

${ }^{\mathrm{b}}$ Includes 24 counties as well as systems for Aberdeen Proving Ground, Annapolis City, BWI Airport, and Ft. Meade

${ }^{c}$ According to the state EMS director, there are no formal EMS organizations below the State level other than individual cities or townships.

${ }^{d}$ By statute, an EMS system can be no smaller than a county unit. Each county has its own EMS system with the exception of Camden and Pasquotank Counties, which are counted together. Also includes data for Cherokee Tribal EMS.

e Pennsylvania EMS systems are incorporated at the regional level, many of which are multi-county

${ }^{f}$ Although occasionally incorporated into surrounding counties for demographic purposes, this study accounts for the Commonwealth's 40 independent cities as individual system or non-system entities. 
Table 4: Characteristics of Non-System Counties ( $n=48$ Respondents to Short Survey)

\begin{tabular}{|c|c|c|c|c|}
\hline Governmental Oversight of EMS or Lead EMS Organization? & $\begin{array}{l}\text { All Counties } \\
(n=48)\end{array}$ & $\begin{array}{c}\mathrm{NJ} \\
(n=14)\end{array}$ & $\begin{array}{c}\text { VA } \\
(n=23)\end{array}$ & $\begin{array}{c}\text { WV } \\
(n=11)\end{array}$ \\
\hline Yes - County Government & $60.4 \%$ & $50.0 \%$ & $69.6 \%$ & $54.6 \%$ \\
\hline Yes - Lead Organization Other Than County & $29.2 \%$ & $28.6 \%$ & $26.1 \%$ & $36.4 \%$ \\
\hline No - No Lead Organization Outside County Government & $10.4 \%$ & $21.4 \%$ & $4.4 \%$ & $9.1 \%$ \\
\hline \multicolumn{5}{|l|}{ EMS Access } \\
\hline Any Access Through 911 & $95.8 \%$ & $92.9 \%$ & $95.7 \%$ & $100.0 \%$ \\
\hline Any Access Through Wireless 911 & $62.5 \%$ & $71.4 \%$ & $60.9 \%$ & $54.6 \%$ \\
\hline Any Access Through 7 or 10 digit & $52.1 \%$ & $78.6 \%$ & $43.5 \%$ & $36.4 \%$ \\
\hline \multicolumn{5}{|l|}{ Provider Agencies } \\
\hline Fire Department & $58.3 \%$ & $64.3 \%$ & $56.5 \%$ & $54.6 \%$ \\
\hline Private & $58.3 \%$ & $57.1 \%$ & $52.2 \%$ & $72.7 \%$ \\
\hline Volunteer/Rescue Squad & $89.6 \%$ & $92.9 \%$ & $100.0 \%$ & $63.6 \%$ \\
\hline Police & $12.5 \%$ & $21.4 \%$ & $13.0 \%$ & $0.0 \%$ \\
\hline Hospital & $25.0 \%$ & $57.1 \%$ & $13.0 \%$ & $9.1 \%$ \\
\hline$>1$ Provider Agency Type & $83.3 \%$ & $92.9 \%$ & $87.0 \%$ & $63.6 \%$ \\
\hline \multicolumn{5}{|l|}{ EMS Financed Through ... } \\
\hline Tax Subsidies & $60.4 \%$ & $71.4 \%$ & $69.6 \%$ & $27.3 \%$ \\
\hline Fees / Bill for Service & $72.9 \%$ & $78.6 \%$ & $56.5 \%$ & $100.0 \%$ \\
\hline Donations/Fundraisers & $79.2 \%$ & $85.7 \%$ & $95.7 \%$ & $36.4 \%$ \\
\hline$>1$ Source of Funding for EMS & $79.2 \%$ & $85.7 \%$ & $87.0 \%$ & $54.6 \%$ \\
\hline Use First Responders? & $72.3 \%$ & $61.5 \%$ & $65.2 \%$ & $100.0 \%$ \\
\hline Use ALS Providers? & $95.7 \%$ & $100.0 \%$ & $91.3 \%$ & $100.0 \%$ \\
\hline
\end{tabular}


Table 5: Size of Systems by State

\begin{tabular}{|c|c|c|c|c|c|c|c|c|}
\hline & $\begin{array}{c}\text { All } \\
\text { Systems } \\
(n=235)\end{array}$ & $\begin{array}{c}D C \\
(n=2)\end{array}$ & $\begin{array}{c}\mathrm{DE} \\
(n=2)\end{array}$ & $\begin{array}{c}\text { MD } \\
(n=25)\end{array}$ & $\begin{array}{c}N C \\
(n=90)\end{array}$ & $\begin{array}{c}\text { PA } \\
(n=15)\end{array}$ & $\begin{array}{c}\text { VA } \\
(n=70)\end{array}$ & $\underset{(n=31)}{W V}$ \\
\hline \multicolumn{9}{|l|}{$\begin{array}{l}\text { Annual Number of EMS } \\
\text { Responses }\end{array}$} \\
\hline Mean (SD) & $\begin{array}{r}19,089 \\
(44,943)\end{array}$ & $\begin{array}{r}66,750 \\
(89,449)\end{array}$ & $\begin{array}{r}81,297 \\
(88,666)\end{array}$ & $\begin{array}{r}26,349 \\
(36,580)\end{array}$ & $\begin{array}{r}11,384 \\
(12,977)\end{array}$ & $\begin{array}{r}114,793 \\
(138,011)\end{array}$ & $\begin{array}{r}9,176 \\
(11,527)\end{array}$ & $\begin{array}{r}10,455 \\
(21,906)\end{array}$ \\
\hline Median & 6,500 & 66,750 & 81,297 & 11,000 & 7,300 & 64,000 & 4,500 & 2,350 \\
\hline Inter-Quartile Range & 13,300 & 126,500 & 125,393 & 19,021 & 10,016 & 69,697 & 9,747 & 8,158 \\
\hline $\begin{array}{l}\text { Mean per Thousand Pop'n Ratio } \\
\text { (averaged across systems) }\end{array}$ & 153.0 & 227.2 & 203.3 & 130.2 & 154.6 & 131.9 & 143.6 & 188.8 \\
\hline \multicolumn{9}{|l|}{$\begin{array}{l}\text { Annual Number of EMS } \\
\text { Transports }\end{array}$} \\
\hline Mean (SD) & $\begin{array}{r}12,566 \\
(30,237) \\
\end{array}$ & $\begin{array}{r}38,500 \\
(51,619) \\
\end{array}$ & $\begin{array}{r}94,948 \\
(.) \\
\end{array}$ & $\begin{array}{r}17,277 \\
(24,436) \\
\end{array}$ & $\begin{array}{r}8,225 \\
(9,646) \\
\end{array}$ & $\begin{array}{r}71,525 \\
(100,792) \\
\end{array}$ & $\begin{array}{r}6,282 \\
(7,660) \\
\end{array}$ & $\begin{array}{r}7,888 \\
(15,428) \\
\end{array}$ \\
\hline Median & 4,688 & 38,500 & 94,948 & 7,000 & 5,000 & 32,065 & 3,800 & 1,700 \\
\hline Inter-Quartile Range & 8,582 & 73,000 & $\mathrm{~N} / \mathrm{A}$ & 10,100 & 6,585 & 65,590 & 5,509 & 7,313 \\
\hline $\begin{array}{l}\text { Mean per Thousand Pop'n Ratio } \\
\text { (averaged across systems) }\end{array}$ & 112.5 & 131.1 & 189.8 & 95.6 & 117.2 & 71.7 & 103.5 & 143.9 \\
\hline \multicolumn{9}{|l|}{ Number of EMS Personnel } \\
\hline Mean (SD) & $\begin{array}{r}493 \\
(1,346)\end{array}$ & $\begin{array}{r}820 \\
(962)\end{array}$ & $\begin{array}{l}1,985 \\
(445)\end{array}$ & $\begin{array}{r}609 \\
(779)\end{array}$ & $\begin{array}{r}239 \\
(403)\end{array}$ & $\begin{array}{r}3,822 \\
(3,958)\end{array}$ & $\begin{array}{r}237 \\
(292)\end{array}$ & $\begin{array}{r}73 \\
(81)\end{array}$ \\
\hline Median & 148 & 820 & 1,985 & 270 & 120 & 2,457 & 150 & 47.5 \\
\hline Inter-Quartile Range & 250 & 1,360 & 630 & 727 & 211 & 4,300 & 210 & 40 \\
\hline $\begin{array}{l}\text { Mean per Thousand Pop'n Ratio } \\
\text { (averaged across systems) }\end{array}$ & 4.4 & 2.6 & 7.6 & 4.6 & 4.9 & 4.9 & 4.3 & 2.6 \\
\hline
\end{tabular}


Table 6: Size of Systems by Rurality ${ }^{a}$ of the Service Area

\begin{tabular}{|c|c|c|c|c|c|c|}
\hline & $\begin{array}{c}\text { All } \\
\text { Systems } \\
(n=235)\end{array}$ & $\begin{array}{l}\text { Large } \\
\text { Metro } \\
(\mathrm{n}=52)\end{array}$ & $\begin{array}{l}\text { Small } \\
\text { Metro } \\
(\mathrm{n}=60)\end{array}$ & $\begin{array}{c}\text { Large } \\
\text { Non-Metro } \\
(n=23)\end{array}$ & $\begin{array}{c}\text { Small } \\
\text { Non-Metro } \\
(n=61)\end{array}$ & $\begin{array}{c}\text { Completely } \\
\text { Rural } \\
(n=39)\end{array}$ \\
\hline \multicolumn{7}{|l|}{ Annual Number of EMS Responses ${ }^{f}$} \\
\hline Mean (SD) & $\begin{array}{r}19,089 \\
(44,943)\end{array}$ & $\begin{array}{l}42,001 a \\
(76,406)\end{array}$ & $\begin{array}{l}23,049 b \\
(43,250)\end{array}$ & $\begin{array}{r}19,374 b c \\
(26,218)\end{array}$ & $\begin{array}{r}6,055 b c \\
(4,103)\end{array}$ & $\begin{array}{l}2,417 c \\
(3,229)\end{array}$ \\
\hline Median & 6,500 & 17,000 & 13,000 & 11,000 & 4,844 & 1,500 \\
\hline Inter-Quartile Range & 13,300 & 40,200 & 17,000 & 8,000 & 5,038 & 1,472 \\
\hline $\begin{array}{l}\text { Mean per Thousand Pop'n Ratio } \\
\text { (averaged across systems) }\end{array}$ & 153.0 & 127.1 & 151.9 & 208.3 & 153.9 & 151.1 \\
\hline \multicolumn{7}{|l|}{ Annual Number of EMS Transports ${ }^{f}$} \\
\hline Mean (SD) & $\begin{array}{r}12,566 \\
(30,237)\end{array}$ & $\begin{array}{l}27,853 a \\
(56,837)\end{array}$ & $\begin{array}{l}14,804 b \\
(19,291)\end{array}$ & $\begin{array}{l}12,258 b \\
(14,463)\end{array}$ & $\begin{array}{l}4,256 b \\
(2,491)\end{array}$ & $\begin{array}{l}1,779 b \\
(2,432)\end{array}$ \\
\hline Median & 4,688 & 9,300 & 9,500 & 8,321 & 3,900 & 1,200 \\
\hline Inter-Quartile Range & 8,582 & 21,300 & 11,600 & 7,282 & 2,400 & 1,411 \\
\hline $\begin{array}{l}\text { Mean per Thousand Pop'n Ratio } \\
\text { (averaged across systems) }\end{array}$ & 112.5 & 86.7 & 107.1 & 152.5 & 121.7 & 113.1 \\
\hline \multicolumn{7}{|l|}{ Number of EMS Personnel ${ }^{f}$} \\
\hline Mean (SD) & $\begin{array}{r}493 \\
(1,346) \\
\end{array}$ & $\begin{array}{l}1,032 a \\
(2,284) \\
\end{array}$ & $\begin{array}{r}634 a b \\
(1,349) \\
\end{array}$ & $\begin{array}{r}470 a b \\
(816) \\
\end{array}$ & $\begin{array}{l}147 b \\
(229)\end{array}$ & $\begin{array}{l}136 b \\
(476) \\
\end{array}$ \\
\hline Median & 148 & 283 & 250 & 254 & 91 & 40 \\
\hline Inter-Quartile Range & 250 & 980 & 623 & 353 & 124 & 40 \\
\hline $\begin{array}{l}\text { Mean per Thousand Pop'n Ratio } \\
\text { (averaged across systems) }\end{array}$ & 4.4 & 3.3 & 3.6 & 4.2 & 3.6 & 8.4 \\
\hline
\end{tabular}

${ }^{a}$ Defined by Rural-Urban Continuum

${ }^{f}$ Represents significant $\mathrm{F}$ at $\mathrm{p}<0.05$ based on one-way ANOVA; Mean separation by Duncan's multiple range test 
Table 7: Access to the System by State

\begin{tabular}{|c|c|c|c|c|c|c|c|c|}
\hline & $\begin{array}{c}\text { All Systems } \\
(n=235)\end{array}$ & $\begin{array}{c}\mathrm{DC} \\
(n=2)\end{array}$ & $\begin{array}{c}\mathrm{DE} \\
(n=2)\end{array}$ & $\begin{array}{c}M D \\
(n=25)\end{array}$ & $\begin{array}{c}\mathrm{NC} \\
(\mathrm{n}=90)\end{array}$ & $\begin{array}{c}\text { PA } \\
(n=15)\end{array}$ & $\begin{array}{c}\text { VA } \\
(n=70)\end{array}$ & $\begin{array}{c}\text { WV } \\
(n=31)\end{array}$ \\
\hline \multicolumn{9}{|l|}{$\begin{array}{r}\text { Highest level of technical sophistication } \\
\text { for system access is... }\end{array}$} \\
\hline Wireless E911 & 58.6 & 50.0 & 0.0 & 56.0 & 61.1 & 66.7 & 73.9 & 19.4 \\
\hline Wireless 911 (but Not Wireless E911) & 16.2 & 50.0 & 50.0 & 12.0 & 16.7 & 26.7 & 11.6 & 19.4 \\
\hline E911 (but Not Wireless 911) & 21.4 & 0.0 & 50.0 & 24.0 & 22.2 & 6.7 & 13.0 & 41.9 \\
\hline 911 (but Not E911) & 3.0 & 0.0 & 0.0 & 0.0 & 0.0 & 0.0 & 1.5 & 19.4 \\
\hline 7- or 10-Digit Number Only & 0.9 & 0.0 & 0.0 & 8.0 & 0.0 & 0.0 & 0.0 & 0.0 \\
\hline \multicolumn{9}{|l|}{ Access to the system is available through } \\
\hline Wireless E 911 & 58.6 & 50.0 & 0.0 & 56.0 & 61.1 & 66.7 & 73.9 & 19.4 \\
\hline Wireless 911 & 31.6 & 100.0 & 50.0 & 28.0 & 30.0 & 66.7 & 29.0 & 22.6 \\
\hline E911 & 94.0 & 50.0 & 100.0 & 92.0 & 97.8 & 100.0 & 97.1 & 77.4 \\
\hline 911 & 25.2 & 100.0 & 0.0 & 36.0 & 16.7 & 60.0 & 17.4 & 38.7 \\
\hline 7- or 10-Digit Number & 26.5 & 50.0 & 50.0 & 32.0 & 26.7 & 40.0 & 21.7 & 22.6 \\
\hline
\end{tabular}


Table 8: Access to the System by Rurality ${ }^{a}$ of the Service Area

\begin{tabular}{|c|c|c|c|c|c|c|}
\hline & $\begin{array}{c}\text { All } \\
\text { Systems } \\
(n=235)\end{array}$ & $\begin{array}{l}\text { Large } \\
\text { Metro } \\
(n=52)\end{array}$ & $\begin{array}{l}\text { Small } \\
\text { Metro } \\
(n=60)\end{array}$ & $\begin{array}{c}\text { Large } \\
\text { Non-Metro } \\
(n=23)\end{array}$ & $\begin{array}{c}\text { Small } \\
\text { Non-Metro } \\
(n=61)\end{array}$ & $\begin{array}{c}\text { Completely } \\
\text { Rural } \\
(n=39)\end{array}$ \\
\hline \multicolumn{7}{|l|}{$\begin{array}{r}\text { Highest level of technical sophistication } \\
\text { for system access is...* }\end{array}$} \\
\hline Wireless E 911 & 58.6 & 56.9 & 68.3 & 69.6 & 57.4 & 41.0 \\
\hline Wireless 911 (but Not E911) & 16.2 & 21.6 & 11.7 & 26.1 & 14.8 & 12.8 \\
\hline E911 (but Not Wireless 911) & 21.4 & 15.7 & 18.3 & 4.4 & 26.1 & 35.9 \\
\hline 911 (but Not E911) & 3.0 & 2.0 & 1.7 & 0.0 & 1.6 & 10.3 \\
\hline 7- or 10-Digit Number Only & 0.9 & 3.9 & 0.0 & 0.0 & 0.0 & 0.0 \\
\hline \multicolumn{7}{|l|}{ Access to the system is available through } \\
\hline Wireless E 911 & 58.6 & 56.9 & 68.3 & 69.6 & 57.4 & 41.0 \\
\hline Wireless $911^{*}$ & 31.6 & 51.0 & 31.7 & 34.8 & 21.3 & 20.5 \\
\hline E911 & 94.0 & 92.2 & 95.0 & 100.0 & 95.1 & 89.7 \\
\hline 911 & 25.2 & 37.3 & 18.3 & 17.4 & 21.3 & 30.8 \\
\hline 7- or 10-Digit Number & 26.5 & 33.3 & 28.3 & 39.1 & 19.7 & 18.0 \\
\hline
\end{tabular}

a Defined by Rural -Urban Continuum
* Represents significant $X^{2}$ at $p<0.05$ 
Table 9: Access to the System by Size of the System ${ }^{a}$

\begin{tabular}{|c|c|c|c|c|}
\hline & $\begin{array}{c}\text { All } \\
\text { Systems } \\
(n=222)\end{array}$ & $\begin{array}{l}\text { Small } \\
(n=74)\end{array}$ & $\begin{array}{c}\text { Medium } \\
(n=75)\end{array}$ & $\begin{array}{l}\text { Large } \\
(n=73)\end{array}$ \\
\hline \multicolumn{5}{|l|}{$\begin{array}{r}\text { Highest level of technical sophistication } \\
\text { for system access is...* }\end{array}$} \\
\hline Wireless E 911 & 58.6 & 50.0 & 64.0 & 64.4 \\
\hline Wireless 911 (but Not E911) & 16.2 & 13.5 & 14.7 & 20.6 \\
\hline E911 (but Not Wireless 911) & 21.4 & 28.4 & 21.3 & 15.1 \\
\hline 911 (but Not E911) & 3.0 & 8.1 & 0.0 & 0.0 \\
\hline 7- or 10-Digit Number Only & 0.9 & 0.0 & 0.0 & 0.0 \\
\hline \multicolumn{5}{|l|}{ Access to the system is available through } \\
\hline Wireless E 911 & 58.6 & 50.0 & 64.0 & 64.4 \\
\hline Wireless $911^{*}$ & 31.6 & 21.6 & 28.0 & 45.2 \\
\hline E911* & 94.0 & 90.5 & 97.3 & 98.6 \\
\hline 911 & 25.2 & 29.7 & 16.0 & 26.0 \\
\hline 7- or 10-Digit Number* & 26.5 & 23.0 & 17.3 & 35.6 \\
\hline
\end{tabular}

a Defined by annual number of responses (not available for 13 systems)

"Represents significant $X^{2}$ at $p<0.05$ 
Table 10: Provider Agency Types by State

\begin{tabular}{|c|c|c|c|c|c|c|c|c|}
\hline & $\begin{array}{c}\text { All Systems } \\
(n=235)\end{array}$ & $\begin{array}{c}D C \\
(n=2)\end{array}$ & $\begin{array}{c}\mathrm{DE} \\
(n=2)\end{array}$ & $\begin{array}{c}\text { MD } \\
(n=25)\end{array}$ & $\begin{array}{c}\mathrm{NC} \\
(n=90)\end{array}$ & $\begin{array}{c}\text { PA } \\
(n=15)\end{array}$ & $\begin{array}{c}\text { VA } \\
(n=70)\end{array}$ & $\begin{array}{c}\text { WV } \\
(n=31)\end{array}$ \\
\hline \multicolumn{9}{|c|}{ Percent with >1 Type of Agency Involved in ... } \\
\hline First Response $^{+}$ & 59.7 & 50.0 & 100.0 & 62.5 & 66.7 & 73.3 & 47.6 & 53.6 \\
\hline Transport & 60.5 & 50.0 & 100.0 & 60.0 & 64.0 & 93.3 & 59.4 & 35.5 \\
\hline Dispatch & 19.0 & 0.0 & 50.0 & 8.0 & 27.3 & 26.7 & 7.3 & 25.8 \\
\hline \multicolumn{9}{|c|}{ First Response: Any Use of . . . } \\
\hline Private & 19.6 & 0.0 & 0.0 & 12.0 & 27.8 & 26.7 & 8.6 & 25.8 \\
\hline Fire & 70.2 & 100.0 & 100.0 & 68.0 & 64.4 & 93.3 & 74.3 & 64.5 \\
\hline Third Service & 28.5 & 0.0 & 100.0 & 25.0 & 46.0 & 13.3 & 9.5 & 25.0 \\
\hline Volunteer & 29.9 & 0.0 & 50.0 & 25.0 & 31. & 26.7 & 36.5 & 17.9 \\
\hline Hospital-Based & 7.7 & 0.0 & 0.0 & 0.0 & 9.2 & 40.0 & 3.2 & 3.6 \\
\hline Other & 18.3 & 0.0 & 50.0 & 24.0 & 17.8 & 46.7 & 14.3 & 9.7 \\
\hline No First Response & 6.8 & 0.0 & 0.0 & 4.4 & 4.6 & 0.0 & 10.6 & 11.1 \\
\hline \multicolumn{9}{|c|}{ First Response: Primary Responsible Agency } \\
\hline Private & 9.0 & 0.0 & 0.0 & 4.4 & 9.2 & 13.3 & 4.6 & 22.2 \\
\hline Fire & 52.3 & 100.0 & 100.0 & 65.2 & 39.1 & 66.7 & 66.7 & 33.3 \\
\hline Third Service & 18.0 & 0.0 & 0.0 & 17.4 & 31.0 & 0.0 & 3.0 & 25.9 \\
\hline Volunteer & 7.6 & 0.0 & 0.0 & 8.7 & 8.1 & 0.0 & 10.6 & 3.7 \\
\hline Hospital-Based & 3.6 & 0.0 & 0.0 & 0.0 & 4.6 & 13.3 & 1.5 & 3.7 \\
\hline Other & 2.7 & 0.0 & 0.0 & 0.0 & 3.5 & 6.7 & 3.0 & 0.0 \\
\hline No First Response & 6.8 & 0.0 & 0.0 & 4.4 & 4.6 & 0.0 & 10.6 & 11.1 \\
\hline \multirow{2}{*}{\multicolumn{9}{|c|}{ Transport: Any Use of . . . }} \\
\hline & & & & & & & & \\
\hline Firgate & 34.9 & $\frac{0.0}{1000}$ & $\frac{30.0}{1000}$ & $\frac{12.0}{720}$ & $\frac{37.8}{10.7}$ & 80.0 & 22.9 & 51.6 \\
\hline Fire & 44.1 & 100.0 & 100.0 & 72.0 & 16.7 & 93.3 & 67.1 & 22.6 \\
\hline Third Service & 39.5 & 0.0 & 50.0 & 20.0 & 68.5 & 26.7 & 14.5 & 35.5 \\
\hline Volunteer & 41.2 & 0.0 & 100.0 & 32.0 & 32.6 & 93.3 & 56.5 & 12.9 \\
\hline Hospital-Based & 11.6 & 0.0 & 0.0 & 4.0 & 12.4 & 66.7 & 4.4 & 6.5 \\
\hline Other & 8.5 & 0.0 & 50.0 & 8.0 & 10.0 & 13.3 & 5.7 & 6.5 \\
\hline
\end{tabular}

${ }^{+}$Among those using first responders 
Table 10: Provider Agency Types by State (continued)

\begin{tabular}{|c|c|c|c|c|c|c|c|c|}
\hline & $\begin{array}{c}\text { All Systems } \\
(n=235)\end{array}$ & $\begin{array}{c}D C \\
(n=2)\end{array}$ & $\begin{array}{c}\mathrm{DE} \\
(n=2)\end{array}$ & $\begin{array}{c}\text { MD } \\
(n=25)\end{array}$ & $\begin{array}{c}N C \\
(n=90)\end{array}$ & $\begin{array}{c}\mathrm{PA} \\
(\mathrm{n}=15)\end{array}$ & $\begin{array}{c}\text { VA } \\
(n=70)\end{array}$ & $\begin{array}{c}\text { WV } \\
(n=31)\end{array}$ \\
\hline \multicolumn{9}{|c|}{\begin{tabular}{|l|l|l|l|l|l|l|} 
Transport: Primary Responsible Agency & & & & & \\
\end{tabular}} \\
\hline Private & 17.5 & 0.0 & 0.0 & 8.7 & 14.0 & 53.3 & 6.1 & 44.8 \\
\hline Fire & 27.4 & 100.0 & 100.0 & 60.9 & 3.5 & 26.7 & 54.6 & 0.0 \\
\hline Third Service & 33.6 & 0.0 & 0.0 & 8.7 & 64.0 & 0.0 & 12.1 & 34.5 \\
\hline Volunteer & 13.9 & 0.0 & 0.0 & 17.4 & 7.0 & 20.0 & 24.2 & 6.9 \\
\hline Hospital-Based & 4.5 & 0.0 & 0.0 & 4.4 & 7.0 & 0.0 & 1.5 & 6.9 \\
\hline Other & 3.1 & 0.0 & 0.0 & 0.0 & 4.7 & 0.0 & 1.5 & 6.9 \\
\hline \multicolumn{9}{|c|}{ Dispatch: Any Use of . . . } \\
\hline Fire & 6.5 & 0.0 & 0.0 & 24.0 & 5.7 & 6.7 & 4.4 & 0.0 \\
\hline Police/Sheriff & 20.0 & 0.0 & 0.0 & 4.0 & 21.1 & 6.7 & 34.3 & 6.5 \\
\hline City/County & 51.5 & 50.0 & 100.0 & 32.0 & 61.1 & 100.0 & 22.9 & 77.4 \\
\hline Public Safety & 25.0 & 50.0 & 0.0 & 44.0 & 18.2 & 6.7 & 34.8 & 16.1 \\
\hline Other & 16.2 & 0.0 & 0.0 & 4.0 & 22.2 & 20.0 & 10.0 & 22.6 \\
\hline \multicolumn{9}{|c|}{ Dispatch: Primary Responsible Agency } \\
\hline Fire & 3.9 & 0.0 & 0.0 & 20.8 & 1.2 & 0.0 & 4.4 & 0.0 \\
\hline Police/Sheriff & 16.2 & 0.0 & 0.0 & 0.0 & 17.2 & 0.0 & 31.9 & 0.0 \\
\hline City/County & 48.0 & 50.0 & 100.0 & 33.3 & 54.0 & 100.0 & 21.7 & 73.3 \\
\hline Public Safety & 21.8 & 50.0 & 0.0 & 41.7 & 12.6 & 0.0 & 34.8 & 13.3 \\
\hline Other & 10.0 & 0.0 & 0.0 & 4.2 & 14.9 & 0.0 & 7.3 & 13.3 \\
\hline
\end{tabular}


Table 11: Provider Agency Types by Rurality ${ }^{\mathrm{a}}$ of the Service Area

\begin{tabular}{|c|c|c|c|c|c|c|}
\hline & $\begin{array}{c}\text { All } \\
\text { Systems } \\
(\mathrm{n}=235)\end{array}$ & $\begin{array}{l}\text { Large } \\
\text { Metro } \\
(n=52)\end{array}$ & $\begin{array}{l}\text { Small } \\
\text { Metro } \\
(n=60)\end{array}$ & $\begin{array}{c}\text { Large } \\
\text { Non-Metro } \\
(n=23)\end{array}$ & $\begin{array}{c}\text { Small } \\
\text { Non-Metro } \\
(n=61)\end{array}$ & $\begin{array}{c}\text { Completely } \\
\text { Rural } \\
(n=39)\end{array}$ \\
\hline \multicolumn{7}{|c|}{ Percent With >1 Type of Agency Involved in } \\
\hline First Response $^{+}$ & 59.7 & 53.1 & 63.8 & 77.3 & 56.9 & 55.9 \\
\hline Transport & 60.5 & 55.8 & 67.2 & 78.3 & 57.4 & 51.3 \\
\hline Dispatch & 19.0 & 9.8 & 20.0 & 26.1 & 21.3 & 21.6 \\
\hline \multicolumn{7}{|c|}{ First Response: Any Use of . . . } \\
\hline Private* $^{*}$ & 19.6 & 5.8 & 21.7 & 30.4 & 19.7 & 28.2 \\
\hline Fire* & 70.2 & 84.6 & 85.0 & 82.6 & 59.0 & 38.5 \\
\hline Third Service & 28.5 & 18.4 & 29.3 & 18.2 & 37.9 & 32.4 \\
\hline Volunteer & 29.9 & 28.6 & 24.1 & 27.3 & 37.9 & 29.4 \\
\hline Hospital-Based & 7.7 & 6.1 & 10.3 & 13.6 & 6.9 & 2.9 \\
\hline Other & 18.3 & 19.2 & 20.0 & 30.43 & 6.56 & 25.6 \\
\hline No First Response & 6.8 & 5.9 & 3.4 & 5.0 & 5.4 & 16.7 \\
\hline \multicolumn{7}{|c|}{ First Response: Primary Responsible Agency* } \\
\hline Private & 9.0 & 2.0 & 6.8 & 15.0 & 8.9 & 19.4 \\
\hline Fire & 52.3 & 76.5 & 61.0 & 50.0 & 41.1 & 22.2 \\
\hline Third Service & 18.0 & 7.8 & 18.6 & 10.0 & 26.8 & 22.2 \\
\hline Volunteer & 7.7 & 3.9 & 3.4 & 10.0 & 12.5 & 11.1 \\
\hline Hospital-Based & 3.6 & 2.0 & 3.4 & 10.0 & 3.6 & 2.8 \\
\hline Other & 2.7 & 2.0 & 3.4 & 0.0 & 1.8 & 5.6 \\
\hline No First Response & 6.8 & 5.9 & 3.4 & 5.0 & 5.4 & 16.7 \\
\hline \multicolumn{7}{|c|}{ Transport: Any Use of ... } \\
\hline Private* & 34.9 & 11.5 & 38.3 & 69.6 & 31.2 & 46.2 \\
\hline Fire* $^{*}$ & 44.7 & 80.8 & 46.7 & 39.1 & 37.7 & 7.7 \\
\hline Third Service* & 39.5 & 21.2 & 46.6 & 26.1 & 47.5 & 48.7 \\
\hline Volunteer & 41.2 & 38.4 & 51.7 & 43.5 & 37.7 & 33.3 \\
\hline Hospital-Based & 11.6 & 9.6 & 17.2 & 21.7 & 6.6 & 7.7 \\
\hline Other & 8.5 & 7.7 & 10.0 & 4.4 & 4.9 & 15.4 \\
\hline
\end{tabular}

${ }^{a}$ Defined by Rural-Urban Continuum

${ }^{+}$Among those using first responders

Represents significant $X^{2}$ at $p<0.05$ 
Table 11: Provider Agency Types by Rurality of the Service Area (continued)

\begin{tabular}{|c|c|c|c|c|c|c|}
\hline & $\begin{array}{c}\text { All } \\
\text { Systems } \\
(n=235)\end{array}$ & $\begin{array}{l}\text { Large } \\
\text { Metro } \\
(n=52) \\
\end{array}$ & $\begin{array}{l}\text { Small } \\
\text { Metro } \\
(\mathrm{n}=60)\end{array}$ & $\begin{array}{c}\text { Large } \\
\text { Non-Metro } \\
(n=23)\end{array}$ & $\begin{array}{c}\text { Small } \\
\text { Non-Metro } \\
(n=61)\end{array}$ & $\begin{array}{c}\text { Completely } \\
\text { Rural } \\
(n=39)\end{array}$ \\
\hline \multicolumn{7}{|c|}{ Transport: Primary Responsible Agency* } \\
\hline Private & 17.5 & 5.9 & 10.3 & 30.0 & 19.3 & 35.1 \\
\hline Fire & 27.4 & 64.7 & 22.0 & 15.0 & 21.1 & 0.0 \\
\hline Third Service & 33.6 & 13.7 & 41.4 & 25.0 & 43.9 & 37.8 \\
\hline Volunteer & 13.9 & 11.8 & 17.2 & 25.0 & 8.8 & 13.5 \\
\hline Hospital-Based & 4.5 & 2.0 & 5.2 & 5.0 & 5.3 & 5.4 \\
\hline Other & 3.1 & 2.0 & 3.5 & 0.0 & 1.8 & 8.1 \\
\hline \multicolumn{7}{|c|}{ Dispatch: Any Use of ... } \\
\hline Fire* & 6.5 & 15.7 & 5.0 & 8.7 & 1.6 & 2.7 \\
\hline Police/Sheriff & 20.0 & 19.2 & 20.0 & 17.4 & 14.8 & 30.8 \\
\hline City/County* & 51.5 & 36.5 & 50.0 & 52.2 & 70.5 & 43.6 \\
\hline Public Safety* & 25.0 & 33.3 & 26.7 & 43.5 & 11.5 & 21.6 \\
\hline Other & 16.2 & 5.8 & 18.3 & 26.1 & 16.4 & 20.5 \\
\hline \multicolumn{7}{|c|}{ Dispatch: Primary Responsible Agency* } \\
\hline Fire & 3.9 & 14.0 & 3.3 & 0.0 & 0.0 & 0.0 \\
\hline Police/Sheriff & 16.2 & 18.0 & 16.7 & 8.7 & 10.0 & 27.8 \\
\hline City/County & 48.0 & 36.0 & 46.7 & 47.8 & 66.7 & 36.1 \\
\hline Public Safety & 21.8 & 30.0 & 21.7 & 39.1 & 10.0 & 19.4 \\
\hline Other & 10.0 & 2.0 & 11.7 & 4.4 & 13.3 & 16.7 \\
\hline
\end{tabular}

\footnotetext{
${ }^{*}$ Represents significant $X^{2}$ at $p<0.05$
} 
Table 12: Provider Agency Types by Size ${ }^{a}$ of System

\begin{tabular}{|c|c|c|c|c|}
\hline & $\begin{array}{c}\text { All } \\
\text { Systems } \\
(n=222)\end{array}$ & $\begin{array}{l}\text { Small } \\
(n=74)\end{array}$ & $\begin{array}{c}\text { Medium } \\
(n=75)\end{array}$ & $\begin{array}{l}\text { Large } \\
(n=73)\end{array}$ \\
\hline \multicolumn{5}{|c|}{ Percent with >1 Type of Agency Involved in . . . } \\
\hline First Response $^{+}$ & 59.7 & 49.2 & 63.5 & 68.1 \\
\hline Transport & 60.5 & 54.8 & 56.8 & 71.6 \\
\hline Dispatch & 19.0 & 18.9 & 13.5 & 27.4 \\
\hline \multicolumn{5}{|c|}{ First Response: Any Use of . . . } \\
\hline Private & 19.6 & 17.6 & 26.7 & 16.2 \\
\hline Fire* & 70.2 & 50.0 & 77.3 & 85.1 \\
\hline Third Service & 28.5 & 23.1 & 33.8 & 29.2 \\
\hline Volunteer & 29.9 & 30.8 & 33.8 & 26.4 \\
\hline Hospital-Based & 7.7 & 4.6 & 6.8 & 12.5 \\
\hline Other & 18.3 & 17.6 & 14.7 & 21.6 \\
\hline No First Response & 6.8 & 13.2 & 1.4 & 4.2 \\
\hline \multicolumn{5}{|c|}{ First Response: Primary Responsible Agency* } \\
\hline Private & 9.0 & 13.2 & 10.0 & 5.6 \\
\hline Fire & 36.8 & 52.9 & 65.3 & 50.8 \\
\hline Third Service & 18.0 & 17.7 & 22.9 & 20.9 \\
\hline Volunteer & 7.6 & 10.3 & 8.6 & 4.2 \\
\hline Hospital-Based & 3.6 & 4.4 & 2.9 & 4.2 \\
\hline Other & 2.7 & 4.4 & 1.4 & 1.4 \\
\hline No First Response & 6.8 & 13.2 & 1.4 & 4.2 \\
\hline \multicolumn{5}{|c|}{ Transport: Any Use of ... } \\
\hline Private & 34.9 & 35.1 & 33.3 & 39.2 \\
\hline Fire* & 44.7 & 31.1 & 37.3 & 63.5 \\
\hline Third Service & 39.5 & 34.3 & 41.9 & 43.2 \\
\hline Volunteer & 41.2 & 43.8 & 36.5 & 43.2 \\
\hline Hospital-Based & 11.6 & 8.2 & 9.5 & 16.2 \\
\hline Other & 8.5 & 12.2 & 5.3 & 8.1 \\
\hline
\end{tabular}

\footnotetext{
${ }^{a}$ Defined by Annual Number of Responses (not available for 13 systems)

${ }^{+}$Among those using first responders
}

Represents significant $X^{2}$ at $p<0.05$ 
Table 12: Provider Agency Types by Size of System (continued)

\begin{tabular}{|c|c|c|c|c|}
\hline & $\begin{array}{c}\text { All } \\
\text { Systems } \\
(\mathrm{n}=222)\end{array}$ & $\begin{array}{c}\text { Small } \\
(n=74)\end{array}$ & $\begin{array}{c}\text { Medium } \\
(n=75)\end{array}$ & $\begin{array}{c}\text { Large } \\
(n=73)\end{array}$ \\
\hline \multicolumn{5}{|c|}{ Transport: Primary Responsible Agency } \\
\hline Private & 17.5 & 23.5 & 14.1 & 15.3 \\
\hline Fire & 27.4 & 16.2 & 26.8 & 37.5 \\
\hline Third Service & 33.6 & 30.9 & 39.4 & 33.3 \\
\hline Volunteer & 13.9 & 17.7 & 14.1 & 9.7 \\
\hline Hospital-Based & 4.5 & 7.4 & 2.8 & 2.8 \\
\hline Other & 3.1 & 4.4 & 2.8 & 1.4 \\
\hline \multicolumn{5}{|c|}{ Dispatch: Any Use of ... } \\
\hline Fire & 6.5 & 2.7 & 5.4 & 8.2 \\
\hline Police/Sheriff* & 20.0 & 33.8 & 18.7 & 10.8 \\
\hline City/County & 51.5 & 43.2 & 56.0 & 58.1 \\
\hline Public Safety & 25.0 & 24.3 & 21.6 & 30.1 \\
\hline Other & 16.2 & 13.5 & 13.3 & 21.6 \\
\hline \multicolumn{5}{|c|}{ Dispatch: Primary Responsible Agency } \\
\hline Fire & 3.9 & 1.4 & 2.7 & 4.2 \\
\hline Police/Sheriff & 16.2 & 28.8 & 15.1 & 6.9 \\
\hline City/County & 48.0 & 37.0 & 53.4 & 55.6 \\
\hline Public Safety & 21.8 & 23.3 & 19.2 & 23.6 \\
\hline Other & 10.0 & 9.6 & 9.6 & 9.7 \\
\hline
\end{tabular}

\footnotetext{
${ }^{*}$ Represents significant $X^{2}$ at $p<0.05$
} 
Table 13: Estimated Population Coverage by Primary EMS Agency Type ${ }^{+}$

\begin{tabular}{|c|c|c|c|c|c|c|c|c|}
\hline & $\begin{array}{l}\text { All } \\
\text { Systems }\end{array}$ & DC & DE & MD & NC & PA & VA & WV \\
\hline \multicolumn{9}{|l|}{ Primary First Response } \\
\hline Private & 11.6 & 0.0 & 0.0 & 0.6 & 6.2 & 24.3 & 1.1 & 25.9 \\
\hline Fire department & 67.2 & 100.0 & 100.0 & 91.4 & 49.9 & 57.6 & 85.2 & 42.6 \\
\hline Government-based/third service & 8.6 & 0.0 & 0.0 & 3.8 & 31.6 & 0.0 & 1.1 & 23.7 \\
\hline Independent volunteer & 2.4 & 0.0 & 0.0 & 4.1 & 4.7 & 0.0 & 3.7 & 1.7 \\
\hline Hospital-based & 3.6 & 0.0 & 0.0 & 0.0 & 3.9 & 6.9 & 0.3 & 1.2 \\
\hline Other & 4.6 & 0.0 & 0.0 & 0.0 & 1.2 & 11.2 & 0.8 & 0.0 \\
\hline No separate first response & 2.0 & 0.0 & 0.0 & 0.0 & 2.5 & 0.0 & 7.8 & 5.0 \\
\hline \multicolumn{9}{|l|}{ Primary Transport Agency } \\
\hline Private & 31.0 & 0.0 & 0.0 & 2.3 & 8.1 & 72.4 & 1.7 & 41.8 \\
\hline Fire department & 36.1 & 100.0 & 100.0 & 91.2 & 2.9 & 12.0 & 72.8 & 0.0 \\
\hline Government-based/third service & 20.2 & 0.0 & 0.0 & 1.3 & 75.1 & 0.0 & 11.1 & 44.4 \\
\hline Independent volunteer & 9.6 & 0.0 & 0.0 & 5.2 & 4.0 & 15.6 & 10.4 & 5.8 \\
\hline Hospital-based & 2.0 & 0.0 & 0.0 & 0.0 & 8.5 & 0.0 & 0.3 & 2.1 \\
\hline Other & 1.1 & 0.0 & 0.0 & 0.0 & 1.4 & 0.0 & 3.8 & 5.8 \\
\hline \multicolumn{9}{|l|}{ Primary Dispatch } \\
\hline Fire department & 6.1 & 0.0 & 0.0 & 31.1 & 4.4 & 0.0 & 3.8 & 0.0 \\
\hline Police/Sheriff & 6.3 & 0.0 & 0.0 & 0.0 & 10.4 & 0.0 & 22.8 & 0.0 \\
\hline City/County & 63.2 & 100.0 & 100.0 & 29.7 & 46.3 & 100.0 & 20.5 & 79.9 \\
\hline Public safety & 16.9 & 0.0 & 0.0 & 38.5 & 13.4 & 0.0 & 45.7 & 13.3 \\
\hline Other & 7.4 & 0.0 & 0.0 & 0.7 & 25.4 & 0.0 & 7.2 & 6.8 \\
\hline \multicolumn{9}{|l|}{ Primary Configuration (see Table 14) } \\
\hline BLS 1st response/BLS transport & 7.9 & 100.0 & 76.2 & 21.6 & 1.3 & 0.0 & 4.1 & 0.7 \\
\hline BLS 1st response/ALS transport & 40.9 & 0.0 & 0.0 & 26.4 & 54.3 & 48.7 & 28.9 & 42.6 \\
\hline ALS 1st response/BLS transport & 7.6 & 0.0 & 23.8 & 6.0 & 5.1 & 12.3 & 2.0 & 3.4 \\
\hline ALS 1st response/ALS transport & 36.0 & 0.0 & 0.0 & 29.5 & 27.0 & 38.2 & 55.9 & 45.8 \\
\hline BLS transport only & 1.6 & 0.0 & 0.0 & 1.5 & 1.5 & 0.9 & 4.0 & 0.0 \\
\hline ALS transport only & 5.9 & 0.0 & 0.0 & 15.1 & 10.8 & 0.0 & 5.1 & 7.5 \\
\hline
\end{tabular}

\footnotetext{
${ }^{+}$Percentage denominators based on those study areas responding to a particular question
} 
Table 14: Response Configurations and Use of Volunteer Providers by State

\begin{tabular}{|c|c|c|c|c|c|c|c|c|}
\hline & $\begin{array}{c}\text { All } \\
\text { Systems } \\
(n=235)\end{array}$ & $\begin{array}{l}D C \\
(n=2)\end{array}$ & $\begin{array}{c}\mathrm{DE} \\
(n=2)\end{array}$ & $\begin{array}{c}\text { MD } \\
(n=25)\end{array}$ & $\begin{array}{c}N C \\
(n=90)\end{array}$ & $\begin{array}{c}P A \\
(n=15)\end{array}$ & $\begin{array}{c}\text { VA } \\
(n=70)\end{array}$ & $\begin{array}{c}\text { WV } \\
(n=31)\end{array}$ \\
\hline$\%$ using first responders & 98.3 & 100.0 & 100.0 & 100.0 & 100.0 & 100.0 & 95.7 & 96.8 \\
\hline $\begin{array}{l}\% \text { in which first responders are most commonly } \\
\text { dispatched for all } 911 \text { Calls }^{+}\end{array}$ & 36.4 & 0.0 & 0.0 & 37.5 & 35.0 & 66.7 & 35.3 & 28.0 \\
\hline $\begin{array}{l}\text { \% in which first responders are most commonly } \\
\text { simultaneously dispatched with transport ambulance }\end{array}$ & 93.4 & 50.0 & 100.0 & 79.2 & 98.7 & 100.0 & 94.0 & 88.0 \\
\hline \multicolumn{9}{|l|}{ Most commonly used response configuration } \\
\hline BLS 1st response, BLS transport & 8.7 & 50.0 & 50.0 & 12.5 & 4.5 & 0.0 & 14.5 & 3.6 \\
\hline BLS 1st response, ALS transport & 31.0 & 0.0 & 0.0 & 16.7 & 41.6 & 46.7 & 26.1 & 17.9 \\
\hline ALS 1st response, BLS transport & 7.0 & 0.0 & 50.0 & 12.5 & 3.4 & 20.0 & 4.4 & 10.7 \\
\hline ALS 1st response, ALS transport & 37.6 & 50.0 & 0.0 & 50.0 & 32.6 & 26.7 & 36.2 & 53.6 \\
\hline BLS transport only & 4.4 & 0.0 & 0.0 & 4.2 & 2.3 & 6.7 & 8.7 & 0.0 \\
\hline ALS transport only & 11.4 & 0.0 & 0.0 & 4.2 & 15.7 & 0.0 & 10.1 & 14.3 \\
\hline $\begin{array}{l}\% \text { with operating procedures that allow response without } \\
\text { use of lights and sirens }\end{array}$ & 69.5 & 0.0 & 100.0 & 64.0 & 83.0 & 80.0 & 61.4 & 51.6 \\
\hline $\begin{array}{l}\% \text { with operating procedures that allow transports } \\
\text { without use of lights and sirens }\end{array}$ & 91.5 & 50.0 & 100.0 & 88.0 & 95.5 & 93.3 & 90.0 & 87.1 \\
\hline $\begin{array}{l}\% \text { with operating procedures that transports to non- } \\
\text { hospital destinations (e.g. urgent care centers) }\end{array}$ & 19.2 & 0.0 & 50.0 & 12.0 & 27.0 & 0.0 & 18.6 & 12.9 \\
\hline$\%$ using volunteer providers & 85.9 & 0.0 & 100.0 & 76.0 & 85.4 & 100.0 & 92.9 & 77.4 \\
\hline $\begin{array}{l}\text { Average percent (and SD) of providers who serve as } \\
\text { volunteers }\end{array}$ & $\begin{array}{r}44.7 \\
(34.1)\end{array}$ & N/A & $\begin{array}{r}40.5 \\
(55.9)\end{array}$ & $\begin{array}{r}62.3 \\
(34.0)\end{array}$ & $\begin{array}{r}43.1 \\
(32.3)\end{array}$ & $\begin{array}{r}40.5 \\
(22.1)\end{array}$ & $\begin{array}{r}53.2 \\
(35.7)\end{array}$ & $\begin{array}{r}15.0 \\
(20.5) \\
\end{array}$ \\
\hline $\begin{array}{l}\text { \% inwhich volunteers typically respond to calls from fire } \\
\text { or EMS station houses }{ }^{\|}\end{array}$ & 38.5 & N/A & 50.0 & 52.6 & 25.0 & 20.0 & 54.7 & 37.5 \\
\hline $\begin{array}{l}\% \text { indicating call coverage is of major concern due to } \\
\text { staffing shortages }\end{array}$ & 69.6 & 0.0 & 50.0 & 62.5 & 66.3 & 80.0 & 69.6 & 83.3 \\
\hline
\end{tabular}

\footnotetext{
${ }^{+}$Among those using first responders

"Among those using volunteers
} 
Table 15: Response Configurations and Use of Volunteer Providers by Rurality ${ }^{\mathrm{a}}$ of the Service Area

\begin{tabular}{|c|c|c|c|c|c|c|}
\hline & $\begin{array}{c}\text { All } \\
\text { Systems } \\
(n=235)\end{array}$ & $\begin{array}{l}\text { Large } \\
\text { Metro } \\
(n=52)\end{array}$ & $\begin{array}{l}\text { Small } \\
\text { Metro } \\
(n=60)\end{array}$ & $\begin{array}{c}\text { Large } \\
\text { Non- } \\
\text { Metro } \\
(n=23)\end{array}$ & $\begin{array}{l}\text { Small } \\
\text { Non- } \\
\text { Metro } \\
(n=61)\end{array}$ & $\begin{array}{c}\text { Completely } \\
\text { Rural } \\
(n=39)\end{array}$ \\
\hline$\%$ using first responders & 98.3 & 100.0 & 98.3 & 95.7 & 98.4 & 97.4 \\
\hline $\begin{array}{l}\% \text { in which first responders are most commonly dispatched for all } 911 \\
\text { calls }\end{array}$ & 36.4 & 42.2 & 18.9 & 22.7 & 47.1 & 51.9 \\
\hline $\begin{array}{l}\text { \% in which first responders are most commonly simultaneously } \\
\text { dispatched with transport ambulance }\end{array}$ & 93.4 & 88.9 & 94.3 & 95.5 & 94.0 & 96.2 \\
\hline \multicolumn{7}{|l|}{ Most commonly used response configuration } \\
\hline BLS 1st response, BLS transport & 8.7 & 5.8 & 8.5 & 13.6 & 6.7 & 13.9 \\
\hline BLS 1st response, ALS transport & 31.0 & 28.9 & 45.8 & 27.3 & 23.3 & 25.0 \\
\hline ALS 1st response, BLS transport & 7.0 & 5.8 & 5.1 & 9.1 & 10.0 & 5.6 \\
\hline ALS 1st response, ALS transport & 37.6 & 51.9 & 25.4 & 40.9 & 38.3 & 33.3 \\
\hline BLS transport only & 4.4 & 0.0 & 8.5 & 0.0 & 6.7 & 2.8 \\
\hline ALS transport only & 11.4 & 7.7 & 6.8 & 9.1 & 15.0 & 19.4 \\
\hline $\begin{array}{l}\text { \% with operating procedures that allow response without use of lights } \\
\text { and sirens* }\end{array}$ & 69.5 & 67.3 & 78.3 & 78.3 & 72.9 & 48.7 \\
\hline $\begin{array}{l}\text { \% with operating procedures that allow transports without use of lights } \\
\text { and sirens }{ }^{*}\end{array}$ & 91.5 & 94.2 & 93.3 & 100.0 & 91.7 & 79.5 \\
\hline $\begin{array}{l}\text { \% with operating procedures that transports to non-hospital destinations } \\
\text { (e.g. urgent care centers)* }\end{array}$ & 19.2 & 13.5 & 23.3 & 4.6 & 16.4 & 34.2 \\
\hline & & & & & & \\
\hline$\%$ using volunteer providers & 85.9 & 78.9 & 90.0 & 95.7 & 85.3 & 84.2 \\
\hline Average percent (and SD) of providers who serve as volunteers ${ }^{\pi}$ & $\begin{array}{r}44.7 \\
(34.1)\end{array}$ & $\begin{array}{r}39.4 \\
(34.0)\end{array}$ & $\begin{array}{r}44.3 \\
(34.8) \\
\end{array}$ & $\begin{array}{r}46.6 \\
(33.7) \\
\end{array}$ & $\begin{array}{r}48.7 \\
(33.0) \\
\end{array}$ & $\begin{array}{r}43.7 \\
(36.5) \\
\end{array}$ \\
\hline $\begin{array}{l}\% \text { in which volunteers typically respond to calls from fire or EMS station } \\
\text { houses }^{\pi_{*}}\end{array}$ & 38.5 & 68.3 & 50.0 & 40.9 & 19.6 & 9.4 \\
\hline$\%$ indicating call coverage is of major concern due to staffing shortages* & 69.6 & 58.0 & 56.7 & 78.3 & 81.4 & 81.6 \\
\hline
\end{tabular}

a Defined by Rural-Urban Continuum

+ Among those using first responders

* Represents significant $X^{2}$ at $p<0.05$

${ }^{\pi}$ Among those using volunteers 
Table 16: Response Configurations and Use of Volunteer Providers by Size ${ }^{a}$ of the System

\begin{tabular}{|c|c|c|c|c|}
\hline & $\begin{array}{l}\text { All Systems } \\
(n=222)\end{array}$ & $\begin{array}{l}\text { Small } \\
(n=74)\end{array}$ & $\begin{array}{l}\text { Medium } \\
(\mathrm{n}=75)\end{array}$ & $\begin{array}{l}\text { Large } \\
(\mathrm{n}=73)\end{array}$ \\
\hline$\%$ using first responders* & 98.3 & 94.6 & 100.0 & 100.0 \\
\hline $\begin{array}{l}\% \text { in which first responders are most commonly } \\
\text { dispatched for all } 911 \text { calls }^{+}\end{array}$ & 36.4 & 50.0 & 32.9 & 28.8 \\
\hline $\begin{array}{l}\% \text { in which first responders are most commonly } \\
\text { simultaneously dispatched with transport ambulance }{ }^{+}\end{array}$ & 93.4 & 96.1 & 95.7 & 90.9 \\
\hline \multicolumn{5}{|l|}{ Most commonly used response configuration } \\
\hline BLS 1st response, BLS transport & 8.7 & 14.1 & 6.9 & 5.5 \\
\hline BLS 1st response, ALS transport & 31.0 & 21.1 & 32.9 & 39.7 \\
\hline ALS 1st response, BLS transport & 7.0 & 8.5 & 4.1 & 6.9 \\
\hline ALS 1st response, ALS transport & 37.6 & 36.6 & 35.6 & 39.7 \\
\hline BLS transport only & 4.4 & 5.6 & 5.5 & 2.7 \\
\hline ALS transport only & 11.4 & 14.1 & 15.1 & 5.5 \\
\hline $\begin{array}{l}\% \text { with operating procedures that allow response without } \\
\text { use of lights and sirens }{ }^{*}\end{array}$ & 69.5 & 57.5 & 69.3 & 81.1 \\
\hline $\begin{array}{l}\% \text { with operating procedures that allow transports } \\
\text { without use of lights and sirens* }\end{array}$ & 91.5 & 82.4 & 93.3 & 97.3 \\
\hline $\begin{array}{l}\% \text { with operating procedures that transports to non- } \\
\text { hospital destinations (e.g. urgent care centers) }\end{array}$ & 19.2 & 20.6 & 16.0 & 21.6 \\
\hline & & & & \\
\hline$\%$ using volunteer providers & 85.9 & 89.0 & 86.7 & 87.8 \\
\hline $\begin{array}{l}\text { Average percent (and SD) of providers who serve as } \\
\text { volunteers }{ }^{\pi f}\end{array}$ & $\begin{array}{r}44.7 \\
(34.1) \\
\end{array}$ & $\begin{array}{l}49.1 a \\
(35.6)\end{array}$ & $\begin{array}{l}50.2 a \\
(35.8)\end{array}$ & $\begin{array}{l}34.3 b \\
(29.0) \\
\end{array}$ \\
\hline $\begin{array}{l}\% \text { in which volunteers typically respond to calls from fire } \\
\text { or EMS station houses }\end{array}$ & 38.5 & 29.2 & 32.8 & 56.9 \\
\hline $\begin{array}{l}\% \text { indicating call coverage is of major concern due to } \\
\text { staffing shortages* }\end{array}$ & 69.6 & 86.3 & 63.0 & 58.1 \\
\hline
\end{tabular}

${ }^{a}$ Defined by Annual Number of Responses (not available for 13 systems)

* Represents significant $X^{2}$ at $p<0.05$

${ }^{+}$Among those using first responders

"Among those using volunteers

${ }^{f}$ Represents significant $\mathrm{F}$ at $\mathrm{p}<0.05$ based on one-way ANOVA; Mean separation by Duncan's multiple range test 
Table 17: Response to Calls Outside Primary Service Areas by State

\begin{tabular}{|c|c|c|c|c|c|c|c|c|}
\hline & $\begin{array}{c}\text { All } \\
\text { Systems } \\
(n=235)\end{array}$ & $\begin{array}{c}D C \\
(n=2)\end{array}$ & $\begin{array}{c}D E \\
(n=2)\end{array}$ & $\begin{array}{c}M D \\
(n=25)\end{array}$ & $\begin{array}{c}N C \\
(n=90)\end{array}$ & $\begin{array}{c}\mathrm{PA} \\
(n=15)\end{array}$ & $\begin{array}{c}\text { VA } \\
(n=70)\end{array}$ & $\begin{array}{l}\text { WV } \\
(n=31)\end{array}$ \\
\hline Percent with mutual aid agreements & 94.4 & 100.0 & 50.0 & 92.0 & 95.5 & 73.3 & 98.6 & 96.8 \\
\hline \multicolumn{9}{|c|}{ Percent with mutual aid agreements that address. . . } \\
\hline Service coverage & 87.9 & 50.0 & 50.0 & 88.0 & 85.2 & 80.0 & 94.2 & 90.3 \\
\hline Communication linkage & 55.6 & 100.0 & 50.0 & 64.0 & 54.6 & 40.0 & 55.1 & 58.1 \\
\hline Licensure or certification of providers & 34.9 & 50.0 & 50.0 & 48.0 & 37.5 & 13.3 & 27.5 & 41.9 \\
\hline Financial reimbursement & 31.0 & 0.0 & 50.0 & 28.0 & 37.5 & 40.0 & 24.6 & 25.8 \\
\hline Liability & 35.8 & 0.0 & 0.0 & 28.0 & 40.9 & 20.0 & 39.1 & 32.3 \\
\hline \multicolumn{9}{|c|}{$\begin{array}{l}\text { How often does first response agency respond to calls outside } \\
\text { primary service area }\end{array}$} \\
\hline Never & 9.8 & 0.0 & 0.0 & 8.0 & 11.4 & 13.3 & 9.4 & 7.1 \\
\hline Seldom & 36.2 & 50.0 & 0.0 & 12.0 & 52.3 & 33.3 & 29.7 & 25.0 \\
\hline Sometimes & 38.8 & 0.0 & 100.0 & 48.0 & 27.3 & 40.0 & 40.6 & 60.7 \\
\hline Often & 11.6 & 50.0 & 0.0 & 32.0 & 3.4 & 13.3 & 17.2 & 3.6 \\
\hline \multicolumn{9}{|c|}{$\begin{array}{l}\text { How often does the transport agency respond to calls outside } \\
\text { primary service area }\end{array}$} \\
\hline Never & 3.1 & 0.0 & 0.0 & 0.0 & 4.7 & 0.0 & 3.1 & 3.3 \\
\hline Seldom & 24.1 & 50.0 & 50.0 & 8.3 & 43.0 & 0.0 & 15.4 & 10.0 \\
\hline Sometimes & 44.2 & 0.0 & 0.0 & 45.8 & 39.5 & 60.0 & 41.5 & 60.0 \\
\hline Often & 28.6 & 50.0 & 50.0 & 45.8 & 12.8 & 40.0 & 40.0 & 26.7 \\
\hline
\end{tabular}

${ }^{+}$Among those using first responders 
Table 18: Response to Calls Outside Primary Service Areas by Rurality ${ }^{a}$ of the Service Area

\begin{tabular}{|c|c|c|c|c|c|c|}
\hline & $\begin{array}{c}\text { All } \\
\text { Systems } \\
(n=235)\end{array}$ & $\begin{array}{l}\text { Large } \\
\text { Metro } \\
(n=52)\end{array}$ & $\begin{array}{l}\text { Small } \\
\text { Metro } \\
(n=60)\end{array}$ & $\begin{array}{c}\text { Large } \\
\text { Non-Metro } \\
(n=23)\end{array}$ & $\begin{array}{c}\text { Small } \\
\text { Non-Metro } \\
(n=61)\end{array}$ & $\begin{array}{c}\text { Completely } \\
\text { Rural } \\
(n=39)\end{array}$ \\
\hline Percent with mutual aid agreements & 94.4 & 94.1 & 93.2 & 95.7 & 95.0 & 94.9 \\
\hline \multicolumn{7}{|c|}{ Percent with mutual aid agreements that address. . . } \\
\hline Service coverage & 87.9 & 86.3 & 88.1 & 95.7 & 86.7 & 87.2 \\
\hline Communication linkage & 55.6 & 70.6 & 54.2 & 47.8 & 53.3 & 46.2 \\
\hline Licensure or certification of providers & 34.9 & 39.2 & 40.7 & 43.5 & 28.3 & 25.6 \\
\hline Financial reimbursement & 31.0 & 25.5 & 37.3 & 43.5 & 28.3 & 25.6 \\
\hline Liability & 35.8 & 33.3 & 37.3 & 43.5 & 30.0 & 41.0 \\
\hline \multicolumn{7}{|c|}{$\begin{array}{l}\text { How often does first response agency respond to calls } \\
\text { outside primary service area }{ }^{*+}\end{array}$} \\
\hline Never & 9.8 & 1.9 & 10.3 & 19.1 & 6.9 & 20.0 \\
\hline Seldom & 36.2 & 32.7 & 48.3 & 23.8 & 27.6 & 42.9 \\
\hline Sometimes & 38.8 & 40.4 & 25.9 & 42.9 & 55.2 & 28.6 \\
\hline Often & 11.6 & 23.1 & 12.1 & 9.5 & 6.9 & 2.9 \\
\hline \multicolumn{7}{|c|}{$\begin{array}{l}\text { How often does the transport agency respond to calls } \\
\text { outside primary service area }\end{array}$} \\
\hline Never & 3.1 & 2.0 & 1.7 & 0.0 & 1.7 & 11.8 \\
\hline Seldom & 24.1 & 15.7 & 27.6 & 21.7 & 24.1 & 32.4 \\
\hline Sometimes & 44.2 & 39.2 & 44.8 & 47.8 & 53.5 & 32.4 \\
\hline Often & 28.6 & 43.1 & 25.9 & 30.4 & 20.7 & 23.5 \\
\hline
\end{tabular}

\footnotetext{
${ }^{\text {a }}$ Defined by Rural-Urban Continuum

Represents significant $X^{2}$ at $p<0.05$

Among those using first responders
} 
Table 19: Response to Calls Outside Primary Service Areas by Size ${ }^{a}$ of the System

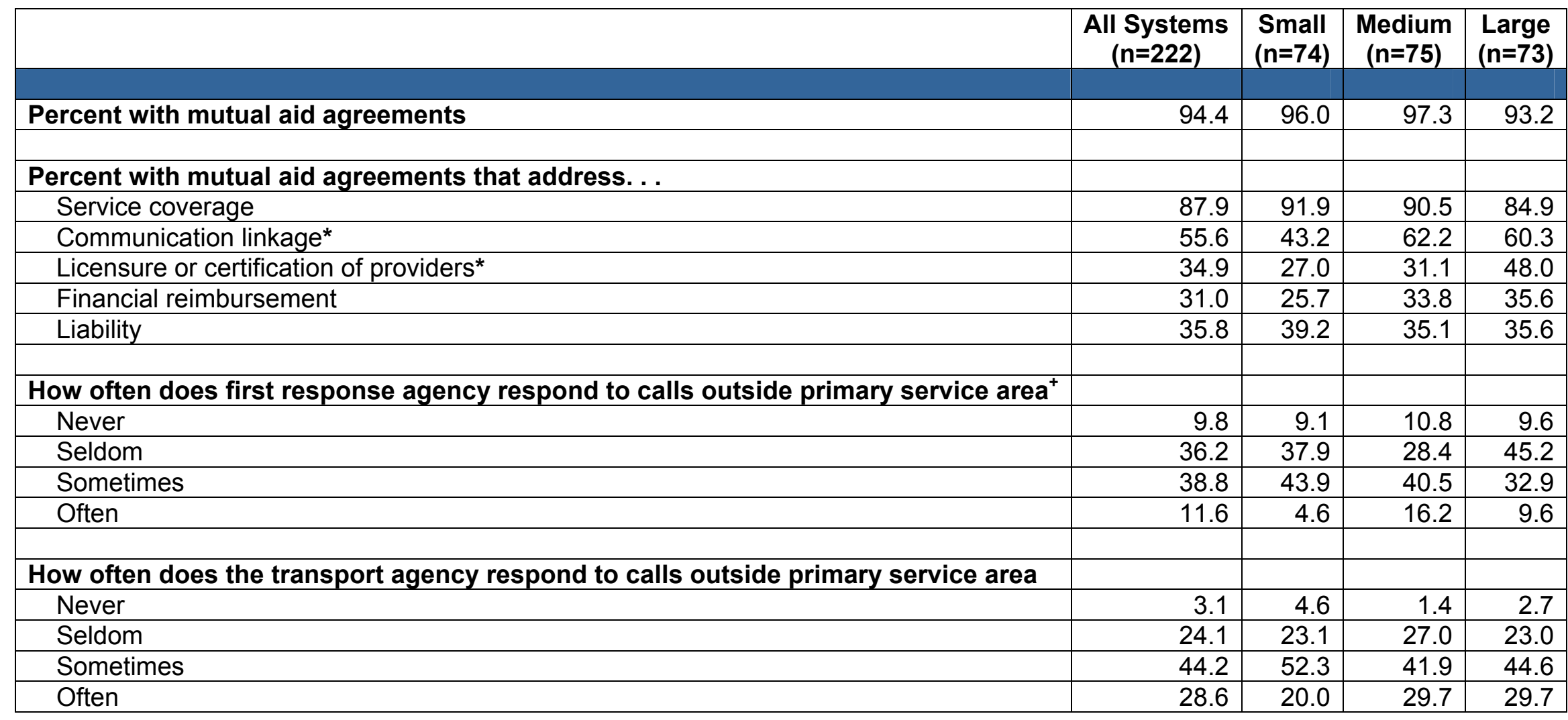

a Defined by Annual Number of Responses (not available for 13 systems)

Represents significant $X^{2}$ at $p<0.05$

${ }^{+}$Among those using first responders 
Table 20: Medical Control by State

\begin{tabular}{|c|c|c|c|c|c|c|c|c|}
\hline & $\begin{array}{c}\text { All } \\
\text { Systems } \\
(n=235)\end{array}$ & $\begin{array}{c}D C \\
(n=2)\end{array}$ & $\begin{array}{c}D E \\
(n=2)\end{array}$ & $\begin{array}{c}\text { MD } \\
(n=25)\end{array}$ & $\begin{array}{c}\mathrm{NC} \\
(\mathrm{n}=90)\end{array}$ & $\begin{array}{c}\text { PA } \\
(n=15)\end{array}$ & $\begin{array}{c}\text { VA } \\
(n=70)\end{array}$ & $\begin{array}{c}\text { WV } \\
(n=31)\end{array}$ \\
\hline \multicolumn{9}{|l|}{$\begin{array}{l}\text { Primary responsibility for medical control } \\
\text { of the system rests with... }\end{array}$} \\
\hline Systemwide, in-house medical director & 39.7 & 50.0 & 50.0 & 52.0 & 39.3 & 33.3 & 31.4 & 51.6 \\
\hline External (e.g., hospital-based) medical director & 50.0 & 50.0 & 0.0 & 36.0 & 58.4 & 40.0 & 54.3 & 35.5 \\
\hline Medical advisory board & 1.3 & 0.0 & 0.0 & 0.0 & 1.1 & 6.7 & 1.4 & 0.0 \\
\hline EMS regulatory agency & 5.1 & 0.0 & 50.0 & 8.0 & 1.1 & 0.0 & 7.1 & 9.7 \\
\hline $\begin{array}{l}\text { Systemized medical direction, but } \\
\text { provided at individual agency level }\end{array}$ & 3.9 & 0.0 & 0.0 & 4.0 & 0.0 & 20.0 & 5.7 & 3.2 \\
\hline
\end{tabular}


Table 21: Medical Control by Rurality ${ }^{\mathrm{a}}$ of the Service Area

\begin{tabular}{|c|c|c|c|c|c|c|}
\hline & $\begin{array}{c}\text { All Systems } \\
(n=235)\end{array}$ & $\begin{array}{l}\text { Large } \\
\text { Metro } \\
(n=52)\end{array}$ & $\begin{array}{l}\text { Small } \\
\text { Metro } \\
(n=60)\end{array}$ & $\begin{array}{c}\text { Large } \\
\text { Non- } \\
\text { Metro } \\
(n=23)\end{array}$ & $\begin{array}{l}\text { Small } \\
\text { Non- } \\
\text { Metro } \\
(n=61)\end{array}$ & $\begin{array}{c}\text { Complet } \\
\text { ely } \\
\text { Rural } \\
(n=39)\end{array}$ \\
\hline \multicolumn{7}{|l|}{$\begin{array}{l}\text { Primary responsibility for medical control } \\
\text { of the system rests with ... }\end{array}$} \\
\hline Systemwide, in-house medical director & 39.7 & 51.9 & 45.0 & 30.4 & 36.7 & 25.6 \\
\hline $\begin{array}{l}\text { External (e.g., hospital-based) medical } \\
\text { director }\end{array}$ & 50.0 & 34.6 & 45.0 & 60.9 & 56.7 & 61.5 \\
\hline Medical advisory board & 1.3 & 0.0 & 1.7 & 4.4 & 1.7 & 0.0 \\
\hline EMS regulatory agency & 5.1 & 7.7 & 3.3 & 0.0 & 3.3 & 10.3 \\
\hline $\begin{array}{l}\text { Systemized medical direction, but } \\
\text { provided at individual agency level }\end{array}$ & 3.9 & 5.8 & 5.0 & 4.4 & 1.7 & 2.6 \\
\hline
\end{tabular}

\footnotetext{
${ }^{a}$ Defined by Rural-Urban Continuum
} 
Table 22: Medical Control by Size ${ }^{a}$ of the System

\begin{tabular}{|c|c|c|c|c|}
\hline & $\begin{array}{c}\text { All } \\
\text { Systems } \\
(n=222)\end{array}$ & $\begin{array}{l}\text { Small } \\
(n=74)\end{array}$ & $\begin{array}{c}\text { Medium } \\
(n=75)\end{array}$ & $\begin{array}{l}\text { Large } \\
(n=73)\end{array}$ \\
\hline \multicolumn{5}{|l|}{$\begin{array}{l}\text { Primary responsibility for medical control } \\
\text { of the system rests with ... }\end{array}$} \\
\hline Systemwide, in-house medical director & 39.7 & 32.4 & 33.8 & 54.1 \\
\hline $\begin{array}{l}\text { External (e.g., hospital-based) medical } \\
\text { director }\end{array}$ & 50.0 & 59.5 & 55.4 & 35.1 \\
\hline Medical advisory board & 1.3 & 0.0 & 2.7 & 1.4 \\
\hline EMS regulatory agency & 5.1 & 5.4 & 6.8 & 4.1 \\
\hline $\begin{array}{l}\text { Systemized medical direction, but } \\
\text { provided at individual agency level }\end{array}$ & 3.9 & 2.7 & 1.4 & 5.4 \\
\hline
\end{tabular}

${ }^{a}$ Defined by Annual Number of Responses (not available for 13 systems) 
Table 23: Financing of the System by State

\begin{tabular}{|l|r|r|r|r|r|r|r|r|}
\hline & $\begin{array}{c}\text { All Systems } \\
(\mathbf{n = 2 3 5})\end{array}$ & \multicolumn{1}{|c|}{$\begin{array}{c}\text { DC } \\
(\mathbf{n = 2})\end{array}$} & $\begin{array}{c}\text { DE } \\
(\mathbf{n = 2})\end{array}$ & $\begin{array}{c}\text { MD } \\
(\mathbf{n = 2 5})\end{array}$ & $\begin{array}{c}\text { NC } \\
(\mathbf{n}=\mathbf{9 0})\end{array}$ & $\begin{array}{c}\text { PA } \\
(\mathbf{n}=\mathbf{1 5})\end{array}$ & $\begin{array}{c}\text { VA } \\
(\mathbf{n}=\mathbf{7 0})\end{array}$ & $\begin{array}{c}\text { WV } \\
(\mathbf{n}=\mathbf{3 1})\end{array}$ \\
\hline Percent receiving funds from ... & & & & & & & & \\
\hline Tax subsidies & & & & & & & & \\
\hline Fees/bill for services & 81.3 & 50.0 & 100.0 & 84.0 & 90.0 & 66.7 & 87.1 & 48.4 \\
\hline Homeland Security grants & 79.6 & 0.0 & 100.0 & 64.0 & 90.0 & 100.0 & 62.9 & 93.6 \\
\hline Other grants & 36.6 & 50.0 & 100.0 & 60.0 & 40.0 & 40.0 & 34.3 & 6.5 \\
\hline Donations/fundraisers & 56.2 & 50.0 & 50.0 & 72.0 & 40.0 & 93.3 & 72.9 & 35.5 \\
\hline & 55.3 & 0.0 & 100.0 & 64.0 & 34.4 & 100.0 & 72.9 & 48.4 \\
\hline Primary source of funding & & & & & & & & \\
\hline Tax subsidies & & & & & & & & \\
\hline Fees/bill for services & 52.5 & 50.0 & 100.0 & 68.2 & 63.2 & 0.0 & 62.1 & 10.3 \\
\hline Homeland Security grants & 39.9 & 0.0 & 0.0 & 22.7 & 33.3 & 100.0 & 22.7 & 86.2 \\
\hline Other grants & 0.9 & 0.0 & 0.0 & 4.6 & 0.0 & 0.0 & 1.5 & 0.0 \\
\hline Donations/fundraisers & 0.9 & 0.0 & 0.0 & 4.6 & 0.0 & 0.0 & 1.5 & 0.0 \\
\hline
\end{tabular}

${ }^{a}$ Percentages may not sum to $100 \%$ across all categories due to other funding sources (not shown), including hospital, Indian Health Service, and airline fees. 
Table 24: Financing of the System by Rurality ${ }^{a}$ of the Service Area

\begin{tabular}{|c|c|c|c|c|c|c|}
\hline & $\begin{array}{l}\text { All Systems } \\
(n=235)\end{array}$ & $\begin{array}{l}\text { Large } \\
\text { Metro } \\
(\mathrm{n}=52)\end{array}$ & $\begin{array}{l}\text { Small } \\
\text { Metro } \\
(\mathrm{n}=60)\end{array}$ & $\begin{array}{c}\text { Large } \\
\text { Non-Metro } \\
(n=23)\end{array}$ & $\begin{array}{c}\text { Small } \\
\text { Non-Metro } \\
(n=61)\end{array}$ & $\begin{array}{c}\text { Completely } \\
\text { Rural } \\
(n=39)\end{array}$ \\
\hline \multicolumn{7}{|c|}{ Percent receiving funds from ... } \\
\hline Tax subsidies* & 81.3 & 88.5 & 91.7 & 78.3 & 77.1 & 64.1 \\
\hline Fees/bill for services* & 79.6 & 61.5 & 80.0 & 82.6 & 88.5 & 87.2 \\
\hline Homeland Security grants & 36.6 & 44.2 & 41.7 & 34.8 & 32.8 & 25.6 \\
\hline Other grants* & 56.2 & 67.3 & 56.7 & 78.3 & 45.9 & 43.6 \\
\hline Donations/fundraisers & 55.3 & 55.8 & 55.0 & 60.9 & 49.2 & 61.5 \\
\hline \multicolumn{7}{|l|}{ Primary source of funding } \\
\hline Tax subsidies & 52.5 & 72.0 & 55.4 & 33.3 & 45.8 & 43.2 \\
\hline Fees/bill for services & 39.9 & 18.0 & 39.3 & 57.1 & 45.8 & 51.4 \\
\hline Homeland Security grants & 0.9 & 4.0 & 0.0 & 0.0 & 0.0 & 0.0 \\
\hline Other arants & 0.9 & 2.0 & 0.0 & 4.8 & 0.0 & 0.0 \\
\hline Donations/fundraisers & 40 & 20 & 36 & 4.8 & 68 & 27 \\
\hline
\end{tabular}

${ }^{\text {a }}$ Defined by Rural-Urban Continuum

Represents significant $X^{2}$ at $p<0.05$ 
Table 25: Financing of the System by Size ${ }^{a}$ of the System

\begin{tabular}{|l|r|r|r|r|}
\hline & \multicolumn{1}{|c|}{$\begin{array}{c}\text { All Systems } \\
(\mathbf{n = 2 2 2})\end{array}$} & \multicolumn{1}{c|}{$\begin{array}{c}\text { Small } \\
(\mathbf{n = 7 4 )}\end{array}$} & \multicolumn{1}{c|}{$\begin{array}{c}\text { Medium } \\
(\mathbf{n = 7 5 )}\end{array}$} & \multicolumn{1}{c|}{$\begin{array}{c}\text { Large } \\
(\mathbf{n = 7 3 )}\end{array}$} \\
\hline Percent receiving funds from ... & & & & \\
\hline Tax subsidies* & 81.3 & 73.0 & 88.0 & 87.8 \\
\hline Fees/bill for services & 79.6 & 79.7 & 81.3 & 79.7 \\
\hline Homeland Security grants & 36.6 & 27.0 & 42.7 & 41.9 \\
\hline Other grants & 56.2 & 60.8 & 56.0 & 52.7 \\
\hline Donations/fundraisers & 55.3 & 67.6 & 50.7 & 50.0 \\
\hline & & & & \\
\hline Primary source of funding & & & & \\
\hline Tax subsidies & 52.5 & 44.3 & 58.0 & 57.5 \\
\hline Fees/bill for services & 39.9 & 50.0 & 33.3 & 38.4 \\
\hline Homeland Security grants & 0.9 & 0.0 & 0.0 & 1.4 \\
\hline Other grants & 0.9 & 0.0 & 1.5 & 0.0 \\
\hline Donations/fundraisers & 4.0 & 5.7 & 5.8 & 1.4 \\
\hline
\end{tabular}

${ }^{a}$ Defined by Annual Number of Responses (not available for 13 systems)

Represents significant $X^{2}$ at $p<0.05$ 
Table 26: Subjective Assessments by State

\begin{tabular}{|c|c|c|c|c|c|c|c|c|}
\hline & $\begin{array}{c}\text { All Systems } \\
(n=235)\end{array}$ & $\begin{array}{c}\mathrm{DC} \\
(\mathrm{n}=2)\end{array}$ & $\begin{array}{c}\mathrm{DE} \\
(\mathrm{n}=2)\end{array}$ & $\begin{array}{c}\text { MD } \\
(n=25)\end{array}$ & $\begin{array}{c}N C \\
(n=90)\end{array}$ & $\begin{array}{c}\text { PA } \\
(n=15)\end{array}$ & $\begin{array}{c}\text { VA } \\
(n=70)\end{array}$ & $\begin{array}{c}\text { WV } \\
(n=31)\end{array}$ \\
\hline \multicolumn{9}{|l|}{ Percent who agree or strongly agree with the following ... } \\
\hline \multicolumn{9}{|l|}{ Resource levels } \\
\hline a. Our system is adequately staffed to meet demand. & 30.2 & 50.0 & 0.0 & 24.0 & 40.0 & 33.3 & 22.9 & 22.6 \\
\hline $\begin{array}{l}\text { b. Our system has enough resources (vehicles, equipment) to } \\
\text { meet demand. }\end{array}$ & 57.5 & 50.0 & 50.0 & 52.0 & 45.6 & 86.7 & 71.4 & 51.6 \\
\hline \multicolumn{9}{|l|}{ Public participation } \\
\hline $\begin{array}{l}\text { c. The population served by our system has a high level of EMS } \\
\text { awareness, participation, or support. }\end{array}$ & 28.5 & 0.0 & 0.0 & 24.0 & 36.7 & 13.3 & 22.9 & 32.3 \\
\hline $\begin{array}{l}\text { d. Defibrillators, available for public access, can be found in } \\
\text { many public places within our system. }\end{array}$ & 43.8 & 50.0 & 100.0 & 72.0 & 31.1 & 86.7 & 42.9 & 35.5 \\
\hline $\begin{array}{l}\text { e. Bystanders often provide CPR prior to EMS arrival at cardiac } \\
\text { arrest calls. }\end{array}$ & 25.1 & 50.0 & 0.0 & 36.0 & 24.4 & 26.7 & 20.0 & 29.0 \\
\hline f. The public is satisfied with our EMS services. & 70.1 & 50.0 & 100.0 & 76.0 & 68.5 & 80.0 & 67.1 & 71.0 \\
\hline \multicolumn{9}{|l|}{ System support } \\
\hline g. Our system has a high level of physician involvement. & 59.2 & 100.0 & 100.0 & 64.0 & 63.3 & 33.3 & 55.7 & 58.1 \\
\hline $\begin{array}{l}\text { h. Hospitals in our system are supportive of our EMS } \\
\text { agencies/providers. }\end{array}$ & 74.5 & 50.0 & 100.0 & 76.0 & 75.6 & 73.3 & 74.3 & 71.0 \\
\hline i. Patient flow through the EMS system is generally smooth. & 79.2 & 50.0 & 100.0 & 64.0 & 86.7 & 80.0 & 71.4 & 87.1 \\
\hline $\begin{array}{l}\text { j. Our EMS system/participating agencies collaborate with non- } \\
\text { EMS organizations. }\end{array}$ & 75.5 & 50.0 & 100.0 & 70.8 & 83.3 & 73.3 & 67.1 & 76.7 \\
\hline \multicolumn{9}{|l|}{ System environment } \\
\hline k. Turf wars are a problem for our EMS providers. & 24.7 & 0.0 & 50.0 & 8.0 & 16.7 & 46.7 & 32.9 & 32.3 \\
\hline I. Politics are a problem within our EMS system. & 40.9 & 50.0 & 100.0 & 44.0 & 30.0 & 60.0 & 47.1 & 41.9 \\
\hline m. EMS providers enjoy working in our EMS sys & 77.0 & 0.0 & 100.0 & 84.0 & 81.1 & 80.0 & 74.3 & 67.7 \\
\hline
\end{tabular}


Table 26: Subjective Assessments by State (cont.)

\begin{tabular}{|c|c|c|c|c|c|c|c|c|}
\hline & $\begin{array}{c}\text { All Systems } \\
(n=235)\end{array}$ & $\begin{array}{c}D C \\
(n=2)\end{array}$ & $\begin{array}{c}\mathrm{DE} \\
(n=2)\end{array}$ & $\begin{array}{c}M D \\
(n=25)\end{array}$ & $\begin{array}{c}\mathrm{NC} \\
(\mathrm{n}=90)\end{array}$ & $\begin{array}{c}\mathrm{PA} \\
(n=15)\end{array}$ & $\begin{array}{c}\text { VA } \\
(n=70)\end{array}$ & $\begin{array}{c}\text { WV } \\
(n=31)\end{array}$ \\
\hline \multicolumn{9}{|l|}{ System change } \\
\hline n. Our EMS system looks much the same as 10 years ago & 17.5 & 0.0 & 50.0 & 24.0 & 17.8 & 13.3 & 18.6 & 9.7 \\
\hline o. Our EMS system will look much the same 10 years from now & 8.1 & 0.0 & 0.0 & 12.0 & 5.6 & 6.7 & 10.0 & 9.7 \\
\hline p. Our system adapts well to change. & 45.5 & 0.0 & 50.0 & 44.0 & 60.0 & 20.0 & 32.9 & 48.4 \\
\hline Mean score (standard deviation) - Resource levels & $\begin{array}{r}2.97 \\
(0.91)\end{array}$ & $\begin{array}{r}3.00 \\
(1.41)\end{array}$ & $\begin{array}{r}2.75 \\
(1.06)\end{array}$ & $\begin{array}{r}2.78 \\
(1.03)\end{array}$ & $\begin{array}{r}2.96 \\
(0.94)\end{array}$ & $\begin{array}{r}3.27 \\
(0.56)\end{array}$ & $\begin{array}{r}2.98 \\
(0.92)\end{array}$ & $\begin{array}{r}3.03 \\
(0.83)\end{array}$ \\
\hline Mean score (standard deviation) - Public participation & $\begin{array}{r}3.06 \\
(0.70)\end{array}$ & $\begin{array}{r}3.25 \\
(1.41)\end{array}$ & $\begin{array}{r}3.38 \\
(0.53)\end{array}$ & $\begin{array}{r}3.35 \\
(0.65)\end{array}$ & $\begin{array}{r}2.97 \\
(0.71)\end{array}$ & $\begin{array}{r}3.15 \\
(0.51)\end{array}$ & $\begin{array}{r}3.05 \\
(0.67)\end{array}$ & $\begin{array}{r}3.02 \\
(0.78)\end{array}$ \\
\hline Mean score (standard deviation) - System support & $\begin{array}{r}3.76 \\
(0.64)\end{array}$ & $\begin{array}{r}3.25 \\
(1.41)\end{array}$ & $\begin{array}{r}4.25 \\
(0.35)\end{array}$ & $\begin{array}{r}3.68 \\
(0.49)\end{array}$ & $\begin{array}{r}3.88 \\
(0.61)\end{array}$ & $\begin{array}{r}3.55 \\
(0.51)\end{array}$ & $\begin{array}{r}3.66 \\
(0.75)\end{array}$ & $\begin{array}{r}3.79 \\
(0.56)\end{array}$ \\
\hline Mean score (standard deviation) - System environment & $\begin{array}{r}3.41 \\
(0.82)\end{array}$ & $\begin{array}{r}3.33 \\
(0.94)\end{array}$ & $\begin{array}{r}2.67 \\
(0.47)\end{array}$ & $\begin{array}{r}3.44 \\
(0.80)\end{array}$ & $\begin{array}{r}3.64 \\
(0.78)\end{array}$ & $\begin{array}{r}2.87 \\
(0.63)\end{array}$ & $\begin{array}{r}3.30 \\
(0.89)\end{array}$ & $\begin{array}{r}3.30 \\
(0.67)\end{array}$ \\
\hline
\end{tabular}


Table 27: Subjective Assessments by Rurality ${ }^{\mathrm{a}}$ of the System

\begin{tabular}{|c|c|c|c|c|c|c|}
\hline & $\begin{array}{c}\text { All } \\
\text { Systems } \\
(n=235)\end{array}$ & $\begin{array}{l}\text { Large } \\
\text { Metro } \\
(n=52)\end{array}$ & $\begin{array}{l}\text { Small } \\
\text { Metro } \\
(n=60)\end{array}$ & $\begin{array}{l}\text { Large } \\
\text { Non- } \\
\text { Metro } \\
(n=23)\end{array}$ & $\begin{array}{l}\text { Small } \\
\text { Non- } \\
\text { Metro } \\
(n=61)\end{array}$ & $\begin{array}{c}\text { Completely } \\
\text { Rural } \\
(n=39)\end{array}$ \\
\hline \multicolumn{7}{|l|}{ Percent who agree or strongly agree with the following ... } \\
\hline \multicolumn{7}{|l|}{ Resource levels } \\
\hline a. Our system is adequately staffed to meet demand. & 30.2 & 34.6 & 33.3 & 17.4 & 27.9 & 30.8 \\
\hline $\begin{array}{l}\text { b. Our system has enough resources (vehicles, equipment) to meet } \\
\text { demand. }\end{array}$ & 57.5 & 65.4 & 55.0 & 52.2 & 49.2 & 66.7 \\
\hline \multicolumn{7}{|l|}{ Public participation } \\
\hline $\begin{array}{l}\text { c. The population served by our system has a high level of EMS } \\
\text { awareness, participation, or support. }\end{array}$ & 28.5 & 26.9 & 31.7 & 17.4 & 24.6 & 38.5 \\
\hline $\begin{array}{l}\text { d. Defibrillators, available for public access, can be found in many public } \\
\text { places within our system.* }\end{array}$ & 43.8 & 65.4 & 48.3 & 34.8 & 29.5 & 35.9 \\
\hline $\begin{array}{l}\text { e. Bystanders often provide CPR prior to EMS arrival at cardiac arrest } \\
\text { calls. }\end{array}$ & 25.1 & 26.9 & 28.3 & 13.0 & 19.7 & 33.3 \\
\hline f. The public is satisfied with our EMS services. & 70.1 & 80.8 & 71.7 & 52.2 & 66.7 & 69.2 \\
\hline \multicolumn{7}{|l|}{ System support } \\
\hline g. Our system has a high level of physician involvement. & 59.2 & 67.3 & 61.7 & 65.2 & 52.5 & 51.3 \\
\hline $\begin{array}{l}\text { h. Hospitals in our system are supportive of our EMS } \\
\text { agencies/providers. }\end{array}$ & 74.5 & 75.0 & 71.7 & 91.3 & 72.1 & 71.8 \\
\hline i. $\quad$ Patient flow through the EMS system is generally smooth. & 79.2 & 67.3 & 78.3 & 78.3 & 86.9 & 84.6 \\
\hline $\begin{array}{l}\text { j. Our EMS system/participating agencies collaborate with non-EMS } \\
\text { organizations.* }\end{array}$ & 75.5 & 60.8 & 72.9 & 91.3 & 85.3 & 74.4 \\
\hline
\end{tabular}

${ }_{*}^{a}$ Defined by Rural-Urban Continuum

Represents significant $X^{2}$ at $p<0.05$ 
Table 27: Subjective Assessments by Rurality ${ }^{a}$ of the System (cont.)

\begin{tabular}{|c|c|c|c|c|c|c|}
\hline$\cdots$ & $\begin{array}{c}\text { All } \\
\text { Systems }\end{array}$ & $\begin{array}{l}\text { Large } \\
\text { Metro } \\
(n=52)\end{array}$ & $\begin{array}{l}\text { Small } \\
\text { Metro } \\
(n=60)\end{array}$ & $\begin{array}{c}\text { Large } \\
\text { Non- } \\
\text { Metro } \\
(n=23)\end{array}$ & $\begin{array}{c}\text { Small } \\
\text { Non- } \\
\text { Metro } \\
(n=61)\end{array}$ & $\begin{array}{c}\text { Completely } \\
\text { Rural } \\
(n=39)\end{array}$ \\
\hline \multicolumn{7}{|l|}{ System environment } \\
\hline k. Turf wars are a problem for our EMS providers. & 24.7 & 15.4 & 20.0 & 26.1 & 27.9 & 38.5 \\
\hline I. Politics are a problem in our EMS system. & 40.9 & 38.5 & 40.0 & 47.8 & 41.0 & 41.0 \\
\hline m. EMS providers enjoy working in our EMS system. & 77.0 & 65.4 & 85.0 & 69.6 & 75.4 & 87.2 \\
\hline \multicolumn{7}{|l|}{ System Change } \\
\hline n. Our EMS system looks much the same as 10 years ago & 17.5 & 11.5 & 15.0 & 17.4 & 23.0 & 20.5 \\
\hline o. Our EMS system will look much the same 10 years from now & 8.1 & 9.6 & 8.3 & 13.0 & 8.2 & 2.6 \\
\hline p. Our system adapts well to change. & 45.5 & 42.3 & 53.3 & 30.4 & 42.6 & 51.3 \\
\hline Mean score (standard deviation) - Resource levels & $\begin{array}{r}2.97 \\
(0.91)\end{array}$ & $\begin{array}{r}3.07 \\
(1.00) \\
\end{array}$ & $\begin{array}{r}3.03 \\
(0.90) \\
\end{array}$ & $\begin{array}{r}2.72 \\
(1.01) \\
\end{array}$ & $\begin{array}{r}2.89 \\
(0.85)\end{array}$ & $\begin{array}{r}3.05 \\
(0.86) \\
\end{array}$ \\
\hline Mean score (standard deviation) - Public participation ${ }^{f}$ & $\begin{array}{r}3.06 \\
(0.70) \\
\end{array}$ & $\begin{array}{l}3.31 a \\
(0.67) \\
\end{array}$ & $\begin{array}{r}3.08 a b \\
(0.67) \\
\end{array}$ & $\begin{array}{l}2.83 b \\
(0.60) \\
\end{array}$ & $\begin{array}{l}2.91 b \\
(0.77) \\
\end{array}$ & $\begin{array}{r}3.06 a b \\
(0.63) \\
\end{array}$ \\
\hline Mean score (standard deviation) - System support & $\begin{array}{r}3.76 \\
(0.64)\end{array}$ & $\begin{array}{r}3.73 \\
(0.67)\end{array}$ & $\begin{array}{r}3.70 \\
(0.71) \\
\end{array}$ & $\begin{array}{r}3.83 \\
(0.55) \\
\end{array}$ & $\begin{array}{r}3.80 \\
(0.64)\end{array}$ & $\begin{array}{r}3.79 \\
(0.55) \\
\end{array}$ \\
\hline Mean score (standard deviation) - System environment & $\begin{array}{r}3.41 \\
(0.82)\end{array}$ & $\begin{array}{r}3.43 \\
(0.85)\end{array}$ & $\begin{array}{r}3.58 \\
(0.92)\end{array}$ & $\begin{array}{r}3.26 \\
(0.66)\end{array}$ & $\begin{array}{r}3.33 \\
(0.75)\end{array}$ & $\begin{array}{r}3.36 \\
(0.78)\end{array}$ \\
\hline
\end{tabular}

a Defined by Rural-Urban Continuum

${ }^{f}$ Represents significant $\mathrm{F}$ at $\mathrm{p}<0.05$ based on one-way ANOVA; Mean separation by Duncan's multiple range test 
Table 28: Subjective Assessments by Size of the System ${ }^{a}$

\begin{tabular}{|c|c|c|c|c|}
\hline & $\begin{array}{c}\text { All } \\
\text { Systems } \\
(n=222)\end{array}$ & $\begin{array}{l}\text { Small } \\
(n=74)\end{array}$ & $\begin{array}{c}\text { Medium } \\
(\mathrm{n}=75)\end{array}$ & $\begin{array}{l}\text { Large } \\
(\mathrm{n}=73)\end{array}$ \\
\hline \multicolumn{5}{|l|}{ Percent who agree or strongly agree with the following ... } \\
\hline \multicolumn{5}{|l|}{ Resource levels } \\
\hline a. Our system is adequately staffed to meet demand. ${ }^{*}$ & 30.2 & 17.6 & 30.7 & 39.2 \\
\hline b. Our system has enough resources (vehicles, equipment) to meet demand. & 57.5 & 62.2 & 52.0 & 54.1 \\
\hline \multicolumn{5}{|l|}{ Public participation } \\
\hline $\begin{array}{l}\text { c. The population served by our system has a high level of EMS awareness, participation or } \\
\text { support. }\end{array}$ & 28.5 & 29.7 & 26.7 & 27.0 \\
\hline d. Defibrillators, available for public access, can be found in many public places in our system. ${ }^{*}$ & 43.8 & 39.2 & 26.7 & 63.5 \\
\hline e. Bystanders often provide CPR prior to EMS arrival at cardiac arrest calls. ${ }^{*}$ & 25.1 & 28.4 & 13.3 & 32.4 \\
\hline f. The public is satisfied with our EMS services. & 70.1 & 65.8 & 65.3 & 78.4 \\
\hline \multicolumn{5}{|l|}{ System support } \\
\hline g. Our system has a high level of physician involvement. & 59.2 & 54.1 & 57.3 & 66.2 \\
\hline h. Hospitals in our system are supportive of our EMS agencies/providers. & 74.5 & 68.9 & 74.7 & 78.4 \\
\hline i. Patient flow through the EMS system is generally smooth. & 79.2 & 79.7 & 82.7 & 74.3 \\
\hline j. $\quad$ Our EMS system/participating agencies collaborate with non-EMS organizations. ${ }^{*}$ & 75.5 & 67.6 & 86.5 & 78.1 \\
\hline
\end{tabular}

${ }^{a}$ Defined by annual number of responses (not available for 13 systems)

Represents significant $X^{2}$ at $p<0.05$ 
Table 28: Subjective Assessments by Size of the System ${ }^{\text {a }}$ (continued)

\begin{tabular}{|c|c|c|c|c|}
\hline & $\begin{array}{l}\text { All Systems } \\
(n=222)\end{array}$ & $\begin{array}{l}\text { Small } \\
(n=74)\end{array}$ & $\begin{array}{c}\text { Medium } \\
(n=75)\end{array}$ & $\begin{array}{l}\text { Large } \\
(n=73)\end{array}$ \\
\hline \multicolumn{5}{|l|}{ System environment } \\
\hline k. Turf wars are a problem for our EMS providers. * & 24.7 & 32.4 & 25.3 & 14.9 \\
\hline I. Politics are a problem within our EMS system. & 40.9 & 44.6 & 36.0 & 39.2 \\
\hline m. EMS providers enjoy working within our EMS system. & 77.0 & 78.4 & 77.3 & 78.4 \\
\hline \multicolumn{5}{|l|}{ System change } \\
\hline n. Our EMS system looks much the same as 10 years ago & 17.5 & 18.9 & 17.3 & 16.2 \\
\hline $\begin{array}{l}\text { o. Our EMS system will look much the same } 10 \text { years from } \\
\text { now }\end{array}$ & 8.1 & 8.1 & 6.7 & 9.5 \\
\hline p. Our system adapts well to change. & 45.5 & 43.2 & 46.7 & 46.0 \\
\hline Mean score (standard deviation) - Resource levels & $\begin{array}{r}2.97 \\
(0.91)\end{array}$ & $\begin{array}{r}2.86 \\
(0.89)\end{array}$ & $\begin{array}{r}2.93 \\
(0.79)\end{array}$ & $\begin{array}{r}3.04 \\
(1.05)\end{array}$ \\
\hline Mean score (standard deviation) - Public participation ${ }^{f}$ & $\begin{array}{r}3.06 \\
(0.70)\end{array}$ & $\begin{array}{l}3.01 b \\
(0.70)\end{array}$ & $\begin{array}{l}2.88 b \\
(0.75)\end{array}$ & $\begin{array}{l}3.27 a \\
(0.59)\end{array}$ \\
\hline Mean score (standard deviation) - System support & $\begin{array}{r}3.76 \\
(0.64)\end{array}$ & $\begin{array}{r}3.70 \\
(0.59)\end{array}$ & $\begin{array}{r}3.78 \\
(0.60)\end{array}$ & $\begin{array}{r}3.80 \\
(0.74)\end{array}$ \\
\hline Mean score (standard deviation) - System environment & $\begin{array}{r}3.41 \\
(0.82)\end{array}$ & $\begin{array}{r}2.31 \\
0.83)\end{array}$ & $\begin{array}{r}3.44 \\
(0.78)\end{array}$ & $\begin{array}{r}3.53 \\
(0.81)\end{array}$ \\
\hline
\end{tabular}

${ }^{a}$ Defined by annual number of responses (not available for 13 systems)

Represents significant $X^{2}$ at $p<0.05$

${ }^{f}$ Represents significant $\mathrm{F}$ at $\mathrm{p}<0.05$ based on one-way ANOVA; Mean separation by Duncan's multiple range test 


\section{Figure 1. Counties by Rural-Urban Continuum}

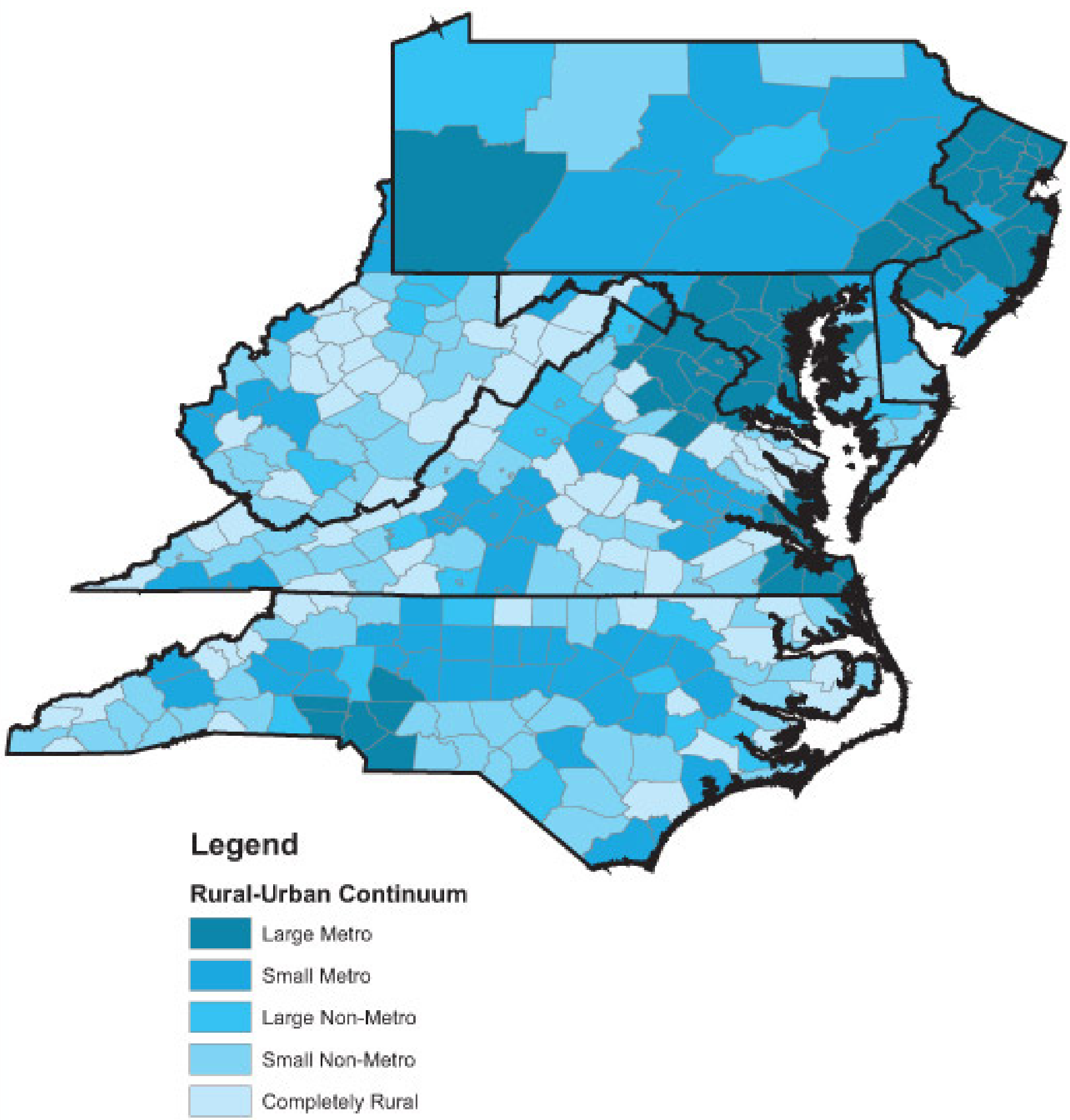




\section{Figure 2. Counties by System Status and Response Status}

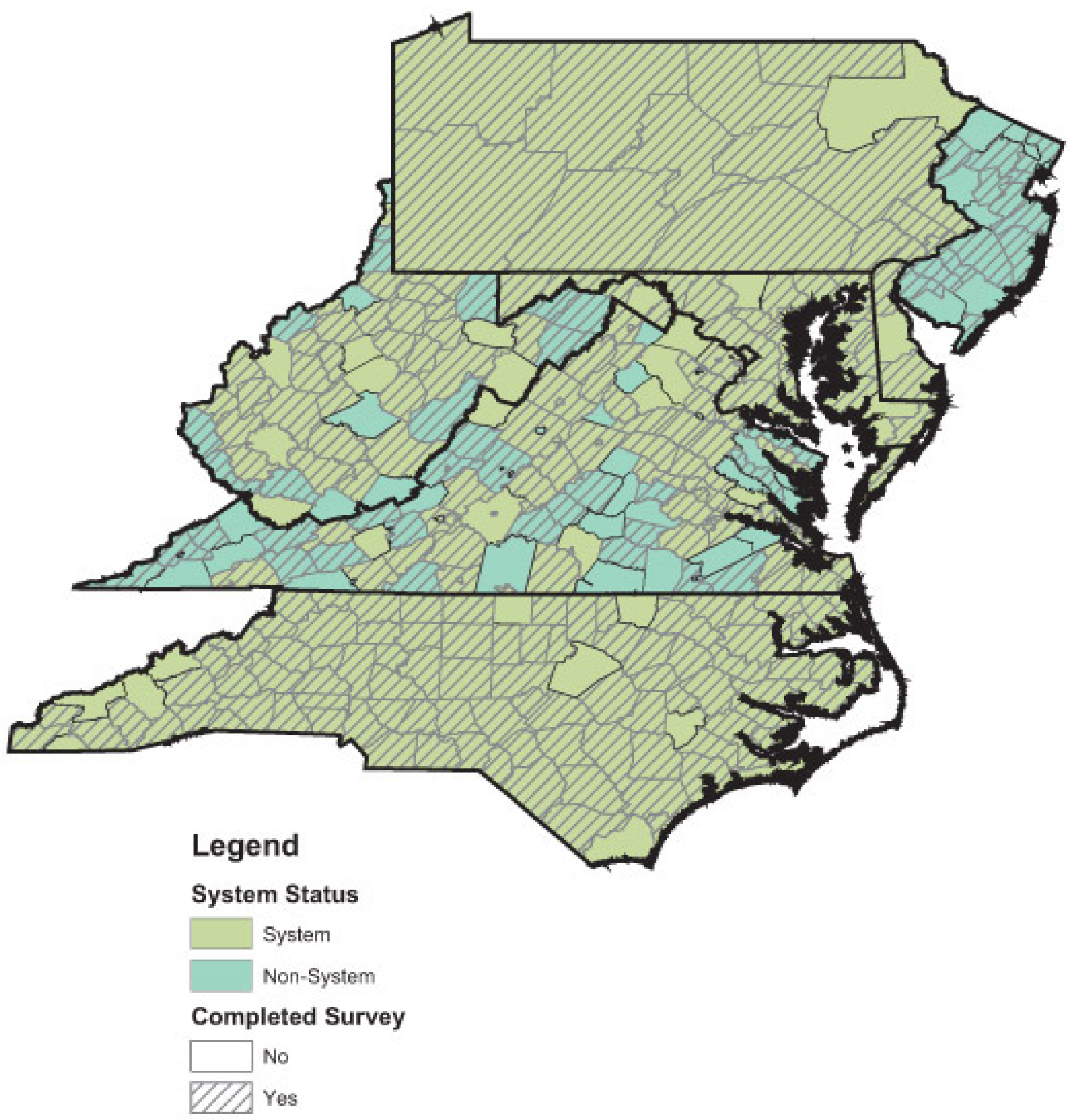




\section{Figure 3. EMS Systems Categorized by Size of Service: Number of EMS Responses}

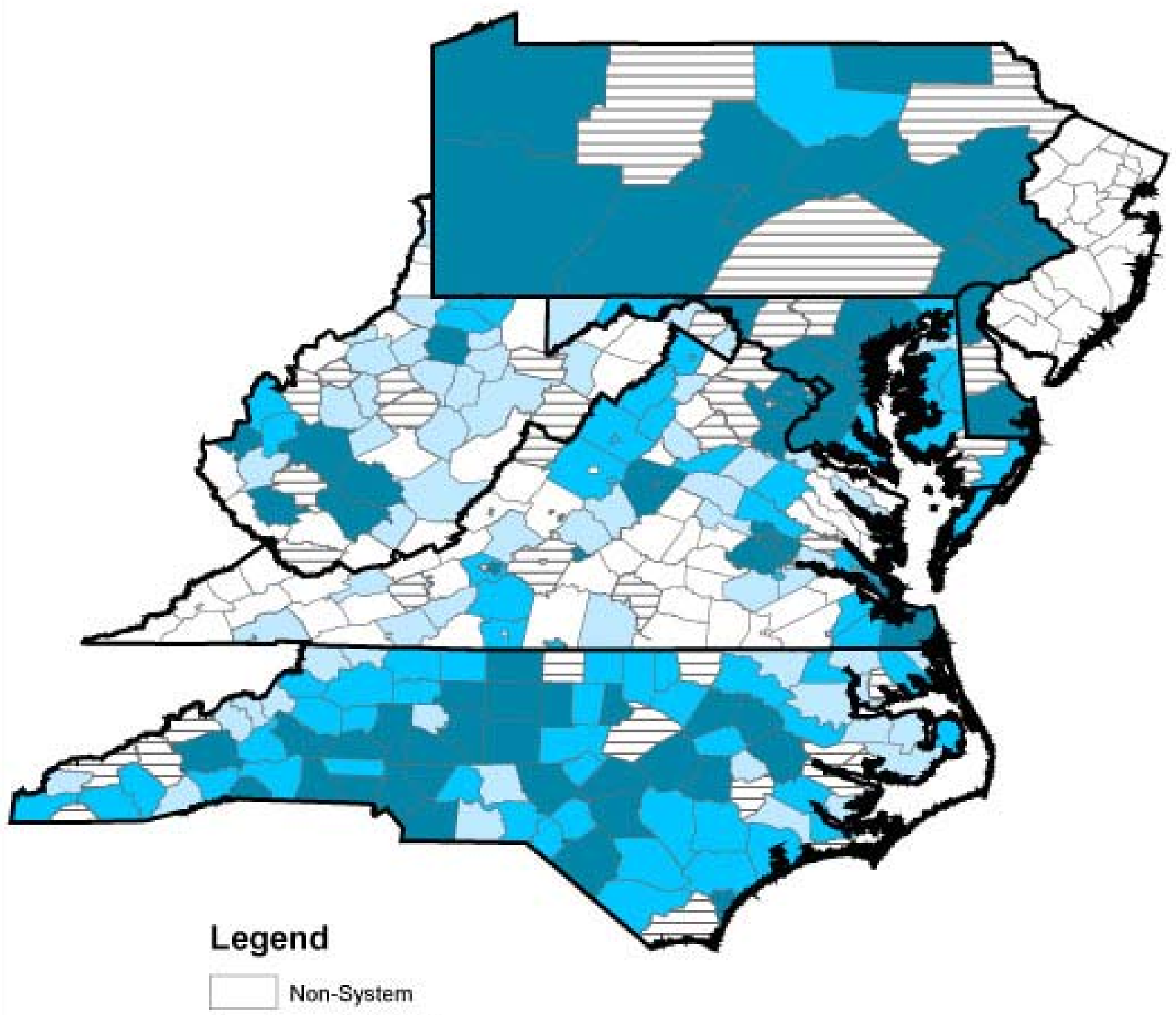

Number of EMS Responses

\begin{tabular}{|l}
\hline$\square$ Nonresponse/Missing \\
Small $(3,968$ or less) \\
Medium $(3,969-12,000)$ \\
Large $(12,001$ or more $)$
\end{tabular}




\section{Figure 4. EMS Systems Categorized by Size of Service: Number of EMS Responses Per 1,000 Population}
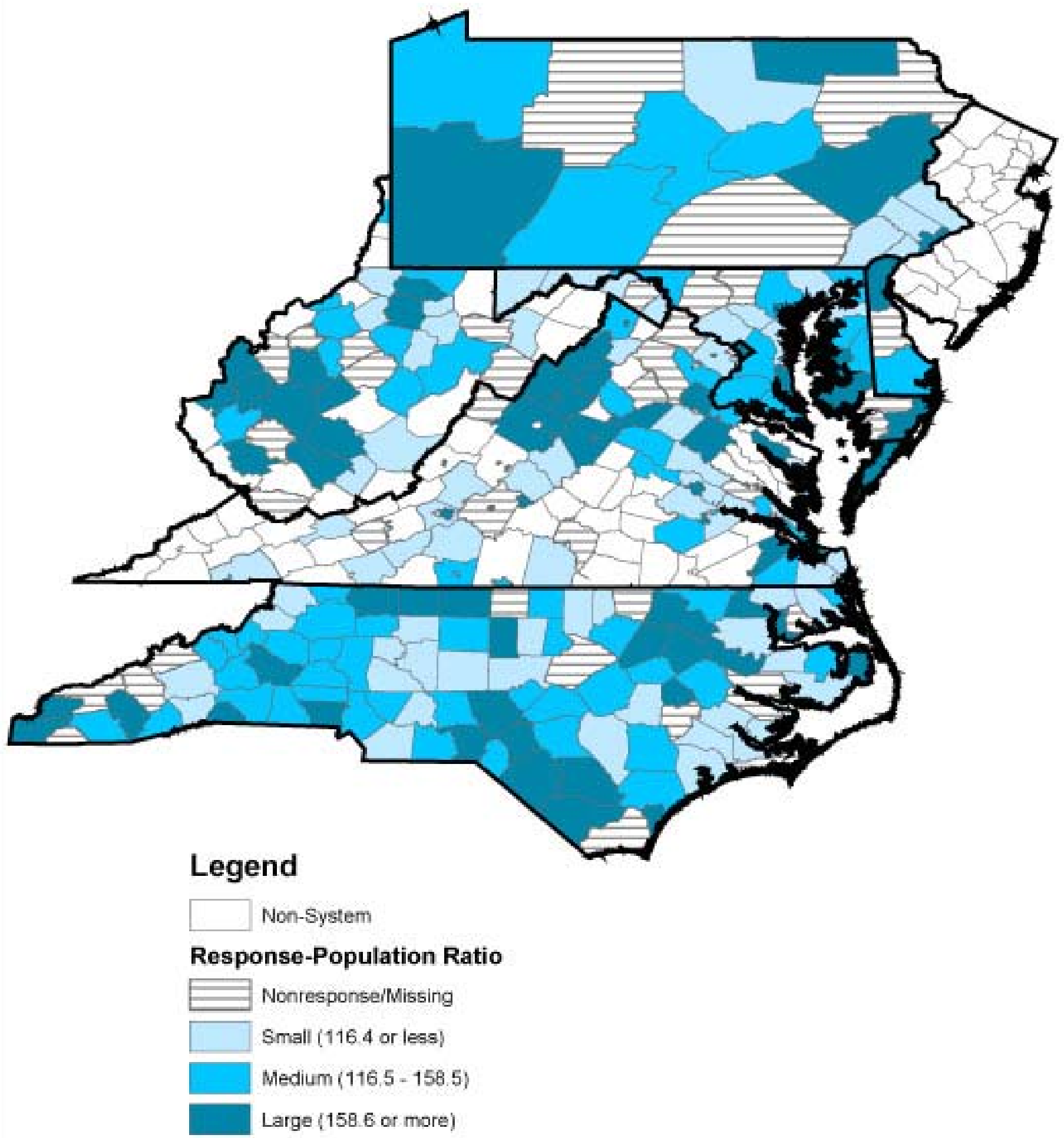


\section{Figure 5. EMS Systems Categorized by Number of Providers Per 1,000 Population}

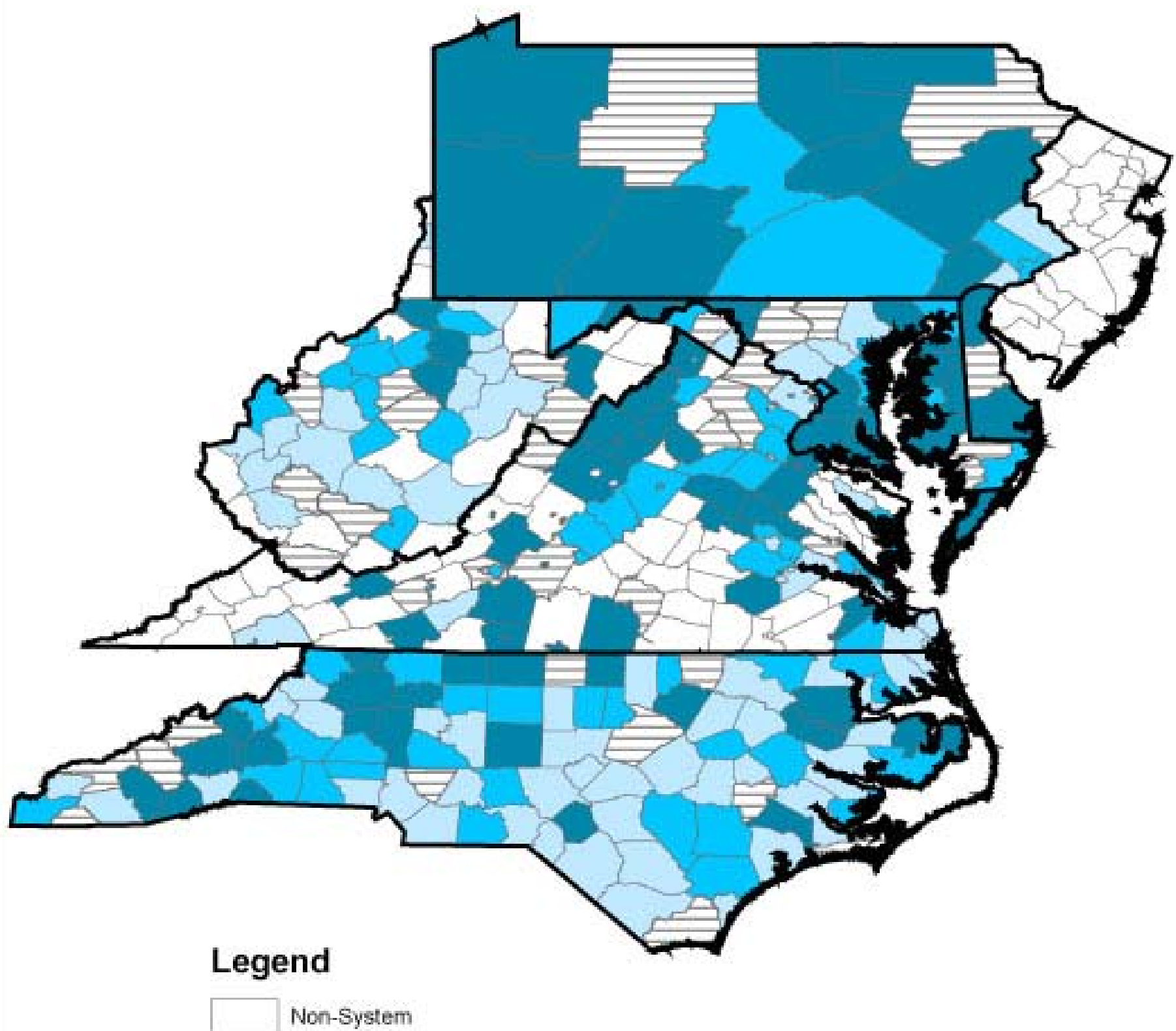

Provider-Population Ratio

\begin{tabular}{l}
\hline Nonresponse/Missing \\
Small $(2.26$ or less $)$ \\
Medium $(2.27-4.32)$ \\
Large $(4.33$ or more $)$
\end{tabular}




\section{Figure 6. EMS Systems Categorized by Wireless 911 Access}

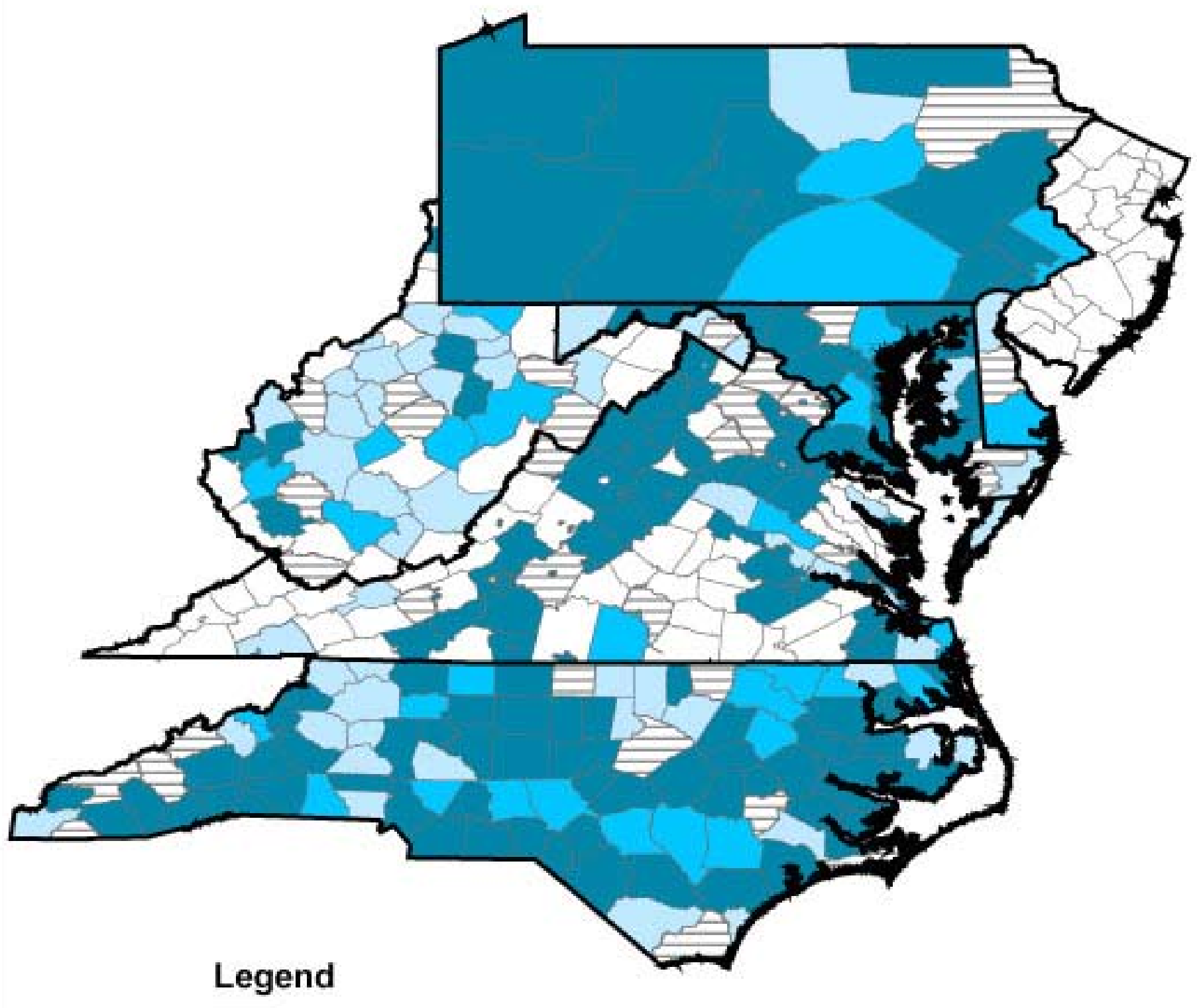




\section{Figure 7. EMS Systems Categorized by Agency Type: First Response}

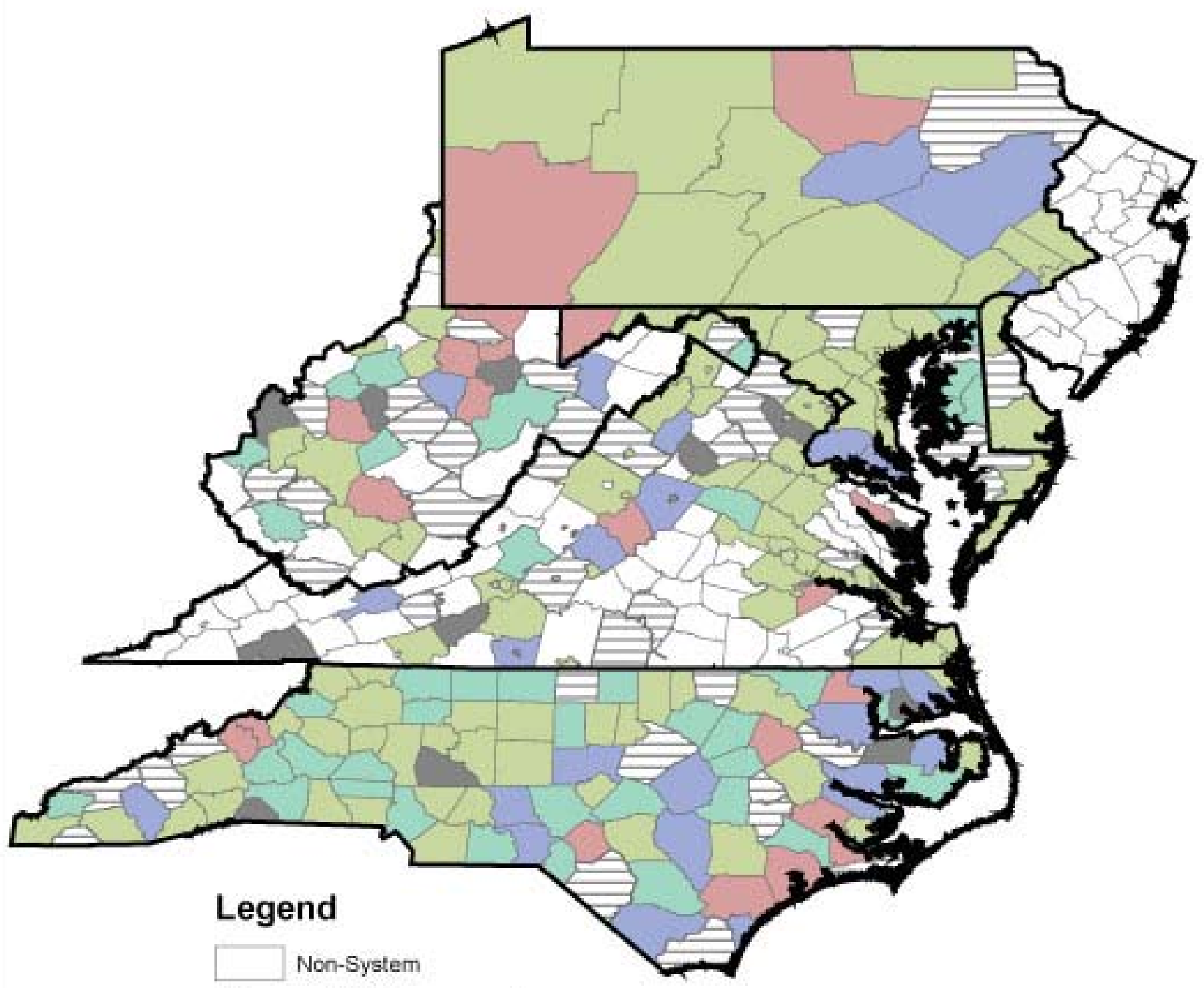

Primary 1st Response Agency

\begin{tabular}{l}
\hline Nonresponse/Missing \\
Private \\
Fire Department \\
Gov't-based/3rd Service \\
Other \\
No 1st Response
\end{tabular}




\section{Figure 8. EMS Systems Categorized by Agency Type: Transport}

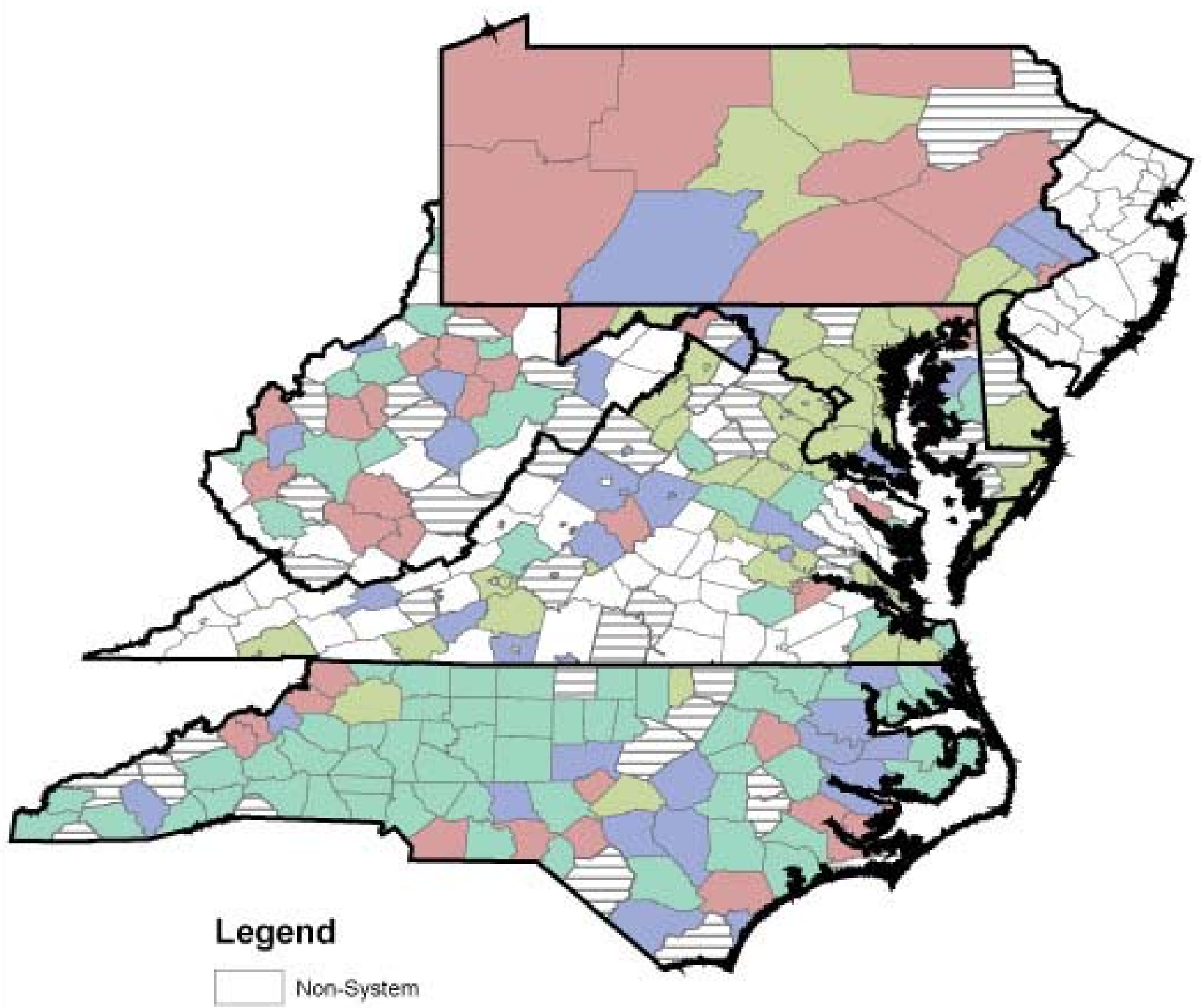

Primary Transport Agency

\begin{tabular}{l}
\hline Nonresponse/Missing \\
Private \\
Fire Department \\
Gov't-based/3rd Service \\
Other
\end{tabular}




\section{Figure 9. EMS Systems Categorized by Agency Type: Dispatch}

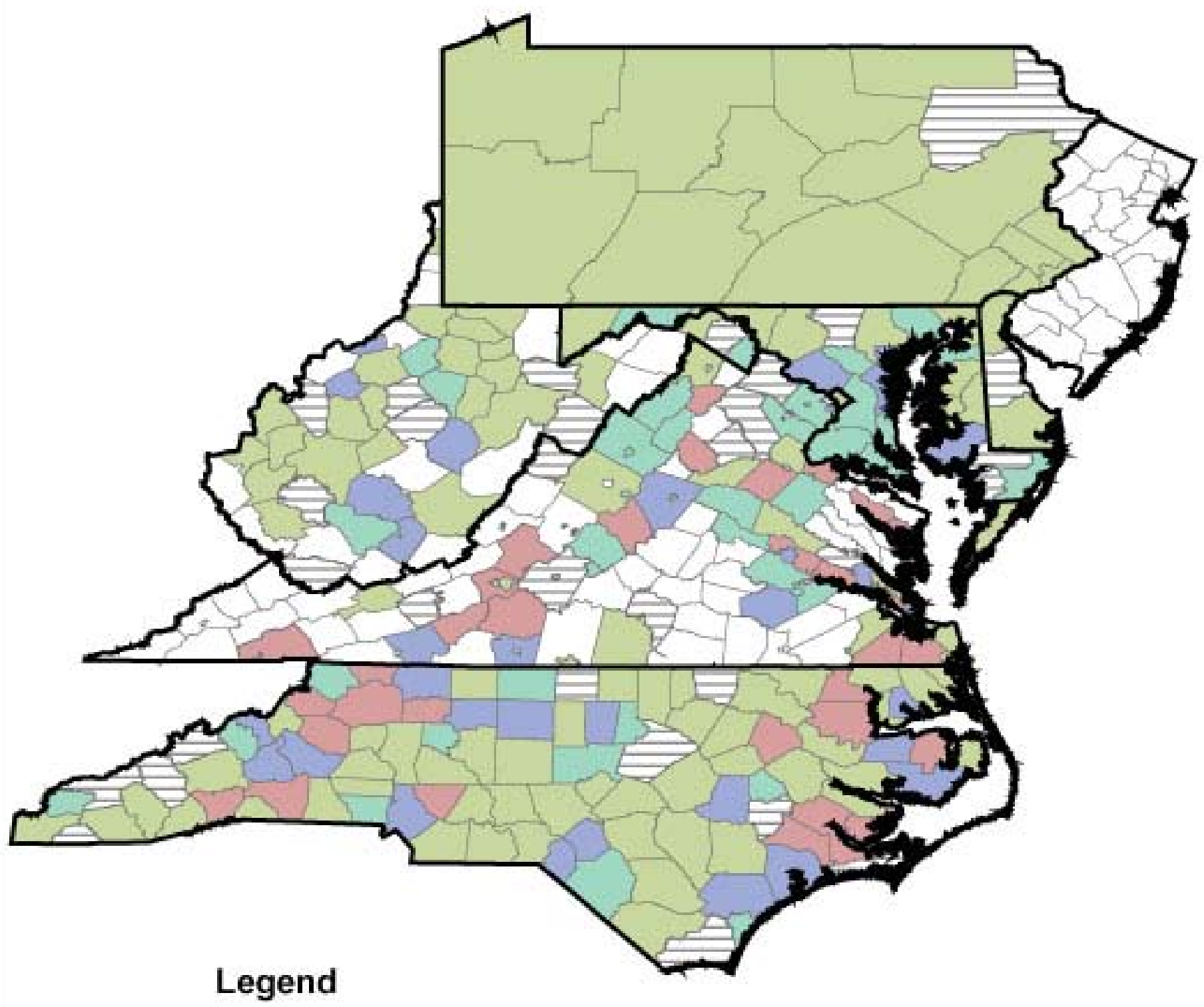

\begin{tabular}{l}
\hline Non-System \\
Primary Dispatch \\
Police/Sheriff \\
City/County \\
Public Safety \\
Other
\end{tabular}




\section{Figure 10. EMS Systems Categorized by Response Configurations}

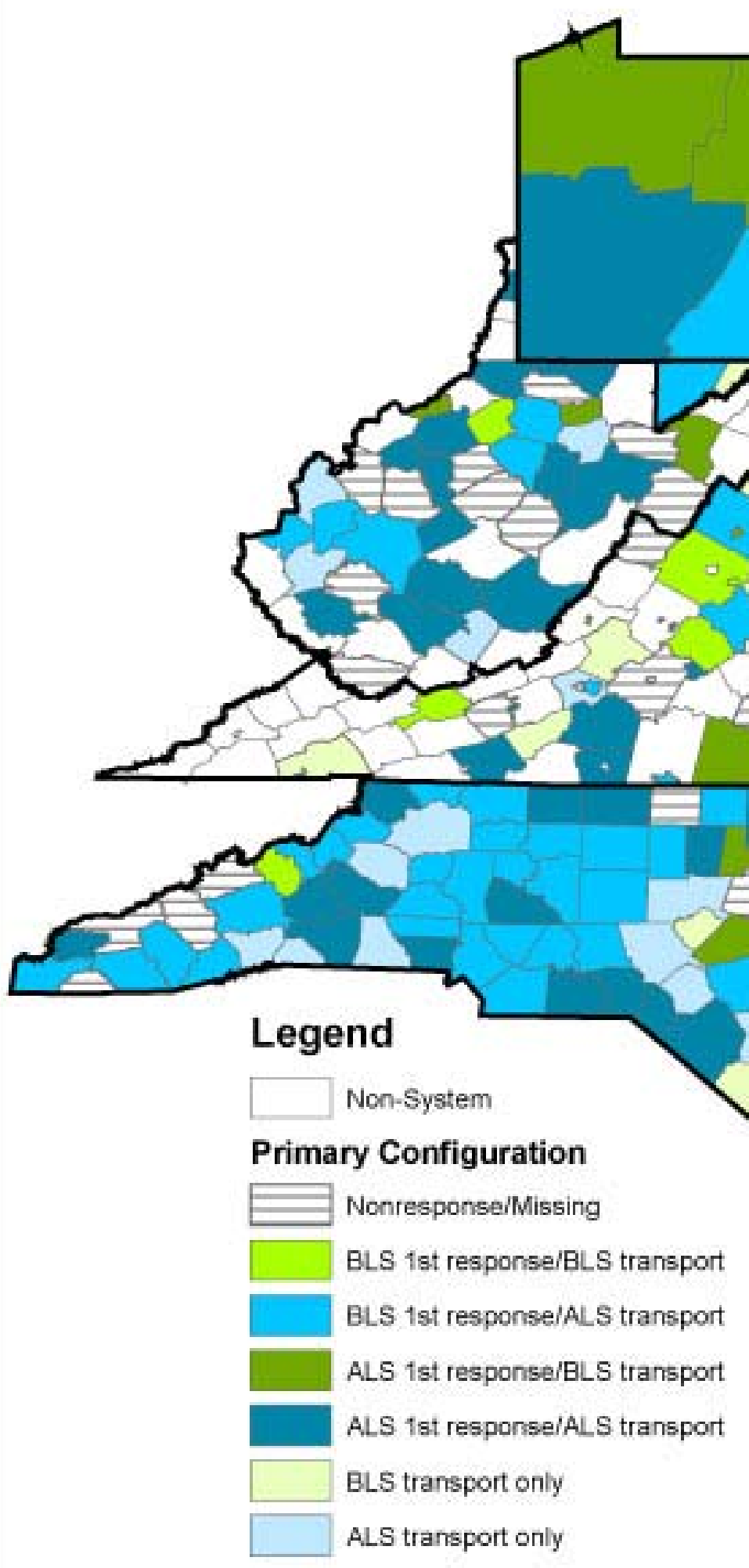




\section{Figure 11. EMS Systems Categorized by How Often Transport Agency Responds to Outside Primary Service Area}
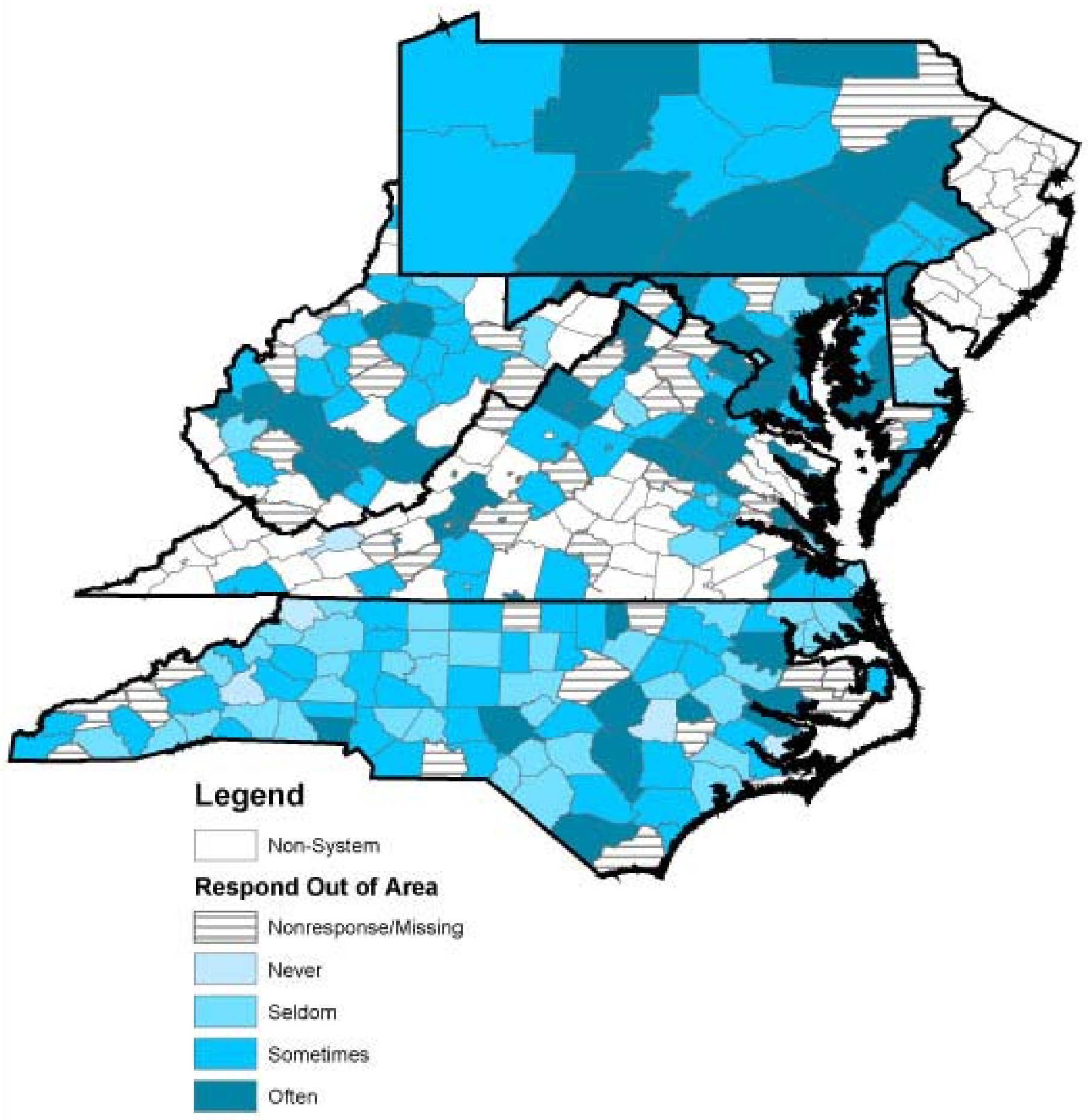


\section{Figure 12. EMS Systems Categorized by Medical Control}

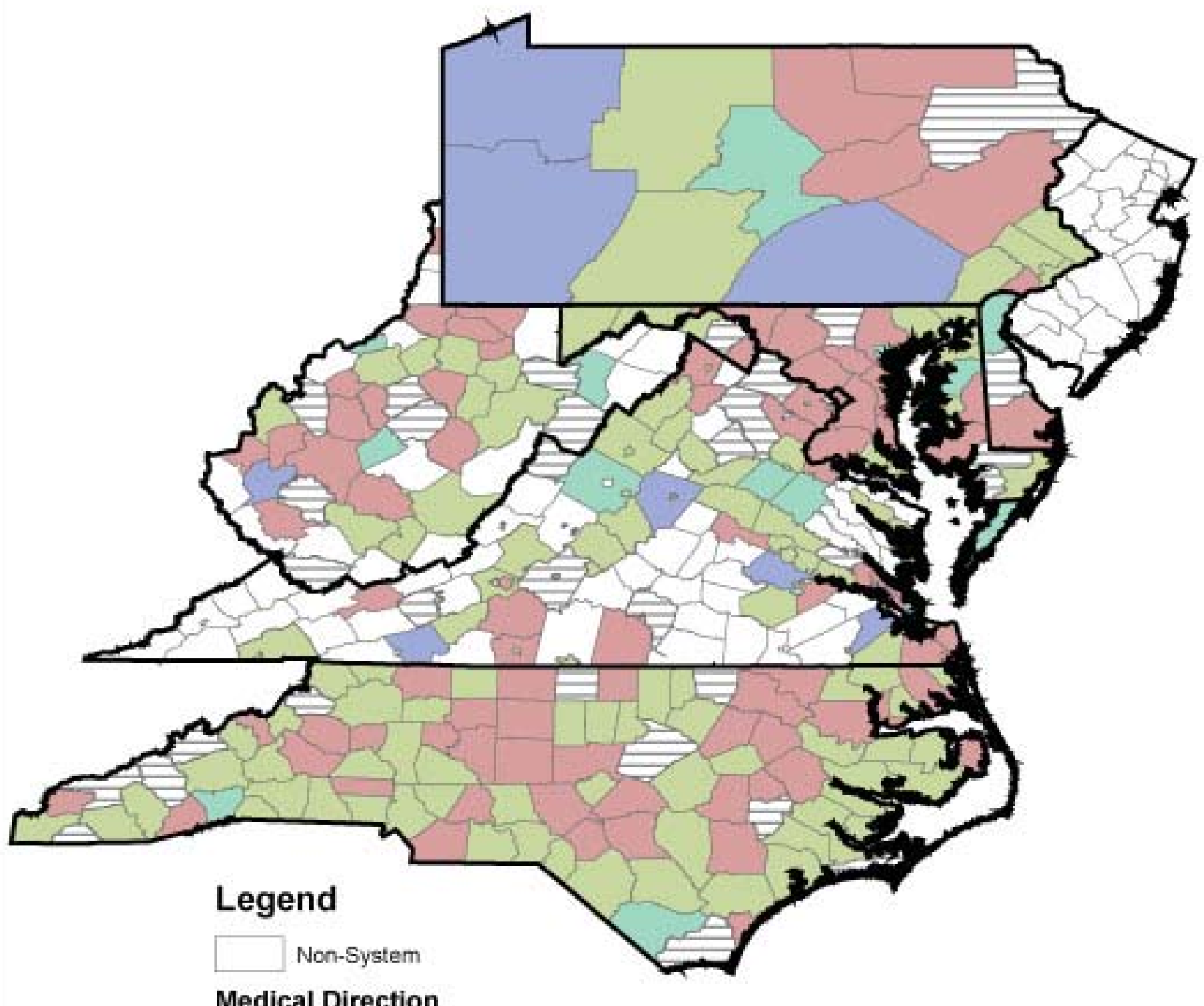

Medical Direction

$\square$ Nonresponse/Missing
Systemwide "In-House"
External (e.g. Hospital-Based)
Other
No Systemwide (but at agencies)




\section{Figure 13. EMS Systems Categorized by Primary Source of Funding}

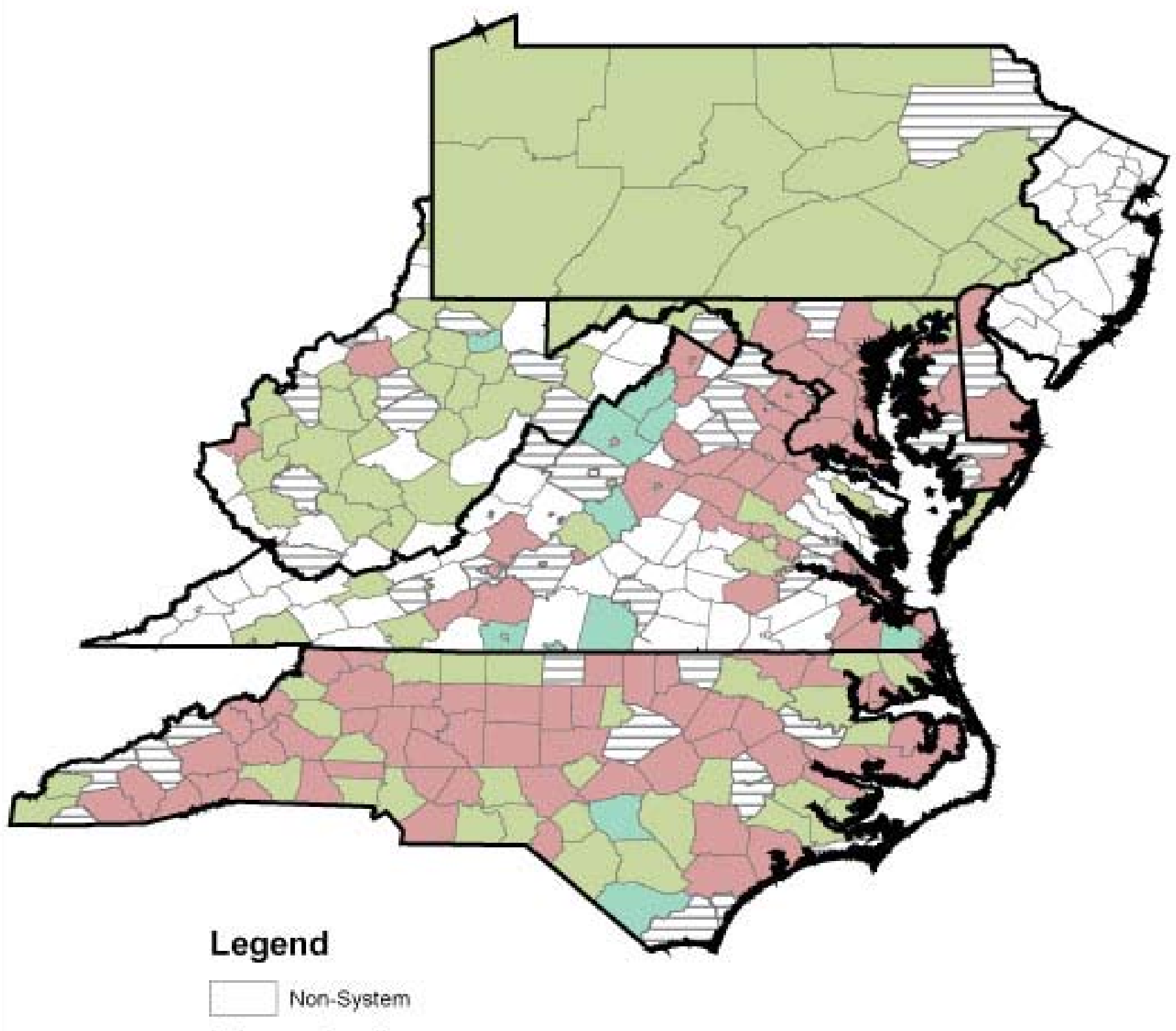

Primary Funding

\begin{tabular}{l}
\hline Nonresponse/Missing \\
Tax Subsidies \\
Fees/Bills \\
Other
\end{tabular}




\section{Figure 14. EMS System* Type by Study}

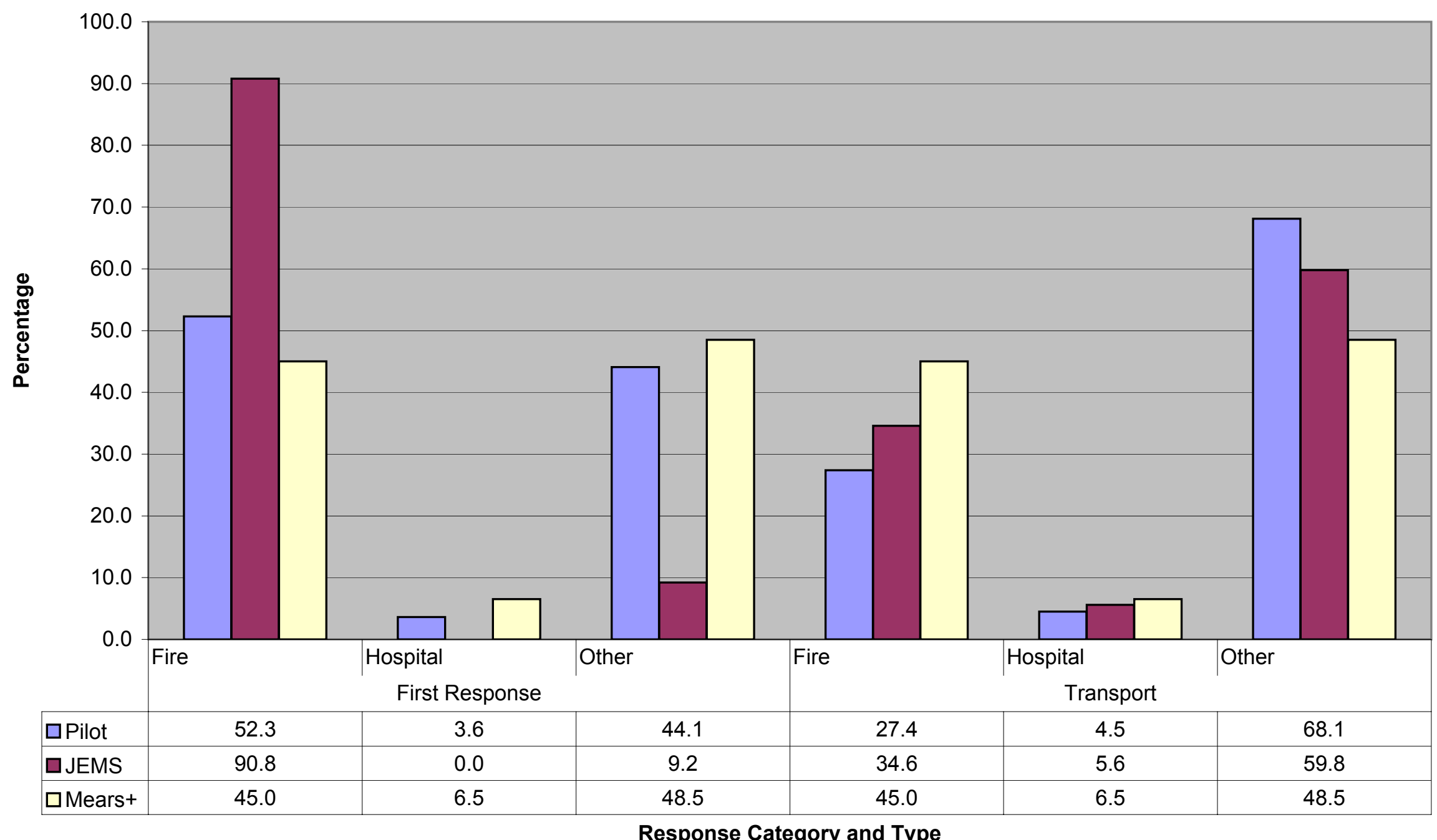

* Primary agency type used for pilot data, study specific definitions for JEMS and Mears

+ Since Mears did not break down systems into first response and transports, percentages are assumed to be the same for both. 


\section{Appendices}

\section{Configurations of EMS Systems}
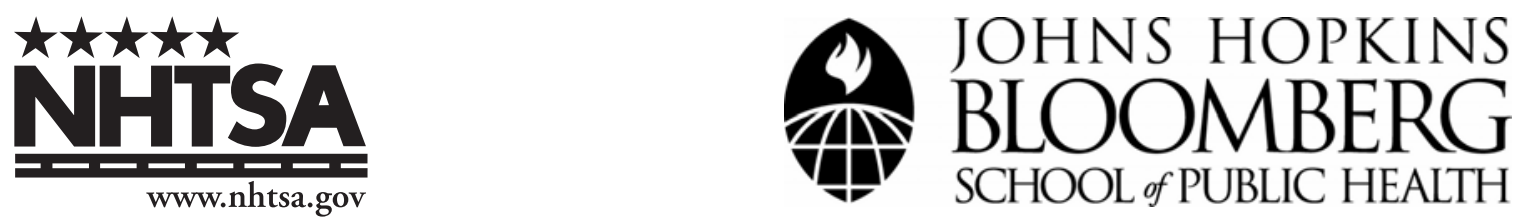
Instructions: Please answer the following questions regarding your EMS system as a whole. Since our goal is to learn more about EMS in your area, please be sure to consider all the agencies, activities, and components that make up your system, excluding those related to interfacility or aeromedical EMS operations.

1. Of the following types of EMS agencies, please indicate which types provide emergency first response (dispatch of medical personnel to scene in a non-transport vehicle) within your system and which is most often used. If your system does not use first responders, please check "No separate first response" under "Primary Type."

\begin{tabular}{|l|c|c|}
\hline Agency Type & $\begin{array}{c}\text { Present Within System } \\
\text { (check all that apply) }\end{array}$ & $\begin{array}{c}\text { Primary Type } \\
\text { (check only one) }\end{array}$ \\
Private, for-profit ambulance service & $\square$ & $\square$ \\
Private, not-for-profit ambulance service & $\square$ & $\square$ \\
Fire dept, single-role (EMS only) personnel & $\square$ & $\square$ \\
Fire dept, multi-role (EMS/FF cross-train) personnel & $\square$ & $\square$ \\
Govt.-based / third service (non-police, non-fire) & $\square$ & $\square$ \\
Independent volunteer ambulance service & $\square$ & $\square$ \\
Public safety dept. / Joint police-fire-EMS & $\square$ & $\square$ \\
Public-utility model & $\square$ & $\square$ \\
Hospital-based & $\square$ & $\square$ \\
Police & $\square$ & $\square$ \\
University & $\square$ & $\square$ \\
Other (specify) & $\square$ \\
No separate first response & $\square$ \\
\hline
\end{tabular}

2. Of the following types of EMS agencies, please indicate which types provide emergency transport (from scene to a health care facility) within your system and which is most often used.

\begin{tabular}{|l|c|c|}
\hline Agency Type & $\begin{array}{c}\text { Present Within System } \\
\text { (check all that apply) }\end{array}$ & $\begin{array}{c}\text { Primary Type } \\
\text { (check only one) }\end{array}$ \\
Private, for-profit ambulance service & $\square$ & $\square$ \\
Private, not-for-profit ambulance service & $\square$ & $\square$ \\
Fire dept, single-role (EMS only) personnel & $\square$ & $\square$ \\
Fire dept, multi-role (EMS/FF cross-train) personnel & $\square$ & $\square$ \\
Govt.-based / third service (non-police, non-fire) & $\square$ & $\square$ \\
Independent volunteer ambulance service & $\square$ & $\square$ \\
Public safety dept. / Joint police-fire-EMS & $\square$ & $\square$ \\
Public-utility model & $\square$ & $\square$ \\
Hospital-based & $\square$ & $\square$ \\
Police & $\square$ & $\square$ \\
University & $\square$ & $\square$ \\
Other (specify) & $\square$ & $\square$ \\
\hline
\end{tabular}


3. Of the following types of agencies, please indicate which agency types provide emergency medical dispatch of response vehicles for your system and which is most often used.

\begin{tabular}{|l|c|c|}
\hline Agency Type & $\begin{array}{c}\text { Present Within System } \\
\text { (check all that apply) }\end{array}$ & $\begin{array}{c}\text { Primary Type } \\
\text { (check only one) }\end{array}$ \\
Public safety dept. / Joint police-fire-EMS & $\square$ & $\square$ \\
Fire department & $\square$ & $\square$ \\
Police department & $\square$ & $\square$ \\
Sheriff's department & $\square$ & $\square$ \\
Private ambulance service & $\square$ & $\square$ \\
Govt.-based / third service EMS & $\square$ & $\square$ \\
Hospital & $\square$ & $\square$ \\
City communications department & $\square$ & $\square$ \\
County communications department & $\square$ & $\square$ \\
Other (specify) & $\square$ & $\square$ \\
\hline
\end{tabular}

4. Please indicate which of the following common response configurations are utilized by your system's provider agencies and indicate which is the most frequently used by those agencies.

Response Configuration

BLS first response, BLS transport

BLS first response, ALS transport

ALS first response, BLS transport

ALS first response, ALS transport

BLS transport only

ALS transport only

Other (specify)

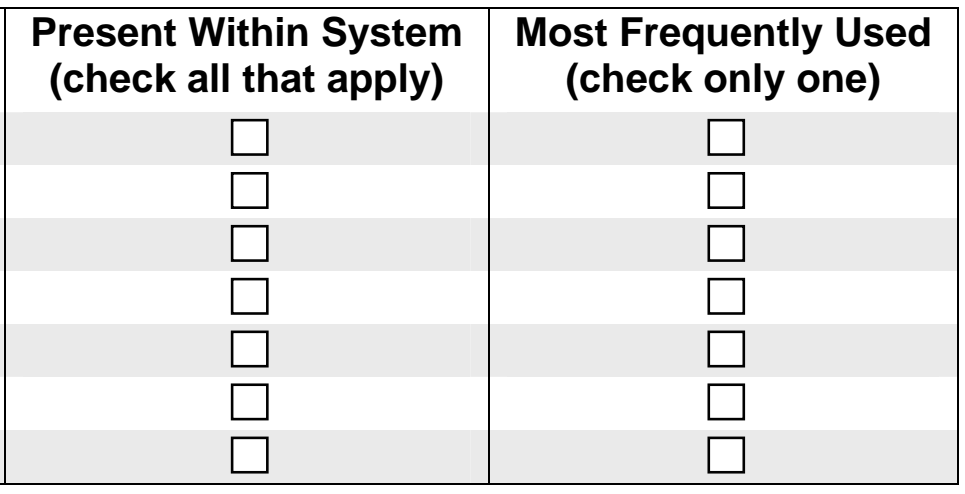

IF YOUR SYSTEM USES FIRST RESPONDERS, PLEASE COMPLETE QUESTIONS 5 AND 6. OTHERWISE, PLEASE SKIP TO QUESTION 7.

5. For which calls are first responders most commonly dispatched within your system?

All 911 calls

Certain calls based on assessment by priority dispatch or other call taking system

Specified emergencies only

Non-emergency assessments

Other (specify)

6. When first responders are used, how are they most commonly dispatched?

First response followed by transport ambulance if necessary

Simultaneous first response and transport ambulance

Other (specify) 
7. Are there operating procedures within your system that allow vehicles to respond to calls without the use of lights and sirens, based on information received by the dispatch agency?
$\square$ Yes
$\square \quad$ No

8. Are there operating procedures within your system that allow vehicles to transport non-emergent patients without the use of lights and sirens, based on information gathered at the scene?
$\square$ Yes
No

9. Does your system allow providers to transport patients from the scene to non-hospital destinations, such as urgent care centers?

$$
\text { Yes }
$$

No

10. Please indicate how often your system's primary emergency first response and transport agencies respond to calls beyond the boundaries of their primary service areas

\begin{tabular}{|c|c|c|c|c|c|}
\hline Routinely Respond Out of Area? & Never & Seldom & Sometimes & Often & Not applicable \\
\hline Primary $1^{\text {st }}$ Response Agency & & $\square$ & $\square$ & $\Gamma$ & $\square$ \\
\hline Primary Transport Agency & $\square$ & $\square$ & $\square$ & $\square$ & \\
\hline
\end{tabular}

11. Please indicate which of the following are addressed in your mutual aid agreements with the EMS systems and/or agencies that border yours (check all that apply).

$\square$ Service coverage

Communication linkage

Licensure or certification of providers

Financial reimbursement

Liability

Other (specify)

Not applicable (no mutual aid agreements)

12. Does your EMS system utilize volunteer providers?

No (skip to question 13)

Yes

a. Please estimate the percentage of providers that serve as volunteers. $\%$

b. From where do volunteers typically respond to calls while on duty?

From their homes, work, or other locations within the designated response area

From fire or EMS station houses 
13. Are there areas within your system where call coverage is a major concern due to significant staffing shortages?

$\square$ Yes
$\square$ No

14. How can individuals within your system access EMS (check all that apply)?

Basic 9-1-1 (all information transmitted verbally)

Enhanced 9-1-1 (caller's phone number \& location appear on screen)

7 or 10 digit number

Wireless 9-1-1 (no geographic information or caller's phone number available)

Wireless Enhanced 9-1-1 (geographic information \& caller's phone number available)

Other (specify)

15. Do any of your system's dispatch agencies offer pre-arrival instructions to callers for certain types of calls?

$\square$ Yes

No

16. On a day-to-day basis, who is primarily responsible for medical control for your system as a whole?

Systemwide, "in-house" medical director

External (e.g. hospital based) medical director

Medical advisory board

EMS regulatory agency

No systemwide medical direction, but provided at the individual agency level

Other (specify)

No medical direction at all

17. Thinking of your system as a whole, how is EMS financed? From the following list of funding sources, please indicate how EMS receives the funds necessary to provide its services and please indicate the primary funding source.

\begin{tabular}{|l|c|c|}
\hline Funding Sources & $\begin{array}{c}\text { Present Within System } \\
\text { (check all that apply) }\end{array}$ & $\begin{array}{c}\text { Primary Source } \\
\text { (check only one) }\end{array}$ \\
Tax subsidies & $\square$ & $\square$ \\
Fees/bill for services & $\square$ & $\square$ \\
Homeland security grants & $\square$ & $\square$ \\
Other grants & $\square$ & $\square$ \\
Donations/fundraisers & $\square$ & $\square$ \\
Other (specify) & $\square$ & $\square$ \\
\hline
\end{tabular}


18. Please provide the following information about your EMS system:
a. Number of EMS care providers, including volunteers, at all levels
b. Number of 9-1-1 calls for service annually
C. Number of EMS responses annually
d. Number of EMS transports annually

19. Please indicate the level with which you agree or disagree with the following statements. ( $\mathbf{S D}=$ Strongly disagree, $\mathbf{D}=$ Disagree, $\mathbf{N}=$ Neutral, $\mathbf{A}=$ Agree, $\mathbf{S A}=$ Strongly Agree)

Resource Levels
a. Our system is adequately staffed to meet demand.
SD
D $\quad \mathbf{N}$
A SA
b. Our system has enough resources (vehicles, equipment) to meet demand.
SD
D $\quad \mathbf{N}$
A SA

\section{Public Participation}

c. The population served by our system has a high level of EMS awareness, participation or support.

SD D N A SA

d. Defibrillators, available for public access, can be found in many public places within our system.

SD $\quad$ D $\quad$ N $\quad$ A $\quad$ SA

e. Bystanders often provide CPR prior to EMS arrival at cardiac arrest calls.

f. The public is satisfied with our EMS services.

SD D N A SA System Support

g. Our system has a high level of physician involvement.

SD

D $\quad \mathbf{N}$

A SA

h. Hospitals in our system are supportive of our EMS agencies/providers.

SD D N A SA

i. Patient flow through the EMS system is generally smooth.

SD $\quad$ D $\quad N \quad$ A $\quad$ SA

j. Our EMS system / participating agencies collaborate with non-EMS organizations.

SD D N A SA

System Environment

k. "Turf wars" are a problem for our EMS providers.

$\begin{array}{lllll}\text { SD } & \text { D } & \text { N } & \text { A } & \text { SA } \\ \text { SD } & \text { D } & \text { N } & \text { A } & \text { SA } \\ \text { SD } & \text { D } & \text { N } & \text { A } & \text { SA }\end{array}$

I. Politics are a problem within our EMS system.

m. EMS providers enjoy working within our EMS system.

System Change

n. Our EMS system looks much the same as 10 years ago

SD D N A SA

o. Our EMS system will look much the same 10 years from now

SD D N A SA

p. Our system adapts well to change.

SD

D $\quad \mathbf{N}$

A SA 
20. If you would like to provide any additional information about your system, including unique characteristics or special situations/arrangements for the organization and provision of EMS in your area, please enter it in the space below. 


\section{Surveying Configurations of EMS Systems}

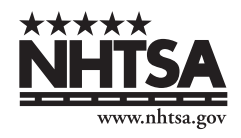

(4) BLONS HOPKINS
BLOMOMERG

1. Do you have a county department, division or agency responsible for the oversight of EMS in your county?

$>$ If yes, please provide contact information in the box below.

Organization:

Contact Person:

Title:

Address:

Phone:

Fax:

E-mail:

If no, is there a single organization outside of the county government that provides oversight of EMS in your county or serves as a "lead" organization for providers in your county (e.g., a large EMS service)? Please provide contact information in the box below.

Organization:

Contact Person:

Title:

Address:

Phone:

Fax:

E-mail:

2. How can individuals within your county access EMS (check all that apply)?

$\square \quad 911$

$\square \quad$ Wireless 911

$\square 7$ or 10 digit number

$\square$ Don't know 
3. Please indicate who provides EMS within your county from the following list of predominant types of EMS agencies (check all that apply):

$\square \quad$ Fire departments

$\square \quad$ Private ambulance service

$\square$ Volunteer ambulance service / rescue squad

$\square$ Police

$\square$ Hospital

$\square$ Other (specify)

$\square$ Don't know

4. Thinking of your county as a whole, how is EMS financed? From the following list of funding sources, please indicate how EMS receives the funds necessary to provide its services (check all that apply).

$\square$ Tax subsidies

$\square \quad$ Fees/bill for services

$\square \quad$ Donations/fundraisers

$\square$ Other (specify)

$\square$ Don't know

5. Are there areas within your county serviced by EMS providers who respond to a scene without an ambulance or vehicle used to transport patients (known as first responders)?

$\square$ Yes

$\square \quad$ No

$\square$ Don't know

6. Are there areas within your county serviced by EMS providers with advanced training (i.e., the ability to use defibrillators and administer medications)?

$\square$ Yes

$\square \quad$ No

$\square$ Don't know

Thank you for your participation. Please return your completed survey in the prepaid envelope included. 
DOT HS 810911

March 2008

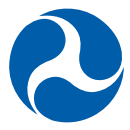

